Aus der Abteilung Pädiatrie II mit Schwerpunkt Neuropädiatrie (Prof. Dr. med. J. Gärtner)

im Zentrum Kinderheilkunde und Jugendmedizin der Medizinischen Fakultät der Universität Göttingen

\title{
Mechanismus der Neuentstehung von Peroxisomen in Saccharomyces cerevisiae
}

\author{
INAUGURAL-DISSERTATION \\ zur Erlangung des Doktorgrades \\ der Medizinischen Fakultät \\ der Georg-August-Universität zu Göttingen \\ vorgelegt von
}

\section{Kenichi Okuda}

aus

Kyoto / Japan

Göttingen 2010 
Dekan : Prof. Dr. med. C. Frömmel

I. Berichterstatterin : Prof. Dr. med. J. Gärtner

II. Berichterstatter : Prof. Dr. rer. nat. M. Thumm

III. Berichterstatter/in :

Tag der mündlichen Prüfung : 05. Oktober 2010 


\section{INHALTVERZEICHNIS}

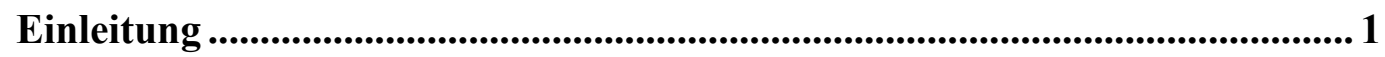

Stoffwechselfunktionen von Peroxisomen .................................................... 1

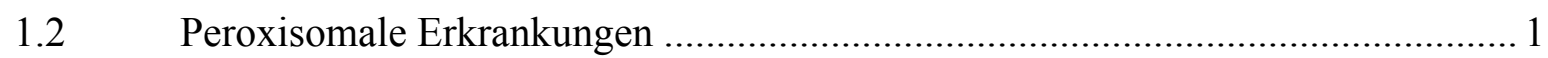

1.3 Modell zur Membranbiogenese von Peroxisomen.............................................. 3

1.4 Transport der peroxisomalen Martixproteine vom Zytosol in Peroxisomen ......... 5

1.5 Neue Entwicklungen in der Forschung der Peroxisomenbiogenese ..................... 6

1.5.1 De-novo-Biogenese und Teilung von Peroxisomen............................................. 6

1.5.2 Peroxisomen und das endoplasmatische Retikulum (ER)................................. 7

1.5.3 Modelle der Peroxisomenbiogenese................................................................ 8

1.6 Aufgabenstellung und Zielsetzung ................................................................. 10

Material und Methoden ........................................................................................ 11

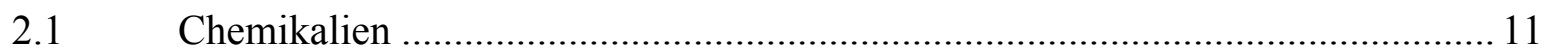

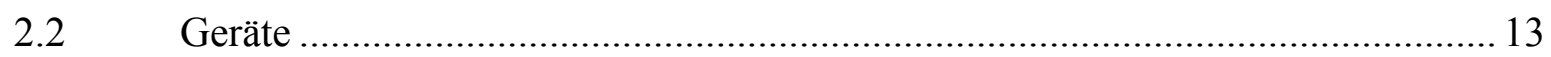

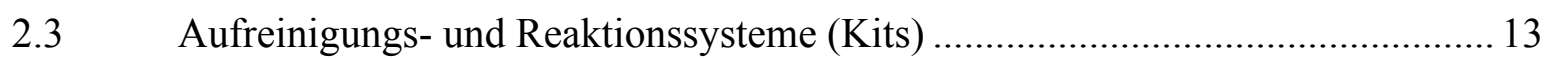

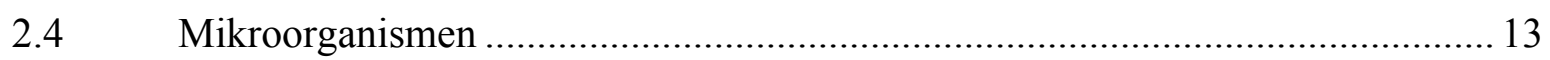

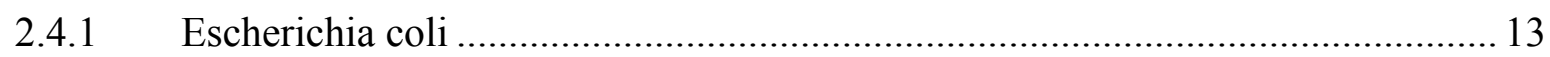

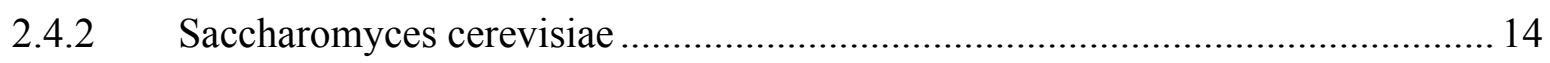

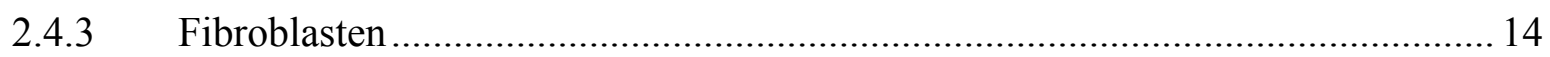

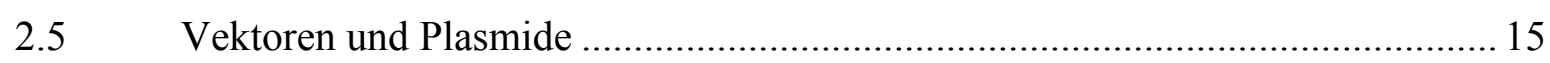

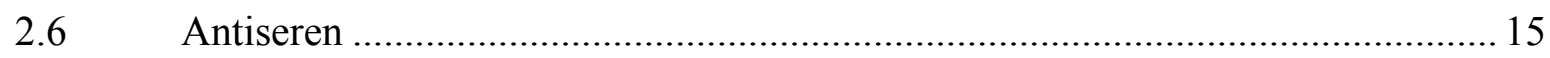

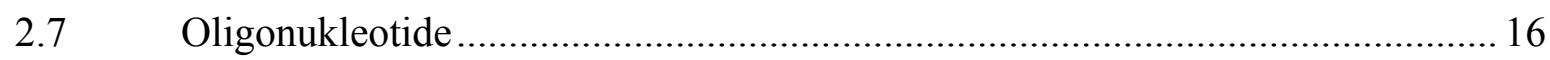

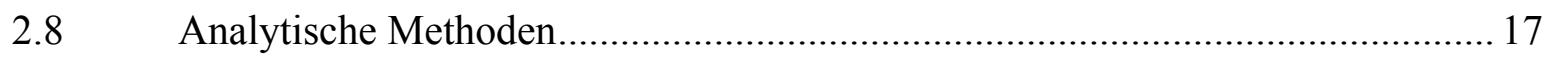

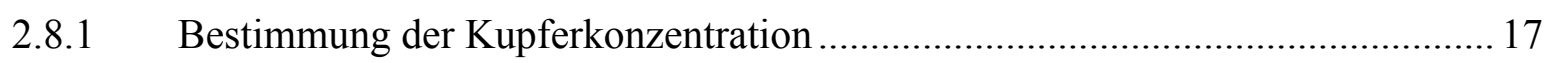

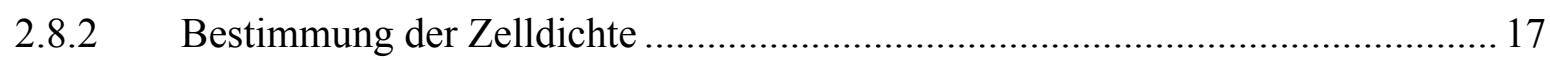

2.8.3 Konzentrationsbestimmung von Nukleinsäuren ............................................ 17

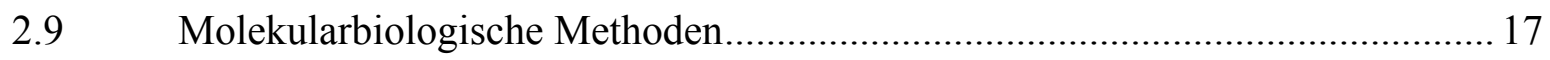

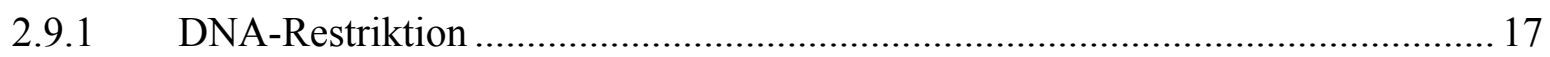

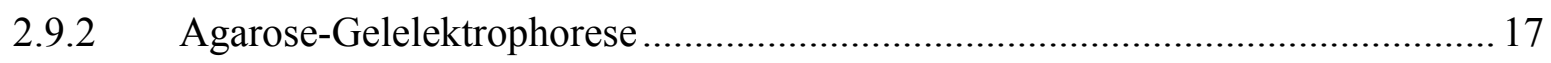

2.9.3 Isolierung von DNA-Fragmenten aus Agarose-Gelen ...................................... 18

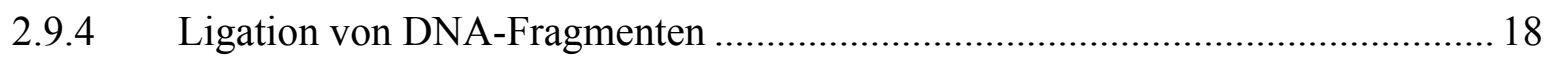

2.9.5 Amplifikation von DNA-Fragmenten mittels PCR (Polymerasekettenreaktion) 19

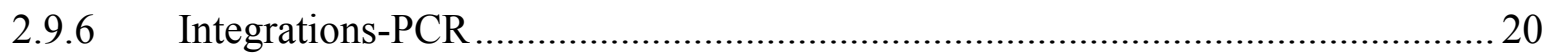


2.9.7 Amplifikation von DNA-Fragmenten aus einem Hefestamm (Kolonie PCR)..... 21

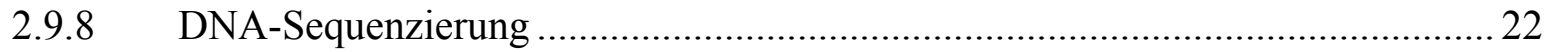

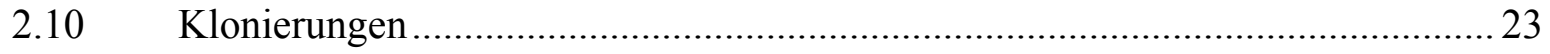

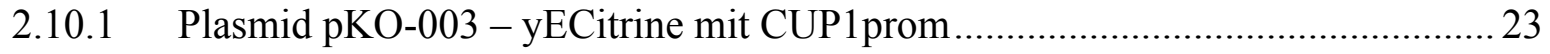

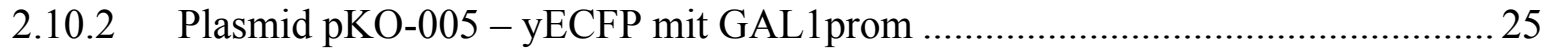

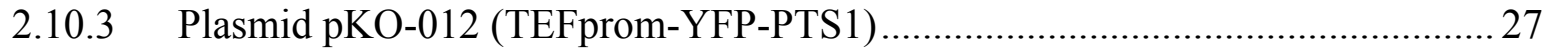

2.10.4 Plasmid pKO-008 (TEFprom-Dendra2-Dendra2-PEX3) .................................... 29

2.10.5 Plasmid pKO-010 (GAL1prom-Dendra2-Dendra2-PEX3) ................................ 31

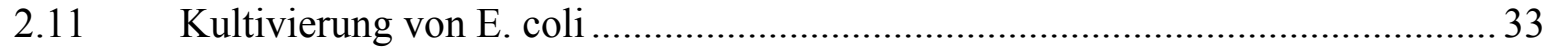

2.12 DNA-Transformation in E. coli und Isolation von Plasmiden ............................ 33

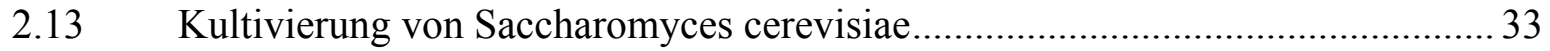

2.14 Hocheffiziente Hefe-DNA-Transformation durch LiAc-Methode........................ 35

2.14.1 Anwendung der hocheffizienten Hefe-DNA-Transformation ............................. 36

2.15 Niedereffiziente Hefe-DNA-Transformation durch LiAc-Methode ..................... 38

2.15.1 Anwendung der niedereffizienten Hefe-DNA-Transformation .......................... 38

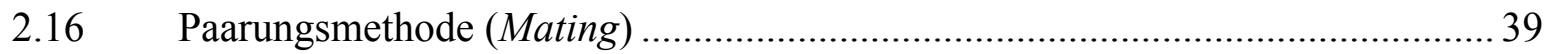

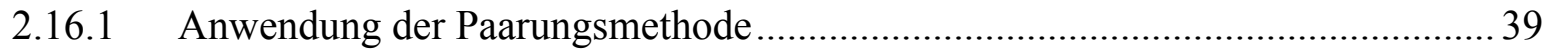

2.17 Einzel-Pulse-Chase-Experiment mit einem haploiden Hefestamm .................... 39

2.18 Doppel-Pulse-Chase-Experiment mit einem diploiden Hefestamm ................... 40

2.19 Batch-Umwandlung (Fluoreszenzkonversion durch UV-Licht) des Dendra2-

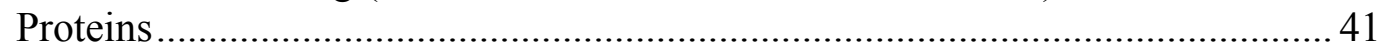

2.20 Doppel-Pulse-Chase-Experiment mit einer Batch-Umwandlung ....................... 41

2.21 Aufschluss von S. cerevisiae-Zellen - Erstellung von Proteinproben ................. 42

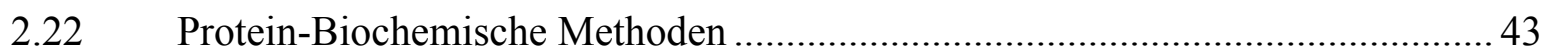

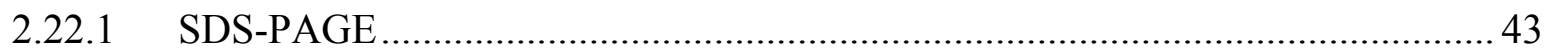

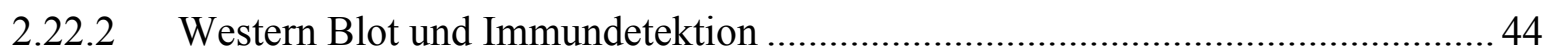

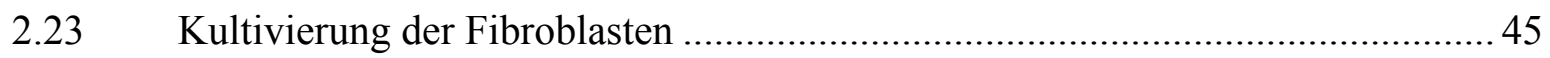

2.24 Probenvorbereitung zur Immunfluoreszenz von Fibroblasten ........................... 45

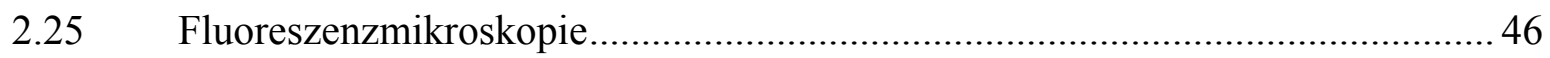

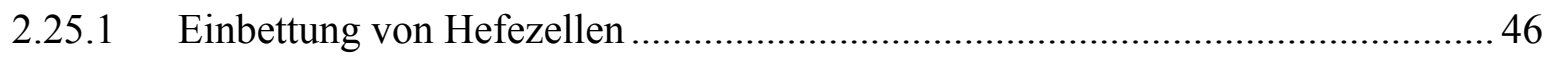

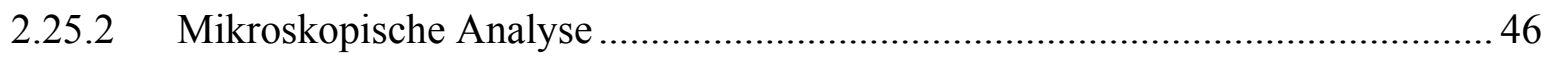

2.26 Verfahren zur Quantifizierung von mikroskopischen Bildern ............................ 46

2.26.1 Quantifizierung der Fluoreszenzkonversion .................................................. 46

2.26.2 Messung von Abstand zwischen Peroxisomen und Zellrand ............................. 47 


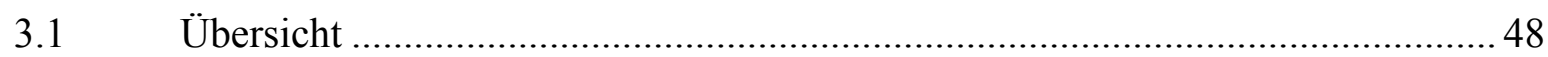

3.2 Experimente zur Peroxisomenbiogenese...................................................... 48

3.2.1 Experiment mit einem diploiden Hefestamm.................................................. 49

3.2.1.1 Nachweisexperimente der haploiden Hefestämme und Optimierung der

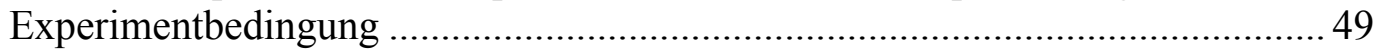

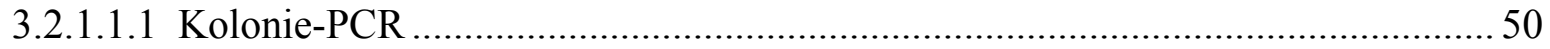

3.2.1.1.1.1 Überprüfung der Anwesenheit des XFP-Genabschnitts............................... 50

3.2.1.1.1.2 Überprüfung der Anwesenheit des nat NT2-Genabschnitts......................... 51

3.2.1.1.1.3 Überprüfung der Anwesenheit des GAL1prom-XFP-PEX3-Genabschnitts 52

3.2.1.1.2 Bestimmung der Kupferkonzentration .......................................................... 53

3.2.1.1.3 Optimale Konzentration des Kupfersulfats ..................................................... 54

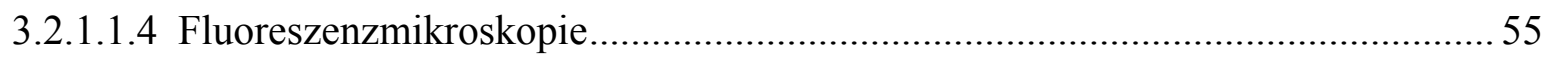

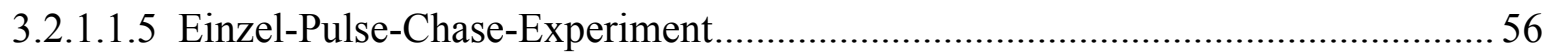

3.2.1.1.5.1 YKO-006 (CUP1prom-YFP-PEX3)……………………………........ 56

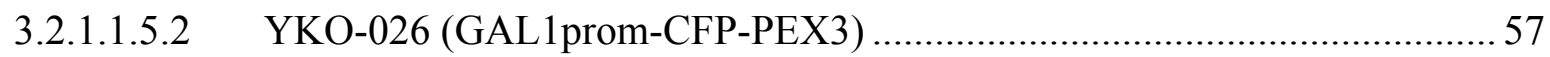

3.2.1.1.6 Nachweis von Peroxisomen durch Kolokalisation von fluoreszierendem Pex3p

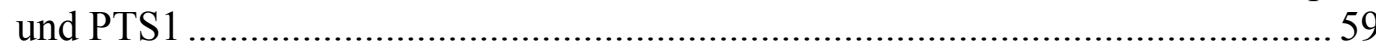

3.2.1.1.7 Überexpression vom Pex3p und Peroxisomenbiogenese ...................................... 61

3.2.1.2 Doppel-Pulse-Chase-Experiment mit einem gepaarten Hefestamm YKO-028 ... 62

3.2.2 Untersuchung mit dem Hefestamm YKO-025 (GAL1p-2x Dendra2-Pex3)........ 63

3.2.2.1 Nachweisexperimente und Etablierung der Fluoreszenzumwandlung ................. 64

3.2.2.1.1 Einzel Pulse-Chase-Experiment mit YKO-025 (GAL1prom- 2x Dendra2-PEX3)

3.2.2.1.2 Dendra-Induktionsexperiment und Farbumwandlung mittels des Lichtes durch den DAPI-Filter.

3.2.2.1.3 Etablierung des Verfahrens zur Fluoreszenzkonversion durch eine externe UV-

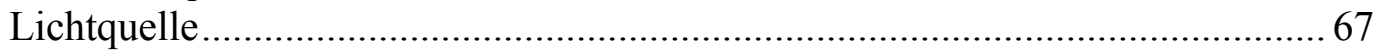

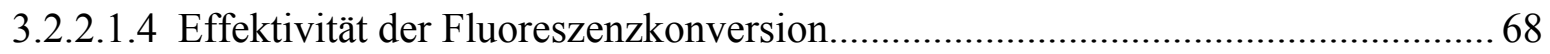

3.2.2.2 Doppel-Pulse-Chase-Experiment und Batch-Umwandlung................................. 69

3.3 Experimente zur Darstellung der räumlichen Beziehung zwischen ER und Peroxisomen ......................................................................................... 71

3.3.1 Immunfluoreszenz in menschlichen Fibroblasten zur Darstellung der räumlichen Beziehung zwichen ER und Peroxisomen ......................................................... 71

3.3.2 Untersuchung mit dem Hefestamm YKO-027 (GAL1prom-CFP-PEX3 mit

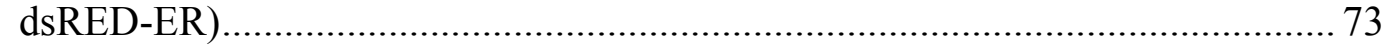

3.3.2.1 Einzel-Pulse-Chase-Experiment mit YKO-027 ................................................ 73

3.3.2.2 Messung des Abstands zwischen Peroxisomen und Zellrand .............................. 74 
3.3.3 Paarung: GAL1prom-CFP-PEX3 + dsREDER mit CUP1prom-YFP-PEX3 _...... 75

3.3.3.1 Doppel-Pulse-Chase-Experiment mit einem gepaarten Hefestamm YKO-029

(GAL1 1 rom-CFP-PEX3 + dsRED-ER mit CUP1prom-YFP-PEX3) .75

4

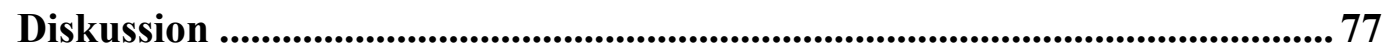

4.1 Fluoreszenzumwandlung von Dendra2-Dendra2-Pex3p in UV-Licht.................78

4.2 Optimale Kupferkonzentration für die Induktion des CUP1-Promotors.............. 79

4.3 Fluoreszenzdoppelmarkierung von Peroxisomen durch Pex3p und PTS1 ......... 80

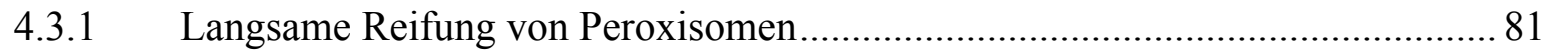

4.3.2 Überexpression vom Pex3p: Funktionsverlust von Peroxisomen........................ 82

4.4 Peroxisomenbiogenese: Reifung oder Fusionierung von Präperoxisomen .......... 83

4.5 Enge Räumliche Beziehung zwischen ER und Peroxisomen ............................ 86

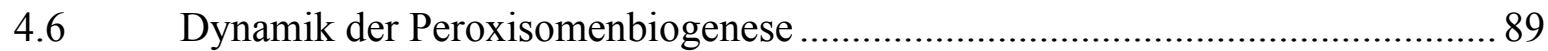

4.7 Modell zur zellulären Dynamik der Peroxisomenbiogenese............................... 91

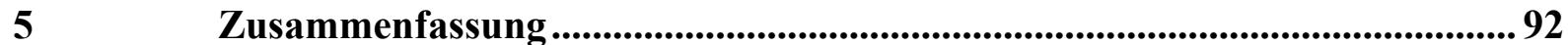




\section{ABKÜRZUNGSVERZEICHNIS}

ABC Adenosine triphosphate binding cassette

ACTH Adrenokortikotropes Hormon

Amp Ampicillin

APS

Ammoniumpersulfat

ATP Adenosintriphosphat

BSA Rinderserumalbumin

DAPI 4',6-Diamidino-2-phenylindol

DMEM Dulbecco's modified Eagles's medium

DMSO Dimethylsulfoxid

DNA Desoxyribonukleinsäure

Drp Dynamin related protein

DTT Dithiothreitol

E. coli Escherichia coli

EDTA Ethylendiamintetraessigsäure

ER Endoplasmatisches Retikulum

FKS Fötales Kälberserum

FP Fluorescent protein

HMG-CoA $\quad \beta$-Hydroxy- $\beta$-methylglutaryl-Coenzym A

LB Lysogeny broth

LMP Low melting point

$\mu \quad$ Mikro

OD Optische Dichte

ORF Offener Leserahmen

PAGE Polyacrylamidgelelektrophorese

PBD Peroxisomenbiogenesedefekte

PBS Phosphate Buffered Saline

PCR Polymerasekettenreaktion (Polymerase chain reaction)

PEG Polyethylenglykol

Pex Peroxin

PFA Paraformaldehyd

PMP Peroxisomales Membranprotein

PMSF Phenylmethylsulfonylfluorid

Prom Promotor

PTS Peroxisome targeting signal

RCDP Rhizomelia chondrodysplasia punctata

ROS Reaktive oxidative Spezies

Rpm Umdrehungen pro Minute (rounds per minute)

RT Raumtemperatur 
S. cerevisiae Saccharomyces cerevisiae

SD Synthetic complete Drop out

SDS Natriumdodecylsulfat

TBE Tris-Borat-EDTA

TBST Tris-buffer-saline-tween20

TCA Trichloressigsäure

TEMED N,N, $\mathrm{N}^{\prime}, \mathrm{N}^{\prime}$-Tetramethylethylendiamin

TRIS Tris(hydroxymethyl)-aminomethan

U Unit (Enzymaktivität)

$\mathrm{Ub} \quad$ Ubiquitin

UV Ultraviolett

$\mathrm{V} \quad$ Volumen

VLCFA Very long chain fatty acids

WT Wildtyp

X-ALD X-linked adrenoleukodystrophy

YNB Yeast nitrogen base

YPD Yeast pepton dextrose

ZNS Zentrales Nervensystem 


\section{AMINOSÄURECODE}

\begin{tabular}{|c|c|c|}
\hline Aminosäure & $\begin{array}{c}\text { Abkürzung im } \\
\text { 1-Buchstaben-Code }\end{array}$ & $\begin{array}{c}\text { Abkürzung im } \\
\text { 3-Buchstaben-Code }\end{array}$ \\
\hline Alanin & A & Ala \\
\hline Arginin & $\mathrm{R}$ & Arg \\
\hline Asparagin & $\mathrm{N}$ & Asn \\
\hline Asparaginsäure & $\mathrm{D}$ & Asp \\
\hline Cystein & $\mathrm{C}$ & Cys \\
\hline Glutamin & $\mathrm{Q}$ & Gln \\
\hline Glutaminsäure & $\mathrm{E}$ & Glu \\
\hline Glycin & G & Gly \\
\hline Histidin & $\mathrm{H}$ & His \\
\hline Isoleucin & I & Ile \\
\hline Leucin & $\mathrm{L}$ & Leu \\
\hline Lysin & $\mathrm{K}$ & Lys \\
\hline Methionin & M & Met \\
\hline Phenylalanin & $\mathrm{F}$ & Phe \\
\hline Prolin & $\mathrm{P}$ & Pro \\
\hline Serin & $\mathrm{S}$ & Ser \\
\hline Threonin & $\mathrm{T}$ & Thr \\
\hline Tryptophan & $\mathrm{W}$ & Trp \\
\hline Tyrosin & $\mathrm{Y}$ & Tyr \\
\hline Valin & $\mathrm{V}$ & Val \\
\hline
\end{tabular}

\section{NUKLEINSÄURECODE}

\begin{tabular}{cc}
\hline Nucleinsäure & Abkürzung \\
\hline Adenin & $\mathrm{A}$ \\
Cytosin & $\mathrm{C}$ \\
Guanin & $\mathrm{G}$ \\
Thymin & $\mathrm{T}$ \\
Uracil & $\mathrm{U}$ \\
\hline
\end{tabular}




\section{TABELLENVERZEICHNIS}

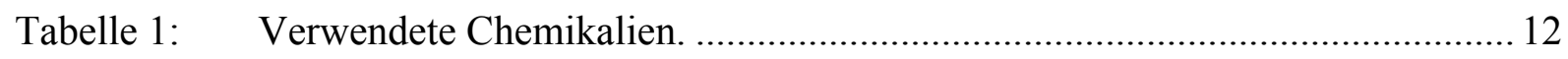

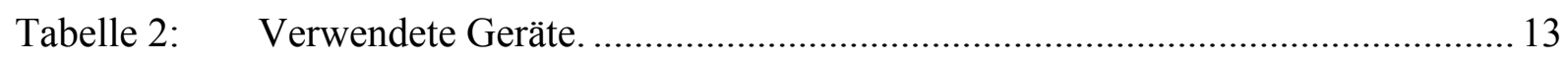

Tabelle 3: Verwendete Aufreinigungs- und Reaktionssysteme. ....................................... 13

Tabelle 4: $\quad$ Stammbezeichnung, Genotyp und Herkunft des verwendeten Escherichia-coli-

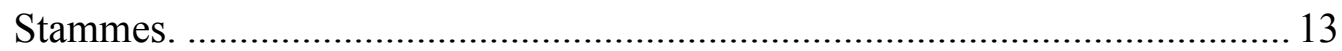

Tabelle 5: $\quad$ Stammbezeichnung, Genotyp und Herkunft der verwendeten Stämme von $S$.

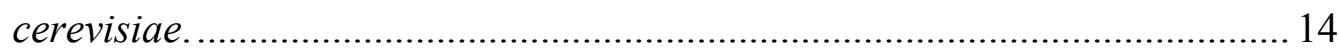

Tabelle 6: Stammbezeichnung, Genotyp und Herkunft der verwendeten Fibroblasten.... 14

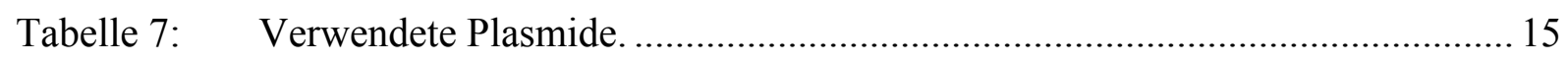

Tabelle 8: Verwendete Antikörper und Herkunft.......................................................... 15

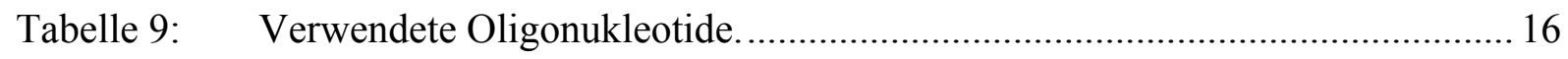

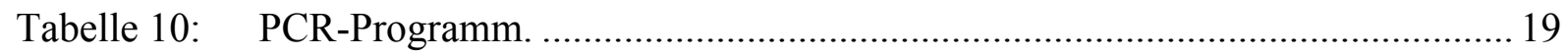

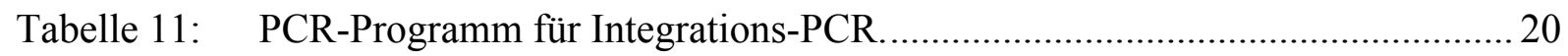

Tabelle 12: PCR-Programm für Kolonie-PCR …......................................................... 21

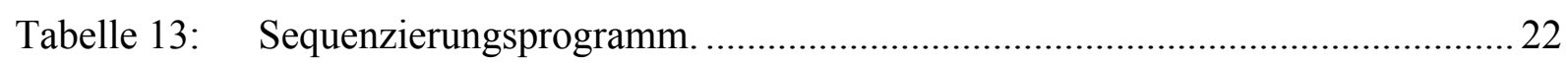

Tabelle 14 Ergebnis der Konzentrationsbestimmung von Kupfersulfat im Medium und in

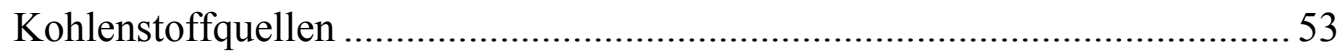




\section{ABbILDUNGSVERZEICHNIS}

Abbildung 1 Membranbiosynthese von Peroxisomen .................................................... 3

Abbildung 2 Matrixproteintransport über die peroxisomale Membran............................... 4

Abbildung 3 Modelle der Peroxisomenbiogenese ......................................................... 9

Abbildung 4 Übersicht für das Klonierungskonstrukt von pKO-003 ................................. 23

Abbildung 5 Restriktionsverdau von Vektor pYM-N4 mit EspEI und EcoRI ................... 24

Abbildung 6 Agarosegelanalyse nach dem Testverdau................................................. 24

Abbildung 7 Übersicht des Klonierungskonstrukts für das Plasmid pKO-005 .................. 25

Abbildung 8 Agarosegelanalyse des Testverdaus von pKO-005 mit einer Negativ- bzw. Positivkontrolle des Ausgangsplasmids ..................................................... 26

Abbildung 9 Klonierungskonstrukt für das Plasmid pKO-012 …...................................... 28

Abbildung 10 Klonierungskonstrukt für das Plasmid pKO-008 …..................................... 29

Abbildung 11 Besonderheit bei der Klonierung vom pKO-008 …....................................... 30

Abbildung 12 Agarosegelanalyse nach dem Testverdau vom pKO-009............................. 31

Abbildung 13 Konstrukt für die Klonierung von Plasmid pKO-010 ................................. 32

Abbildung 14 Konstrukt der Integrations-PCR ….......................................................... 36

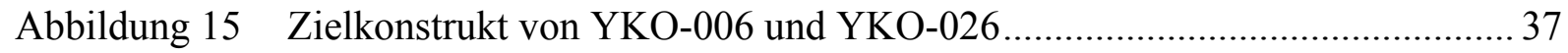

Abbildung 16 Konstrukt und Ergebnis der Kolonie-PCR zum Nachweis eines Genabschnittes von Fluoreszenzproteinen ............................................... 51

Abbildung 17 Konstrukt und Ergebnis der Kolonie-PCR zum Nachweis der Anwesenheit des natNT2-Genabschnittes

Abbildung 18 Konstrukt und Ergebnis von Kolonie-PCR zum Nachweis von GAL1prom-

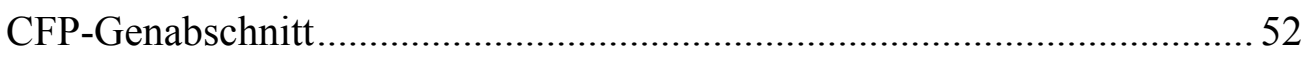

Abbildung 19 Induktion vom yEYFP-Pex3p in unterschiedlicher Kupferkonzentration..... 54

Abbildung 20 16-stündige Induktion mit Negativkontrolle mit WT (BY4741).................. 55

Abbildung 21 Analyse von Einzel-Pulse-Chase-Experiment mit dem Hefestamm, YKO-006

Abbildung 22 Analyse von Einzel-Pulse-Chase-Experiment mit dem Hefestamm YKO-026 
Abbildung 23 Mikroskopische Analyse von Pulse-Chase-Experiment mit YKO-025 (GAL1prom-CFP-PEX3 mit YFP-PTS1). 59

Abbildung 24 Mikroskopische Analyse von Pulse-Chase-Experiment mit YKO-017 (CUP1prom-YFP-PEX3 mit eqFP-611-PTS1).

Abbildung 25 Überexpression von Pex3p im Hefestamm YKO-017 (CUPprom-YFP-PEX3 mit YFP-PTS1)

Abbildung 26 Doppel-Pulse-Chase-Experiment mit YKO-028 (CUP1prom-YFP-PEX3 mit GAL1prom-CFP-PEX3)

Abbildung 27 Ergebnis von Einzel-Pulse-Chase-Experiment mit YKO-025 (GAL1prom-2x Dendra2-PEX3)

Abbildung 28 Farbumwandlung vom 2x Dendra-Pex3p bei einer Bestrahlung mit dem Licht durch den DAPI-Filter 66

Abbildung 29 Batch-Umwandlung der Zellen sämtlich mit Medium vom YKO-025 67

Abbildung 30 Grauwertanalyse vor und nach der Fluoreszenzkonversion von Dendra2Pex3p von YKO-025 68

Abbildung 31 Doppel-Pulse-Chase-Experiment mit einer Fluoreszenzumwandlung mit YKO-025 (GAL1prom-2x Dendra2-PEX3) .70

Abbildung 32 Mikroskopische Analyse der Immunfluoreszenz in Fibroblasten (Wildtyp und PEX19 ${ }^{-/-}$) mit PDI- und Anti-Pex3p-Antikörper .72

Abbildung 33 Pulse-Chase-Experiment mit YKO-027 (GAL1prom-CFP-PEX3 mit DsREDER). 73

Abbildung 34 Quantifizierung von Abstand zwischen Peroxisomen und Zellrand 74

Abbildung 35 Doppel-Pulse-Chase-Experiment mit dem YKO-028 (GAL1prom-CFP-PEX3 + dsRED-ER mit CUP1prom-YFP-PEX3)

Abbildung 36 Vereinfachte Darstellung der Methode zur Fluoreszenzdarstellung und schematische Darstellung der Genotypen von drei Hefestämmen unter einer Manipulation des PEX3-Gens 77

Abbildung 37 Grundprinzip einer Doppel-Markierung von Peroxisomen durch fluoreszierendes PTS1 80

Abbildung 38 Detaillierte Darstellung von Doppel-Pulse-Chase-Experiment mit YKO-025 eine Stunde nach der Beendigung der zweiten Induktion .85

Abbildung 39 Darstellung von ringförmigen Strukturen mit 2xDendra-Pex3p 87 
Abbildung 40 Detaillierte Darstellung des Einzel-Pulse-Chase-Experiments mit dem YKO027 eine Stunde nach der Beendigung der einstündigen Induktion mit Galactose..... 90

Abbildung 41 Detail der Aufnahme des Einzel-Pulse-Chase-Experiments mit YKO-027 vier Stunden nach der Beendigung der Induktion mit Galactose, sowie detaillierte Darstellung des Doppel-Pulse-Chase-Experiments drei Stunden nach der Beendigung der zweiten Induktion im Kupfersulfat 90

Abbildung 42 Modell der zellulären Dynamik der Peroxisomenbiogenese 91 


\section{Einleitung}

Peroxisomen wurden zum ersten Mal im Jahre 1954 von der Arbeitsgruppe von RHODIN in Mausnieren beschrieben [RHODIN 1954]. Damals wurden sie als Microbodies, und später von DE Duve als Peroxisomen bezeichnet [DE DuVE und BAudhuin 1966].

In dieser Einleitung wird zuerst auf die Stoffwechselfunktionen von Peroxisomen sowie auf peroxisomale Erkrankungen eingegangen. Danach wird ein Überblick über die Entwicklung der Forschung in der Peroxisomenbiogenese gegeben. Abschließend werden Aufgabenstellung und Zielsetzung dieser Arbeit genannt.

\subsection{Stoffwechselfunktionen von Peroxisomen}

Peroxisomen beteiligen sich an vielfältigen Stoffwechselprozessen in den eukaryotischen Zellen: Beispielsweise seien der Stoffwechsel der Lipide, Reaktive Sauerstoffspezies (ROS), sowie Oxidation und Peroxidation in verschiedenen Soffwechselwegen genannt. Zum Fettmetabolismus gehört die $\beta$-Oxidation, die zur Verkürzung der sehr langkettigen Fettsäuren (VLCFA) führt [WANDERS et al. 1995, REDDY und MANNAERTS 1994].

Zur peroxisomalen Fettstoffwechselfunktion gehören nicht nur der Abbau von VLFCA, sondern auch die Biosynthese verschiedener Fettsäurederivate wie Ether-Phospholipide, Glyoxylsäure, Phytansäure, Pipecolsäure, Gallensäuren sowie Plasmalogenen. Hierbei übernehmen Peroxisomen die wichtigsten Teilschritte. Die Plasmalogene sind die wichtigsten cerebralen und hepatischen Phospholipide. Bei der Beseitigung der ROS sind Oxidase, Peroxidase und Kalatase die wichtigen peroxisomalen Enzyme, die die Teilschritte des Stoffwechsels der ROS ermöglichen, so dass diese letztendlich zu $2 \mathrm{H}_{2} \mathrm{O}$ und $\mathrm{O}_{2}$ abgebaut und die Zelle somit entgiftet wird [DOENECKE et al. 2005, HasiliK 2007, HetTema und TABAK 2000, SCHRADER und FAHIMI 2006 a].

\subsection{Peroxisomale Erkrankungen}

Peroxisomen sind nicht nur von zellbiologischer Bedeutung, sondern auch von medizinischem Interesse. Peroxisomale Erkrankungen lassen sich entsprechend ihrer Pathophysiologie in zwei Gruppen aufgliedern: Peroxisomale Einzelprotein- bzw. 
Einzelenzymedefekte und Peroxisomenbiogenesedefekte (PBD) [GÄRTNER 2000, RAYMOND 2001, Moser 2000, WANDERS et al. 1995, FOLZ und Trobe 1991].

$\mathrm{Zu}$ den Einzelproteindefekten gehört als häufigste Erkrankung dieser Gruppe die Xchromosomale Adrenoleukodystrophie (X-ALD). Diese X-chromosomale Krankheit beruht auf einem Defekt des ATP-bindenden Membranproteins, des sog. ABC-Transporters, das für den Transport der VLCFA in Peroxisomen verantwortlich zu sein scheint [WANDERS und WATERHAM 2004]. Eine Defizienz dieses Transporters führt zur Akkumulation der VLCFA im ganzen Körper, u.a. in den Zellen zur Myelinisierung der Nerven im ZNS, in den Zellen der Nebennierenrinde und in Leydig-Zellen in Hoden [WELLER et al. 2003, Moser 2000, RAYMOND 2001, WANDERs et al. 1995]. Die schwerste Form der X-ALD, die kindliche cerebrale Form, wird meist im frühen Schulkindesalter manifest. Die Symptome bestehen neurologisch in Verhaltensstörung, Ataxie, Sehstörung, epileptischen Anfällen, sowie endokrinologisch in einer Nebenniereninsuffizienz im Sinne von Morbus Addison. Die Erkrankung verläuft rasch progredient. Die Kinder sind nach wenigen Jahren blind, taub und schließlich dezerebiert [GÄRTNER 2007, HOFFMANN und MAYATEPEK 2005]. Weitere Erkrankungsformen sind die im frühen Erwachsenenalter auftretende Adenomyeloneuropathie und ein isoliert auftretender Morbus Addison.

Ein PBD manifestiert sich als Ausfall mehrerer oder aller peroxisomalen Enzyme. Diese Krankheitsbilder werden autosomal-rezessiv vererbt. PBD lässt sich in zwei phänotypische Gruppierungen aufteilen: Zellweger-Spektrum und Rhizomelia chondrodysplasia punctata (RCDP). Das Zellweger-Spektrum betrifft ca. 80\% der Patienten. Dieses lässt sich wiederum nach seinem Schweregrad in drei Phänotypen aufteilen: Zellweger-Syndrom (Zerebrohepatorenales Syndrom) als die schwerste Form, neonatale Adrenoleukodystrophie als mittelschwere Form und Morbus Refsum als die mildeste Form. Die Prognose dieser Erkrankung ist generell schlecht: Die Patienten mit der schwersten Form sterben innerhalb der ersten Lebensmonate. Die Patienten mit milderen Krankheitsformen überleben mehrere Jahre oder auch Jahrzehnte, jedoch mit einer schweren körperlichen und geistigen Behinderung [GÄRTNER 2007, WELLER et al. 2003, DANA und TUNNESSEN 1999, BAES et al. 1997].

Die klinischen Leitsymptome bei PBD sind Dysmorphien wie große Fontanelle, hohe Stirn, flache Nasenwurzel, Epikanthus, antevertierte Nares, Vierfingerfurche, dysplastische Ohren und Knorpelverkalkungen. Es bestehen schwere neurologische Störungen wie muskuläre Hypotonie, Epilepsie, Fütterungsschwierigkeiten sowie hepatointestinale Funktionsstörungen (Hepatomegalie, konjugierte Hyperbilirubinämie) [HOFFMANN und MAYATEPEK 2005, 
Clayton und Thompson 1988, Brosius und Gärtner 2002, KeAne et al. 2007, Folz und TROBE 1991].

Die RCDP ist durch eine schwere Skelettbeteiligung charakterisiert: Im Gegensatz zum ZS liegt eine Verkürzung der proximalen Röhrenknochen vor. Die Prognose ist ebenso schlecht: Viele Patienten sterben bereits vor dem ersten Lebensjahr, einige Patienten überleben jedoch auch länger [GÄRTNER 2007, WELLER et al. 2003].

\subsection{Modell zur Membranbiogenese von Peroxisomen}

Die Proteine, die sich am Einbau und Import peroxisomaler integraler Membranproteine in die peroxisomale Membran sowie am Transport der Matrixproteine beteiligen, sind als Peroxine (Pex) bezeichnet. Deren Gene werden PEX-Gen genannt. Diese Gene sind universal sowohl bei Hefen als auch bei Menschen [SACKSTEDER und GOULD 2000].

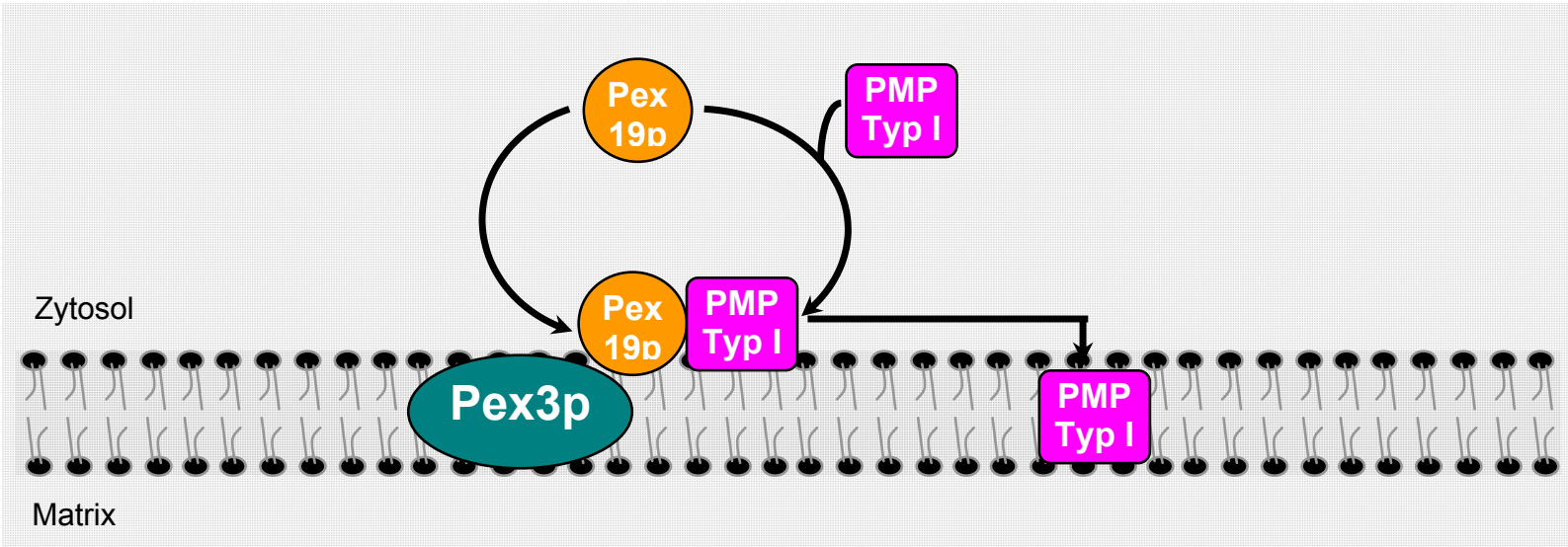

Abbildung 1: Membranbiosynthese von Peroxisomen. Pex19p interagiert mit PMPs vom Typ I im Zytosol und befördert diese an die peroxisomale Membran. Pex3p befindet sich ubiquitär in der peroxisomalen Membran und dient als ein Rezeptor für Pex19p. An der peroxisomalen Membran fungiert Pex19p als Chaperon für PMPs und unterstützt die Integration von PMPs vom Typ I in die peroxisomale Membran. (nach THOMS und ERDMANN 2005 a, S. 325)

Hierbei gibt es in menschlichen Zellen drei Peroxine, die für die peroxisomale Membranbiogenese essentiell sind: Pex3p, Pex16p und Pex19p. Pex3p und Pex19p beteiligen sich an der Zielsteuerung von peroxisomalen Membranproteinen (PMPs), ein essentieller Prozess für die Peroxisomenbildung. Ein Modell der Interaktion von Pex3p, Pex19p sowie PMP ist vereinfacht in der Abbildung 1 dargestellt. Es wird angenommen, dass Pex19p folgende Funktionen besitzt: Pex19p hält sich teilweise im Zytosol auf, interagiert mit einigen 
PMPs im Zytosol, damit die PMPs in die peroxisomale Membran gelangen können. Dabei fungiert Pex19p als ein löslicher Rezeptor für den Import der PMPs. An der peroxisomalen Membran unterstützt Pex19p die Integration von PMPs in die peroxisomale Membran als Chaperon. Die PMPs, die auf diesem Weg vom Zytosol direkt in die peroxisomale Membran gelangen, sind als PMP vom Typ I bezeichnet [FUJIKI et al. 2006, FANG et al. 2004, THOMS und ERDMANn 2005 a, JoNeS et al. 2004, RotTEnSTEINER et al. 2004, SACKSTEDER et al. 2000, SNYDER et al. 2000].

Pex3p ist nicht nur selbst ein PMP, sondern auch am Transport von PMPs vom Typ I beteiligt. Es ist ein Rezeptor für Pex19p an der peroxisomalen Membran. PMPs vom Typ I werden nach einer Interaktion mit Pex3p in die peroxisomale Membran eingebaut. Der genaue Prozess ist derzeit jedoch nicht bekannt. Pex3p und Pex19p sind nicht nur für die Lokalisation von PMPs, sondern auch für die Stabilität der peroxisomalen Membran verantwortlich [TORO et al. 2009, MATSUZAKI und FUJIKI 2008, VAN DER ZAND et al. 2006, Hettema et al. 2000, Muntau et al. 2000, SHIMOZAWA et al. 2000, BAERENDS et al. 1997].

Die Mutation bzw. Abwesenheit eines der beiden Proteine führt zur Abwesenheit von Peroxisomen. Die PEX3- bzw. PEX19-deletierten Zellen weisen ubiquitär im Zytosol PMPs sowie peroxisomale Enzyme auf, welches auf die Abwesenheit von Peroxisomen hinweist. Jedoch führt die erneute Expression von Pex3p bzw. Pex19p zur Peroxisomenbildung [HeTtema et al. 2000, KraGt et al. 2005, HoEPFNER et al. 2005, FABER et al. 2002, FuJiKi et al. 2006, THOMS und ERDMANN 2005 a].

Einige PMPs, zu denen ebenso Pex3p gehört, gelangen nicht direkt vom Zytosol, sondern über das endoplasmatische Retikulum (ER) in die peroxisomale Membran. Diese PMPs sind als PMPs vom Typ II bezeichnet. Pex3p spielt beim Transport der PMPs vom Typ II eine wichtige Rolle [HEILAND und ERDMANN 2005, ThOMs und ERDMANN 2005 b, FANG et al. 2004, JONES et al. 2004, GEUZE et al. 2003, TABAK et al. 2003].

Bei vielen PMPs wurde bisher gezeigt, dass sie über das ER in Peroxisomen gelangen [MA und SUBRAMANI 2009].

Jedoch wurden in Saccharomyces cerevisiae noch nicht PMPs vom Typ I beobachtet, die direkt in Peroxisomen gelangen. Es wird daher angenommen, dass alle PMPs in Saccharomyces cerevisiae Pex3p-abhängig über das ER in Peroxisomen gelangen [MUNCK et al. 2009, TABAK et al. 2008]. 


\subsection{Transport der peroxisomalen Martixproteine vom Zytosol in Peroxisomen}

Für funktionsfähige Peroxisomen sind nicht nur PMPs, sondern auch peroxisomale Matrixproteine essentiell. Diese bestehen überwiegend aus peroxisomalen Enzymen und werden vom Zytosol in Peroxisomen transportiert. In diesem Abschnitt wird der Mechanismus des Matrixproteintransports in Peroxisomen erläutert. Hierbei spielen zwei Peroxine sowie zwei Peroxisome Targeting Signals (PTSs) eine essentielle Rolle: Nämlich Pex5p, Pex7p, PTS1 sowie PTS2. In Abbildung 2 ist dieser Prozess schematisch dargestellt.

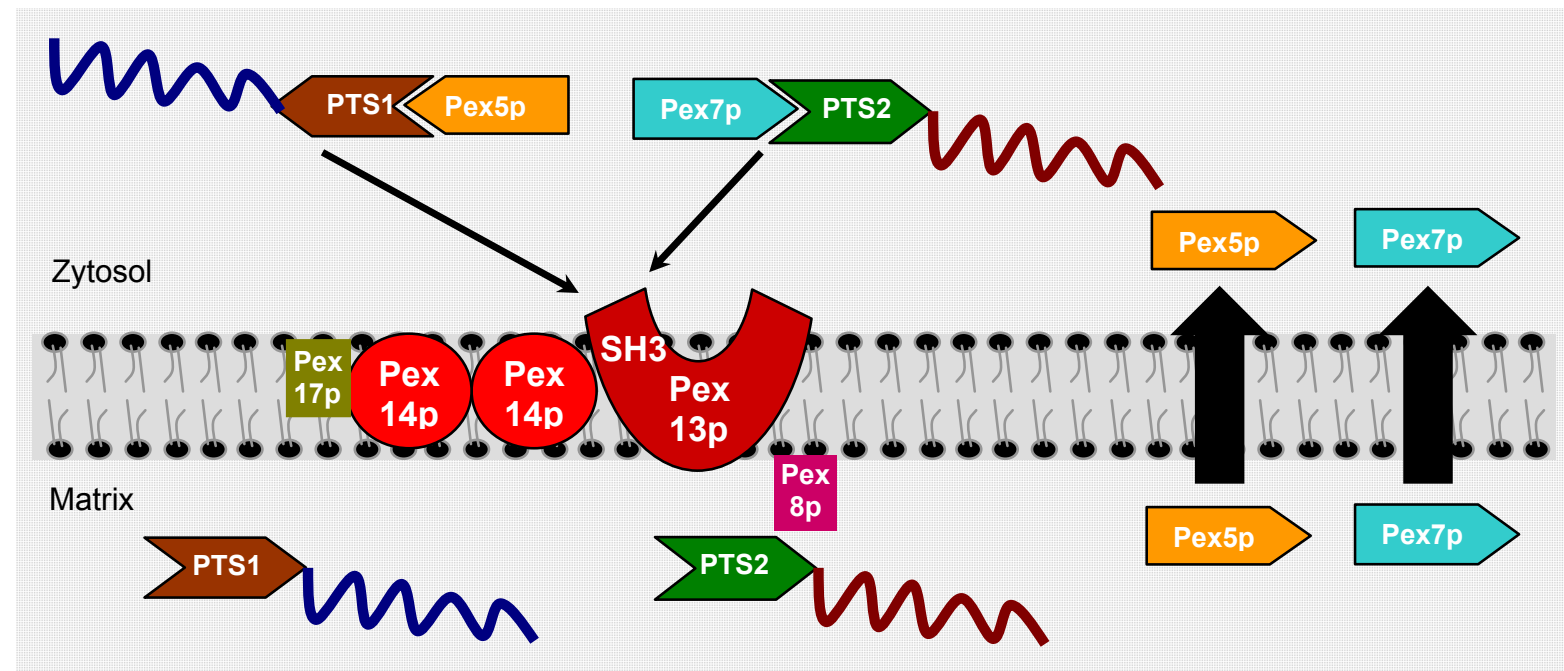

Abbildung 2: Matrixproteintransport über die peroxisomale Membran. PTS1 tragende peroxisomale Matrixproteine werden von Pex5p erkannt. PTS2 tragende peroxisomale Matrixproteine wird von Pex7p erkannt. Dieser Komplex bindet sich an Pex13p, Pex14p sowie Pex17p an der peroxisomalen Membran und gelangt auf unbekannte Weise in die peroxisomale Matrix. Pex5p bzw. Pex7p wird von PTS1 bzw. PTS2 dissoziiert und ins Zytosol freigesetzt. (nach HEILAND und ERDMANN 2005, S. 325)

Im Zytosol befinden sich Pex5p und Pex7p, die als lösliche Rezeptoren für PTS1 und PTS2 fungieren. Die Matrixproteine werden zunächst an freien zytosolischen Ribosomen synthetisiert. Sie enthalten entweder C- oder N-terminal ein PTS.

PTS1 ist ein Tripeptid bestehend aus Serin-Lysin-Leucin (SKL). Pex5p ist der Rezeptor für das PTS1 tragende peroxisomale Matrixprotein im Zytosol. Pex5p trägt im C-terminus eine Bindungsstelle für PTS1. Mehr als 90\% der bekannten peroxisomalen Matrixproteine tragen ein PTS1. PTS2 umfasst ca. 20 Aminosäuren. Pex7p bindet die PTS2 tragenden Matrixproteine. Weniger als $10 \%$ der bekannten peroxisomalen Matrixproteine tragen ein PTS2 [THOMS und ERDMANN 2005 a, LAZAROw 2003, BROWN und BAKER 2008, DAMMAI und SUBRAMANi 2001, KUNAU et al. 2001]. 
An der peroxisomalen Membran sind Pex17p, Pex14p, Pex13p wichtig. Sie interagieren mit dem Pex5p-PTS1-Matrixprotein-Komplex bzw. Matrixprotein-PTS2-Pex7p-Komplex. Der genaue Transportprozess ist derzeit noch nicht bekannt. Nachdem das Matrixprotein an den Zielort gelangt ist, wird Pex5p bzw. Pex7p von PTS1- bzw. PTS2-Proteinkomplex dissoziiert. PTS und das Matrixprotein bleiben in der peroxisomalen Matrix. Pex $5 p$ und Pex $7 p$ werden ins Zytosol freigesetzt [ThOMs und ERDMANn 2006, SACKSTEDER und Gould 2000, SMITH und SCHNELL 2001, KLEIN et al. 2001].

\subsection{Neue Entwicklungen in der Forschung der Peroxisomenbiogenese}

In diesem Abschnitt wird auf einige Aspekte der Neuentwicklung in der Forschung zu der Peroxisomenbiogenese eingegangen: Vermehrung von Peroxisomen anhand der Publikation von Motley und Hettema (2007) und räumliche Beziehung zwischen ER und Peroxisomen anhand der Arbeit von HoEPFNER et al. (2005). Schließlich werden neue Modelle der Peroxisomenbiogenese dargestellt.

\subsubsection{De-novo-Biogenese und Teilung von Peroxisomen}

Peroxisomen sind in der Lage, sich nicht nur durch Teilung, sondern auch durch Neubildung zu vermehren [HOEPFNER et al. 2005, SCHRADER und FAHIMI 2006 b].

Motley und Hettema (2007) experimentierten mit einem Hefestamm, dessen PEX3-Gen deletiert war, und ein Wildtyp mit intaktem PEX3-Gen. Die beiden Hefestämme waren in der Lage, PTS1 mit unterschiedlichen Fluoreszenzproteinen zu markieren. Diese beiden Hefestämme wurden miteinander gepaart. Durch die Paarung beider Hefestämme wurde das fehlende PEX3-Gen des PEX3-deletierten Hefestamms ausgeglichen. Die Markierung von PTS1 führte dann zur Markierung von reifen Peroxisomen. Der Paarungsvorgang wurde mittels mikroskopischer Filmaufnahme verfolgt. Nach der Paarung ließ sich feststellen, dass keine neuen Peroxisomen gebildet wurden, sondern die Vermehrung von Peroxisomen lediglich durch Teilung erfolgte, falls die Zellen bereits Peroxisomen besaßen. In Abwesenheit präexistierender Peroxisomen entstanden allerdings neue Peroxisomen. Die Autoren beobachteten außerdem, dass bei einem Teilungsarrest von Peroxisomen durch die Entfernung des Dynamin-ähnlichen Proteins, Vps1, keinerlei Vermehrung der Peroxisomen stattfand. Vps1 ist für die peroxisomale Teilung essentiell. Dieser Befund erhärtete die Aussage der Autoren, dass Peroxisomen in Anwesenheit von bereits existierenden 
Peroxisomen nicht neu gebildet werden, sondern sich durch Teilung vermehren. Aufgrund dieser Beobachtung schlagen die Autoren das Wachstums- und Teilungsmodell der Peroxisomenneubildung vor: Vorstufen von Peroxisomen fusionieren mit reifen Peroxisomen. Die Vermehrung von Peroxisomen erfolgt nur durch Teilung von reifen Peroxisomen. Ausschließlich in Abwesenheit präexistierender Peroxisomen findet Neubildung der Peroxisomen statt.

\subsubsection{Peroxisomen und das endoplasmatische Retikulum (ER)}

Es gibt einen Hinweis darauf, dass das ER an der Neubildung der Peroxisomen beteiligt ist [Titorenko und Mullen 2006, BAscom et al. 2003, TABAK et al. 2003]. HoEPFNER et al. (2005) führten mit einem Hefestamm, der das ER mit Fluoreszenzprotein markiert, ein Experiment durch. Die Hefestämme waren ebenso in der Lage, Pex3p bzw. Pex19p mit Fluoreszenz zu markieren, sowie mit einem regulierbaren Promotor die Induktion von Pex3p bzw. Pex19p zu steuern. Eine Stunde nach Neuinduktion von Pex3p bzw. Pex19p ließ sich feststellen, dass die beiden Peroxine mit dem ER kolokalisiert waren. Dieses Ergebnis wies darauf hin, dass sich Pex3p und Pex19p vor der Peroxisomenentstehung im ER aufhielten. Es scheint, dass der Transportweg über das ER in Peroxisomen für einige PMPs einen essentiellen Transportmechanismus bei der Peroxisomenbildung darstellt. Wie bereits erläutert gibt es die sog. PMPs vom Typ II, die vom Zytosol auf diesem Weg in die Peroxisomen gelangen [Heiland und ERdmann 2005, GEuZE et al. 2003, Titorenko und RACHUBINSKI 1998].

Bei der Peroxisomenentstehung aus dem ER sowie beim Transport von PMP vom Typ II spielt jedoch ein anderer Mechanismus eine Rolle als ein Vesikeltransport von ER unter Einwirkung vom Coat Protein Complex (COP). SouTH et al. (2001), GEUZE et al. (2003) sowie VOORN-BROUwER et al. (2001) berichten, dass die Inhibition von COP I und COP II bei den menschlichen Fibroblasten keine Blockade für die Vesikelentstehung mit Pex3p vom ER darstellte, und somit die Peroxisomenbiogenese nicht blockiert war. Die Peroxisomenentstehung aus dem ER sowie Proteintransport zwischen ER und Peroxisomen sind nach diesen Autoren nicht von vesikulärer Natur. Jedoch stellen SALOMONS et al. (1997) in Hansenula polymorpha fest, dass die Blockierung der Vesikelbildung am ER durch Brefeldin A zur Akkumulation von neu synthetisiertem peroxisomalem Membran- und Matrixprotein am ER führt und Peroxisomen nicht neu gebildet werden können. 
Für die Peroxisomenbiogenese sind nicht nur Membranproteine essentiell, sondern auch Membranlipide u.a. Phospholipide. Da Peroxisomen nicht komplette Enzyme für die Biosynthese von Phospholipiden besitzen, ist die Versorgung von Phospholipiden auf einen Transport dieser vom Zytosol angewiesen. Die Phospholipide werden ebenso teilweise über das ER in Peroxisomen transportiert. Hierbei gibt es ebenso einen Hinweis darauf, dass es einen speziellen nicht-vesikulären Transportmechanismus der Phospholipide zwischen Peroxisomen und ER gibt [RAYCHAUDHURI und PRINZ 2008].

Nach KIM et al. (2006) ist Pex16p bei menschlichen Zellen in der Peroxisomenneubildung ein wichtiger Faktor: Sie berichten, dass in Anwesenheit von Pex16p mehr Peroxisomen zu erkennen waren, als in dessen Abwesenheit. Pex16p fördert den Proteintransport aus dem ER in Peroxisomen.

Es gibt jedoch die Meinung, dass das ER an der Peroxisomenbiogenese möglicherweise nicht beteiligt ist. SOUTH et al. (2001) führten ein Experiment mit Hefestämmen mit deletiertem SEC61-Gen durch, deren Proteintransportweg vom Zytosol zum ER somit blockiert war. Es wurde festgestellt, dass Peroxisomenbildung trotzdem stattfand.

\subsubsection{Modelle der Peroxisomenbiogenese}

In Abbildung 3 sind mögliche Modelle der Peroxisomenbiogenese dargestellt.

Die ersten beiden Modelle sind „Reifungsmodelle“.

Im ersten Modell entstehen Peroxisomenvorstufen, sog. Präperoxisomen aus dem ER durch die Einwirkung von Dynamin-ähnlichen Proteinen (Drps). In diesem Fall wird angenommen, dass die Drps für den Transport vom Pex3p aus dem ER wichtig sind. Mehrere PräPeroxisomen fusionieren miteinander, und reifen zu einem Peroxisom [KUNAU 2005, VAN DER ZAND et al. 2006].

Nach dem zweiten Modell entstehen Präperoxisomen zuerst aus dem ER und fusionieren zunächst miteinander. Sie verlängern sich und werden zu reifen Peroxisomen, die sich unter Einwirkung von Drp zu mehreren Peroxisomen teilen. Die Drps sind essentielle Faktoren für peroxisomale Teilung in diesem Modell [THOMS und ERDMANN 2005 b]. 
Das dritte Modell ist ein „Wachstums- und Teilungsmodell“. Zuerst entstehen Präperoxisomen aus dem ER. Diese fusionieren dann mit reifen Peroxisomen. Das ER versorgt bereits vorhandene Peroxisomen mit Lipiden und PMPs vom Typ II. Reife Peroxisomen teilen sich, und vermehren sich unter Einwirkung von Drps [MOTLEY und HeTtema 2007, TANAKA et al. 2007, SCHRADER und FAHIMI 2008].

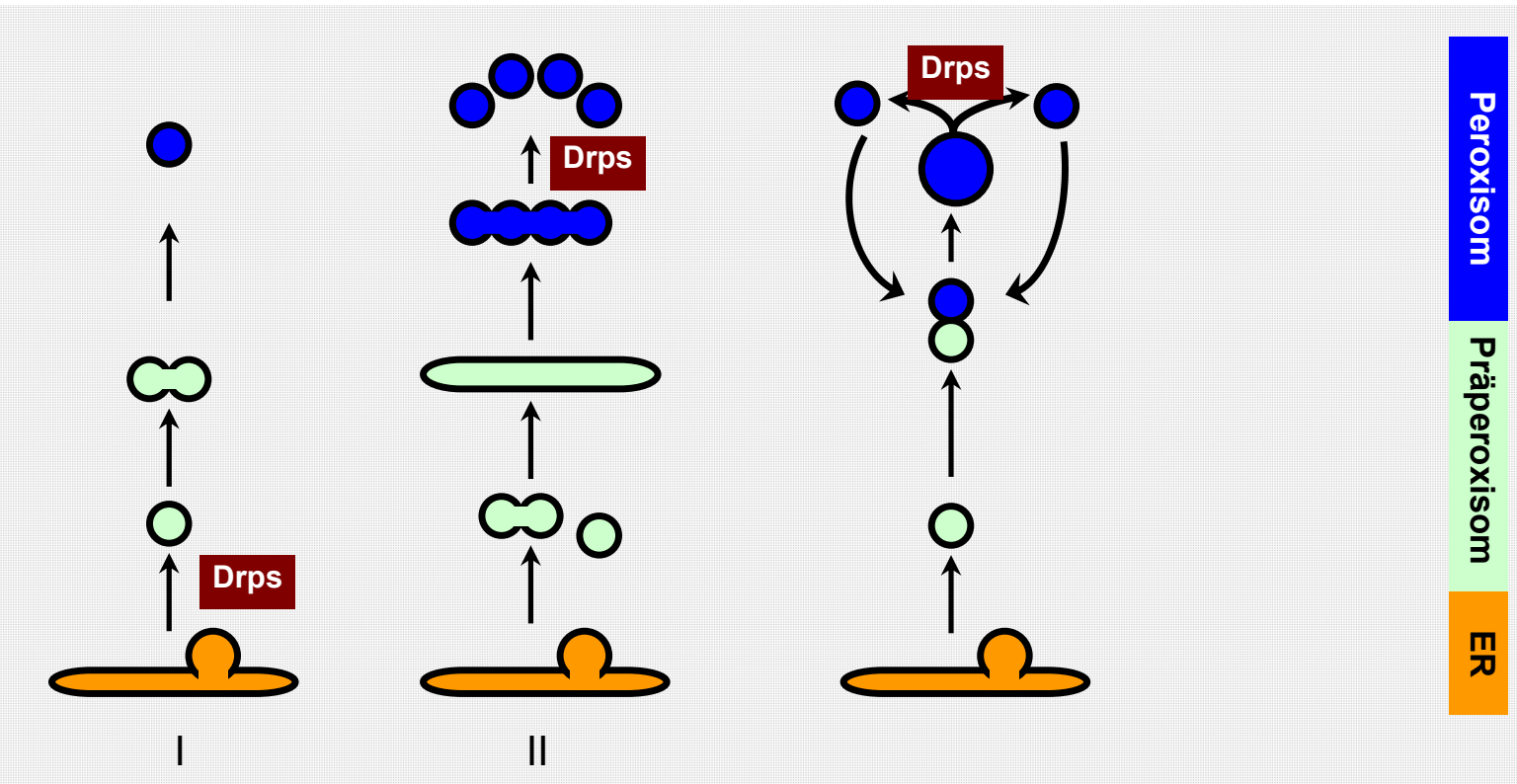

Abbildung 3: Modelle der Peroxisomenbiogenese. Nach den ersten beiden Modellen (I und II) entstehen Peroxisomen neu aus dem ER. Aus dem ER stammende Strukturen (Präperoxisomen) werden zu reifen Peroxisomen, die Matrixproteine importieren. Nach dem Modell I sind Drps die Faktoren für die Entstehung von Präperoxisomen aus dem ER. Im Modell II fusionieren Präperoxisomen zuerst miteinander, werden zu reifen Peroxisomen und sich unter Einwirkung von Drps teilen. Das Modell III ist sog. Teilungsmodell: Peroxisomen entstehen aus dem ER. Sie vermehren sich durch Teilung von bereits vorhandenen Peroxisomen. Das ER versorgt Präperoxisomen mit Lipiden und PMPs vom Typ II. Diese fusioniert mit präexistierenden Peroxisomen. Drps sind die wichtigen Faktoren für Teilung von Peroxisomen. (nach MOTLEY Und HETTEMA 2007, S. 400) 


\subsection{Aufgabenstellung und Zielsetzung}

Die Fragestellung dieser Arbeit besteht darin, zum Verständnis der Peroxisomenbiogenese beizutragen und die Peroxisomenneubildung in An- und Abwesenheit von bereits existierenden Peroxisomen zu untersuchen. Es soll die Frage geklärt werden, ob Vorstufen von Peroxisomen entstehen und zu reifen Peroxisomen werden (Reifungsmodell), oder ob Vorstufen von Peroxisomen miteinander fusionieren (Fusionsmodell). Dazu müssen zuerst neue Untersuchungsmethoden etabliert werden. Zunächst soll eine Reihe von Hefestämmen unter Manipulation des PEX3-Gens vom Wildtyp-Hefestamm hergestellt werden, um Pex3pInduktion unter Kontrolle zu stellen, sowie Peroxisomen unter Fluoreszenzlicht darzustellen. Nach Charakterisierung dieser Hefestämme werden die Hauptexperimente durchgeführt. Darüber hinaus wird auf die Fragestellung zur räumlichen Beziehung zwischen Peroxisomen und ER in menschlichen Fibroblasten sowie Hefezellen durch die Darstellung von dem ER und Peroxisomen eingegangen. 


\section{MATERIAL UND METHODEN}

\subsection{Chemikalien}

Chemikalien wurde, sofern nicht anders vermerkt, von folgenden Firmen bezogen:

\begin{tabular}{|c|c|}
\hline Produkt & Firma \\
\hline $4 \times$ SDS-Ladepuffer & Carl Roth \\
\hline Aceton & Sigma-Aldrich \\
\hline Agar & Carl Roth \\
\hline Agarose & Bioline \\
\hline Aminosäuren & Sigma-Aldrich oder Carl Roth \\
\hline Ammoniumpersulfat & Sigma-Aldrich \\
\hline Ammoniumsulfat & Carl Roth \\
\hline Ampicillin & Serva \\
\hline Bacto-Trypton & Carl Roth \\
\hline BigDye & Qiagen \\
\hline BigDye-Puffer & Qiagen \\
\hline Biotin & Sigma-Aldrich \\
\hline Borsäure & Carl Roth \\
\hline Bromphenolblau & Carl Roth \\
\hline Calciumchlorid & Sigma-Aldrich \\
\hline clonNAT & WERNER BioAgents \\
\hline Coral Load PCR Puffer & Qiagen \\
\hline DMEM (high glucose) & PAA Laboratories \\
\hline DMSO & Carl Roth \\
\hline DTT & Sigma-Aldrich \\
\hline EDTA & Slgma-Aldrich \\
\hline Eisen(III)chlorid & Sigma-Aldrich \\
\hline Essigsäure & Carl Roth \\
\hline Ethanol & Sigma-Aldrich \\
\hline Ethidiumbromid & Carl Roth \\
\hline FKS & Biochrom \\
\hline Formamin & Carl Roth \\
\hline Formaldehyd & Carl Roth \\
\hline Galactose & Carl Roth \\
\hline GeneRuler DNA Ladder Mix SM0331 & Fermentas \\
\hline Glucose & Carl Roth \\
\hline Glycerin & Sigma-Aldrich \\
\hline Hefeextrakt & Carl Roth \\
\hline Hefe-Stickstoff-Base (YNB) & Sigma-Aldrich \\
\hline Inositol & Sigma-Aldrich \\
\hline Kaliumiodid & Sigma-Aldrich \\
\hline Kaliumphosphat & Sigma-Aldrich \\
\hline
\end{tabular}




\begin{tabular}{|c|c|}
\hline Kupfersulfat & Sigma-Aldrich \\
\hline Lachsspermien-DNA & Sigma-Aldrich \\
\hline LMP Agarose & Sigma-Aldrich \\
\hline Lumi-Light Western Blotting Substrate & Roche \\
\hline Magermilch & BioRad Laboratories \\
\hline Magnesiumchlorid & Sigma-Aldrich \\
\hline Magnesiumsulfat & Sigma-Aldrich \\
\hline Mangansulfat & Sigma-Aldrich \\
\hline$\beta$-Mercaptoethanol & Sigma-Aldrich \\
\hline Methanol & Sigma-Aldrich \\
\hline Natriumchlorid & Sigma-Aldrich \\
\hline Natriummolybdän & Sigma-Aldrich \\
\hline Natronlauge & Sigma-Aldrich \\
\hline Niacin & Sigma-Aldrich \\
\hline Nitrocellulose-Folie $(0,45 \mu \mathrm{m})$ & Whatmann \\
\hline Oligonukleotide & Metabion \\
\hline p-Aminobenzoesäure & Sigma-Aldrich \\
\hline Pantothensäure & Sigma-Aldrich \\
\hline PBS & PAA Laboratories \\
\hline PEG 3350 & Sigma-Aldrich \\
\hline Pepton & Carl Roth \\
\hline Pfu-DNA-Polymerase & Promega \\
\hline PMSF & Merck \\
\hline ProSieve Color Protein Markers & Lonza \\
\hline ProLong Gold & Invitrogen \\
\hline Puffer für Pfu-DNA-Polymerase & Promega \\
\hline Puffer für Restriktionsnuklease & New England BioLabs \\
\hline Puromycin & Serva \\
\hline Pyridoxine- $\mathrm{HCl}$ & Sigma-Aldrich \\
\hline Raffinose-Hydrochlorid & Carl Roth \\
\hline Restriktionsendonukleasen & New England BioLabs \\
\hline Rotiphorese Gel 30\% & Carl Roth \\
\hline Salzsäure $(\mathrm{HCl})$ & Sigma-Aldrich \\
\hline SDS & Sigma-Aldrich \\
\hline Taq-DNA-Polymerase & Qiagen \\
\hline TCA & Sigma-Aldrich \\
\hline TEMED & Carl Roth \\
\hline Thiamin- $\mathrm{HCl}$ & Sigma-Aldrich \\
\hline TRIS & Carl Roth \\
\hline Triton-X100 & Carl Roth \\
\hline Tween 20 & Carl Roth \\
\hline Tween 40 & Sigma-Aldrich \\
\hline Vent-DNA-Polymerase & New England BioLabs \\
\hline Zinksulfat & Sigma-Aldrich \\
\hline
\end{tabular}

\section{Tabelle 1: Verwendete Chemikalien.}




\subsection{Geräte}

\begin{tabular}{|l|l|}
\hline \multicolumn{1}{|c|}{ Geräte } & \\
\hline Zeitrifuge für Falcons (Rotatanta) & Hettich \\
\hline pH-Meter G820 & Schott Garät \\
\hline Thermocycler T3000 & Biometra \\
\hline Vortex & Janke \& Kunkel \\
\hline Brutschrank & Hettich \\
\hline Schüttler & New Brunswick \\
\hline BioPhotometer & Eppendorf \\
\hline Drehrad & Schütt \\
\hline Luminescent Image Analyzer & FUJI Film \\
\hline Sterilfilter & Sartorius \\
\hline Mikroskop AXIO & Zeiss \\
\hline AXIO CAM HR & Zeiss \\
\hline UV-Lampe 365 nm & Bachofer \\
\hline T3 Thermocycler & Biometra \\
\hline Fastblot B43 & Biometra \\
\hline Standard Power Pack P25 & Biometra \\
\hline Mini PROTEIN Tetra Cell & BioRad \\
\hline X-Cite Serie 120 (UV-Licht) & EXFO \\
\hline Zentrifuge Mikro 200R & Hettich \\
\hline 3100 Avant Genetik Analyzer & Biometra \\
\hline Centrifuge 5415D & Eppendorf \\
\hline Thermomixer 5436 & Eppendorf \\
\hline
\end{tabular}

Tabelle 2: $\quad$ Verwendete Geräte.

\subsection{Aufreinigungs- und Reaktionssysteme (Kits)}

\begin{tabular}{|l|l|}
\hline \multicolumn{1}{|c|}{ Bezeichnung } & \multicolumn{1}{c|}{ Firma } \\
\hline High Pure PCR Product Purification Kit & Roche \\
\hline Ligate-IT Kit & Usb \\
\hline Nucleospin Extrakt II & Macherey-Nagel \\
\hline Nucleospin Plasmid & Macherey-Nagel \\
\hline
\end{tabular}

Tabelle 3: $\quad$ Verwendete Aufreinigungs- und Reaktionssysteme.

\subsection{Mikroorganismen}

\subsubsection{Escherichia coli}

\begin{tabular}{|c|c|c|}
\hline Stamm & Genotyp & Quelle \\
\hline $\begin{array}{l}\text { CH3-Blue } \\
\text { competent } \\
\text { Cells }\end{array}$ & $\begin{array}{l}\mathrm{F}^{-} \Delta m c r \mathrm{~A} \Delta(\text { mrr-hsdRMS-mcrBC) } \text { \$80/acZ } \Delta \mathrm{M} 15 \\
\Delta / a c X 74 \text { recA1 endA1 ara } \Delta 139 \Delta(\text { ara, leu }) 7697 \text { ga/U } \\
\text { ga/K } \lambda r p s L\left(\mathrm{Str}^{\mathrm{R}}\right)\end{array}$ & Bioline $\mathrm{GmbH}$, Deutschland \\
\hline
\end{tabular}

Tabelle 4: $\quad$ Stammbezeichnung, Genotyp und Herkunft des verwendeten Escherichia-coliStammes. 


\subsubsection{Saccharomyces cerevisiae}

Die verwendeten $S$. cerevisiae-Stämme und jeweiligen Mutanten sind im Folgenden zu entnehmen.

\begin{tabular}{|c|c|c|}
\hline Stamm & Relevanter Genotyp & Quelle \\
\hline BY 4741 & MATa $\triangle$ leu2 $\Delta$ ura3 $\Delta$ his3 $\Delta$ met15 & EuroScarf, Frankfurt am Main* \\
\hline BY 4742 & MATa $\Delta$ leu2 $\Delta$ ura3 $\Delta$ his3 $\Delta l y s 2$ & EuroScarf, Frankfurt am Main* \\
\hline YST1108 & MATa $\Delta l e u 2$ Lura3 $\Delta$ his3 $\Delta l y s 2$ ppex3 & S. THOMS \\
\hline YKO-006 & $\begin{array}{l}\text { MATa } \triangle \text { leu2 } \triangle \text { ura3 } \triangle \text { his3 } \triangle m e t 15 \\
\text { natNT2-CUP1prom-yECitrine-PEX3 }\end{array}$ & diese Arbeit \\
\hline YKO-017 & $\begin{array}{l}\text { MATa } \triangle \text { leu2 } \Delta \text { ura3 } \triangle \text { his3 } \triangle m e t 15 \\
\text { natNT2-CUP1prom-yECitrine-PEX3 } \\
\text { Plasmid: TEFprom-eqFP611-PTS1 URA3 }\end{array}$ & diese Arbeit \\
\hline YKO-021 & $\begin{array}{l}\text { MATa } \triangle \text { leu2 } \triangle \text { ura3 } \triangle \text { his3 } \triangle \text { lys2 } \\
\text { natNT2-GAL1prom-yECFP-PEX3 } \\
\text { Plasmid: TEFprom-YFP-PTS1 URA3 }\end{array}$ & diese Arbeit \\
\hline YKO-025 & $\begin{array}{l}\text { MATa } \triangle l e u 2 \text { } \triangle \text { ura3 } \triangle \text { his3 } \triangle l y s 2 \triangle p e x 3 \\
\text { Plasmid: GAL1prom-Dendra2-Dendra2-PEX3 } \\
\text { LEU2 }\end{array}$ & diese Arbeit \\
\hline YKO-026 & $\begin{array}{l}\text { MATa } \Delta \text { leu2 } \Delta \text { ura3 } \triangle \text { his3 } \Delta / y s 2 \\
\text { natNT2-GAL1prom-yECFP-PEX3 }\end{array}$ & diese Arbeit \\
\hline YKO-027 & $\begin{array}{l}\text { MATa } \triangle \text { leu2 } \triangle \text { ura3 } \triangle \text { his3 } \triangle \text { lys2 } \\
\text { natNT2-GAL1prom-yECFP-PEX3 dsREDER- } \\
\text { KDEL }\end{array}$ & diese Arbeit \\
\hline YKO-028 & $\begin{array}{c}\text { MATa } \triangle \text { leu2 } \Delta \text { ura3 } \triangle \text { his3 } \Delta \text { met15 } \\
\text { natNT2-CUP1prom-yECitrine-PEX3 } \\
\text { X } \\
\text { MATa } \triangle \text { leu2 } \Delta \text { ura3 } \triangle \text { his } 3 \text { } \triangle l y s 2 \\
\text { natNT2-GAL1prom-yECFP-PEX3 }\end{array}$ & diese Arbeit \\
\hline YKO-029 & $\begin{array}{l}\text { MATa } \triangle \text { leu2 } \triangle \text { ura3 } \triangle \text { his3 } \triangle m e t 15 \\
\text { natNT2-CUP1prom-yECitrine-PEX3 } \\
\quad \mathrm{X} \\
\text { MATa } \triangle \text { leu2 } \Delta \text { ura3 } \triangle \text { his3 } \triangle l y s 2 \\
\text { natNT2-GAL1prom-yECFP-PEX3 dsREDER- } \\
\text { KDEL }\end{array}$ & diese Arbeit \\
\hline
\end{tabular}

${ }^{*}$ EUROSCARF, European Saccharomyces cerevisiae Archive for Functional Analysis, Frankfurt/Main

Tabelle 5: $\quad$ Stammbezeichnung, Genotyp und Herkunft der verwendeten Stämme von S. cerevisiae.

\subsubsection{Fibroblasten}

\begin{tabular}{|l|l|l|}
\hline \multicolumn{1}{|c|}{ Bezeichnung } & \multicolumn{1}{|c|}{ Relevanter Genotyp } & \multicolumn{1}{c|}{ Quelle } \\
\hline FM & Wildtyp & Arbeitsgruppe GÄRTNER \\
\hline $19^{-}$ & PEX19 & Arbeitsgruppe GÄRTNER \\
\hline
\end{tabular}

Tabelle 6: $\quad$ Stammbezeichnung, Genotyp und Herkunft der verwendeten Fibroblasten. 


\subsection{Vektoren und Plasmide}

In dieser Dissertation verwendete Vektoren und Plasmide sind im Folgenden aufgelistet.

\begin{tabular}{|c|c|c|}
\hline Bezeichnung & Relevanter Genotyp & Quelle \\
\hline pYM-N4 & natNT2-CUP1prom-yEGFP AmpR & JANKE et al. 2004 \\
\hline pYM-N25 & natNT2-GAL1prom-yEGFP AmpR & JANKE et al. 2004 \\
\hline pKT-211 & SpHIS5 yECitrineA206R AmpR & SHEFF und THORN 2004 \\
\hline pKT-212 & CaURA3: yECFPA206R AmpR & SHEFF und THORN 2004 \\
\hline PST815 & URA3 TEF AmpR & MUMBERG 2005 \\
\hline PST818 & URA3 TEF-eqFP611-PTS1 AmpR & MUMBERG 2005 \\
\hline pRS415TEF-PEX3 & LEU2 TEFprom-PEX3 & S. THOMS \\
\hline PST272 & TRP1 TEF-EYFP-PTS1 MET25 AmpR & S. THOMS \\
\hline pKW2207 & Dendra2-Dendra2 HIS5 AmpR & K. WEISS \\
\hline DsRed-KDEL & LEU2 KDEL.DsREDER AmpR & P. NOVICK \\
\hline pKO-003 & natNT2-CUP1prom-yECitrineA206R AmpR & diese Arbeit \\
\hline pKO-006 & natNT2-GAL1prom-yECFPA206R AmpR & diese Arbeit \\
\hline pKO-008 & LEU2 TEFprom-Dendra2-Dendra2-PEX3 & diese Arbeit \\
\hline pKO-010 & LEU2 GAL1prom-Dendra2-Dendra2-PEX3 & diese Arbeit \\
\hline pKO-012 & URA3 TEF-EYFP-PTS1 & diese Arbeit \\
\hline
\end{tabular}

Tabelle 7: Verwendete Plasmide.

\subsection{Antiseren}

\begin{tabular}{|c|c|c|c|c|c|}
\hline \multirow[b]{2}{*}{ Bezeichnung } & \multirow{2}{*}{$\begin{array}{c}\text { Antikörper } \\
\text { gegen }\end{array}$} & \multirow{2}{*}{$\begin{array}{l}\text { Erzeugt } \\
\text { von }\end{array}$} & \multicolumn{2}{|c|}{ Verdünnung } & \multirow[b]{2}{*}{ Quelle } \\
\hline & & & $\begin{array}{l}\text { Western } \\
\text { blot }\end{array}$ & $\begin{array}{c}\text { Immun- } \\
\text { fluoreszenz }\end{array}$ & \\
\hline PDI & ER & Mouse & & $1: 200$ & antibodies-online $\mathrm{GmbH}$ \\
\hline Anti Pex3p & Pex3p & Rabbit & $1: 5000$ & $1: 400$ & Arbeitsgruppe ERDMANN \\
\hline Anti GFP & GFP & Rabbit & $1: 5000$ & & Abcam \\
\hline Anti Ig HRP & Rabbit & Goat & $1: 10000$ & & Imgenex \\
\hline Cy3 & Rabbit & Goat & & $1: 10000$ & $\begin{array}{l}\text { Jackson Immuno } \\
\text { Research }\end{array}$ \\
\hline Cy5 & Mouse & Goat & & $1: 10000$ & $\begin{array}{l}\text { Jackson Immuno } \\
\text { Research }\end{array}$ \\
\hline
\end{tabular}

Tabelle 8: $\quad$ Verwendete Antikörper und Herkunft. 


\subsection{Oligonukleotide}

\begin{tabular}{|c|c|c|}
\hline Bezeichnung & Nukleotidsequenz (5'-3') & Verwendung \\
\hline OST 408 & CCTGTGTCTGCTCGAACC & $\begin{array}{l}\text { Antisense-Primer PEX3 } \\
\text { Kontrollprimer für Kolonie PCR }\end{array}$ \\
\hline OST 409 & GGCAGTAACCTGGCCCC & $\begin{array}{l}\text { Sense-Primer GAL1prom } \\
\text { Kontrollprimer für Kolonie PCR }\end{array}$ \\
\hline OST 422 & $\begin{array}{l}\text { GTAGTTAATACTAGTCATCGTAAAAGC } \\
\text { AGAAGCACGAAACAACGTACGCTGCA } \\
\text { GGTC GAC }\end{array}$ & $\begin{array}{l}\text { Sense-Primer } 40 \mathrm{~N} \text { downstream ATG } \\
\text { von PEX3 und } 20 \mathrm{~N} \text { von ATG mit S1 } \\
\text { [JANKE et al. 2004] }\end{array}$ \\
\hline OST 423 & $\begin{array}{l}\text { GATGTCTCTGCAGAAGCGAACGTGAT } \\
\text { CTTTGATTTGGGGCCATCATCGATGAA } \\
\text { TTCTCTGTCG }\end{array}$ & $\begin{array}{l}\text { Antisense-Primer 40N } \\
\text { reverskomprimentär downstrearn } \\
\text { ATG von PEX3 mit S4 [JANKE et al. } \\
\text { 2004] }\end{array}$ \\
\hline OST 425 & CGGCCATCAAAATGTATGG & $\begin{array}{l}\text { Antisense-Primer (natNT2 (230- } \\
248) \text { ) } \\
\text { Kontrollprimer für Kolonie-PCR }\end{array}$ \\
\hline OST 426 & GAATTGAGTGGCAATAGCA & $\begin{array}{l}\text { Sense-Kontrollprimer (PEX3 ORF } \\
(347-326))\end{array}$ \\
\hline OST 442 & $\begin{array}{l}\text { GCTCTAGATCCGGAATGTCTAAAGGTG } \\
\text { AAGAATTA }\end{array}$ & $\begin{array}{l}\text { Sense-Primer: XFP aus pKT211/212 } \\
\text { zusätzlich mit Schnittstelle für Xbal } \\
\text { und Bspl }\end{array}$ \\
\hline OST 443 & $\begin{array}{l}\text { GCGAATTCTCTGTCGGGGCACCAGCA } \\
\text { CCGGCACCAGCACCTTTGTACAATTC } \\
\text { ATCCATACC }\end{array}$ & $\begin{array}{l}\text { Antisense-Primer: XFP aus } \\
\text { pKT211/212 zusätzlich mit } \\
\text { Schnittstelle für EcoRI }\end{array}$ \\
\hline OST 446 & $\begin{array}{l}\text { GTCTAGAATGAACACCCCGGGAATTAA } \\
\text { C }\end{array}$ & $\begin{array}{l}\text { Sense-Primer: Dendra2 aus } \\
\text { pKW2207 zusätzlich mit } \\
\text { Schnittstelle für Xbal }\end{array}$ \\
\hline OST 455 & $\begin{array}{l}\text { CCACTAGTATGTCTAAAGGTGAAGAAT } \\
\text { TA }\end{array}$ & $\begin{array}{l}\text { Sense-Primer: XFP aus pKT211/212 } \\
\text { zusätzlich mit Schnittstelle für Spel }\end{array}$ \\
\hline OST488 & $\begin{array}{l}\text { GCGGATCCAGATCTACCACCACCCTT } \\
\text { G }\end{array}$ & $\begin{array}{l}\text { Antisense-Primer: } 1 \times \text { bzw. } 2 x \\
\text { Dendra2 aus pKW2207 zusätzlich } \\
\text { mit Schnittstelle für BamHI }\end{array}$ \\
\hline T3 & GCGCGAAATTAACCCTCACTAAAG & \\
\hline $\mathrm{T} 7$ & TAATACGACTCACTATAGGG & \\
\hline
\end{tabular}

Tabelle 9: $\quad$ Verwendete Oligonukleotide. 


\subsection{Analytische Methoden}

\subsubsection{Bestimmung der Kupferkonzentration}

Für die Kupferbestimmung des Nährmediums wurde jeweils ein 1-ml-Aliquot des Mediums sowie der Zuckerlösung bereitgestellt. Die erstellten Lösungen wurden im Labor Abteilung Klinische Chemie, Universitätsmedizin Göttingen zur Konzentrationsbestimmung weiter verarbeitet.

\subsubsection{Bestimmung der Zelldichte}

Die Zelldichte wurde mit einem Biophotometer (Eppendorf) bei einer Wellenlänge von 600 $\mathrm{nm}$ bestimmt. Eine $\mathrm{OD}_{600 \mathrm{~nm}}$ von 1,0 entspricht dabei ca. $3 \times 10^{7}$ S. cerevisiae-Zellen pro ml Kultur.

\subsubsection{Konzentrationsbestimmung von Nukleinsäuren}

Nukleinsäurekonzentrationen wurden mit einem Spektralphotometer bestimmt. Eine $\mathrm{OD}_{260}$ von 1,0 entspricht ca. $50 \mu \mathrm{g}$ doppelsträngiger DNA.

\subsection{Molekularbiologische Methoden}

\subsubsection{DNA-Restriktion}

Die Restriktion von DNA mittels Restriktionsendonukleasen erfolgte unter den vom Hersteller angegebenen Bedingungen.

Hierfür wurde folgender Ansatz erstellt:

DNA

Restriktionsendonuklease $10 \%(\mathrm{~m} / \mathrm{v})$

$2 \mathrm{mg} / \mathrm{ml}$
Menge je nach Fragestellung und Endvolumen

Menge je nach Fragestellung und Endvolumen

Puffer nach Angabe des Herstellers

BSA nach Angabe des Herstellers.

Je nach Eigenschaft des Restriktionsenzyms wurde die Probe bei vom Hersteller angegebener Temperatur von einer Stunde bis 18 Stunden inkubiert.

\subsubsection{Agarose-Gelelektrophorese}

Für die elektrophoretische Auftrennung von DNA wurden horizontale Agarose-Gele mit Konzentrationen zwischen $0,8 \%$ und 2\% (w/v) an Agarose verwendet. Die Agarose wurde in TBE-Puffer gelöst, und mit Ethidiumbromid so versetzt, dass sich daraus eine Endkonzentration von $0,5 \mu \mathrm{g} / \mathrm{ml}$ ergab. Die zu analysierende DNA wurde mit 1/10 Volumen 
sechsfach konzentriertem DNA-Probenpuffer versetzt. Die Elektrophorese fand bei $120 \mathrm{~V}$ für mindestens 30 Minuten bei RT statt.

TBE (Tris-Borat-EDTA)-Puffer:

$\begin{array}{ll}90 \mathrm{mM} & \text { Tris/Base } \\ 90 \mathrm{mM} & \text { Borsäure } \\ 2 \mathrm{mM} & \text { EDTA, pH 8,0. }\end{array}$

6x DNA Probenpuffer:

$\begin{array}{ll}0,5 \%(\mathrm{w} / \mathrm{v}) & \text { Bromphenolblau } \\ 0,1 \mathrm{M} & \text { EDTA } \\ 50 \%(\mathrm{w} / \mathrm{v}) & \text { Glycerin. }\end{array}$

\subsubsection{Isolierung von DNA-Fragmenten aus Agarose-Gelen}

Zur Isolierung von DNA-Fragmenten aus Agarose-Gelen wurde das Nucleospin Extract II Kit (Macherey-Nagel) verwendet. Die DNA-Fragmente wurden zunächst elektrophoretisch aufgetrennt, und unter Einwirkung von UV-Licht dargestellt, und aus dem Agarosegel ausgeschnitten. Die weiteren Aufreinigungsschritte erfolgten nach Angaben des Herstellers.

\subsubsection{Ligation von DNA-Fragmenten}

Zur Ligation von DNA-Fragmenten wurde das Ligate-IT Kit (USB) verwendet. Der Prozess erfolgte nach Angaben des Herstellers. 


\subsubsection{Amplifikation von DNA-Fragmenten mittels PCR (Polymerasekettenreaktion)}

Zur Durchführung der PCR z.B. zur Amplifikation eines DNA-Abschnittes für fluoreszierendes Protein mit Restriktionsschnittstellen wurde Plasmid-DNA als Matrize eingesetzt. Die Reaktion erfolgte in einem T3 Thermocycler (Biometra) nach folgender Zusammensetzung:

10\% (v/v) 10x PCR-Puffer der jeweiligen DNA-Polymerase

$0,2 \mathrm{mM} \quad \mathrm{dNTPs}$

25 pmol Spezifische Oligonukleotide (sense/antisense)

20-100 ng DNA-Matritze

1-2 U DNA-Polymerase (taq- und Vent Polymerase)

Endvolumen $50 \mu 1$.

\begin{tabular}{|l|l|l|}
\hline \multicolumn{1}{|c|}{ Reaktion } & \multicolumn{1}{c|}{ Temperatur } & \multicolumn{1}{c|}{ Zeit } \\
\hline 1 Denaturierung & $95^{\circ} \mathrm{C}$ & 40 Sek. \\
\hline 2 Denaturierung & $95^{\circ} \mathrm{C}$ & 40 Sek. \\
\hline 3 Hybridisierung & $\begin{array}{l}\text { Oligonukleotid-Primer- } \\
\text { abhängig }\end{array}$ & Produktgrößenabhängig \\
\hline 4 Amplifikation & $72{ }^{\circ} \mathrm{C}$ & 7 Min. \\
\hline 5 Amplifikation & $72{ }^{\circ} \mathrm{C}$ & Unendlich \\
\hline 6 Kühlen & $4{ }^{\circ} \mathrm{C}$ & \\
\hline
\end{tabular}

Tabelle 10: $\quad$ PCR-Programm.

Die Schritte von zwei bis vier wurden 27 mal wiederholt.

Die PCR-Ansätze wurden mit Hilfe vom High Pure PCR Product Purification Kit aufgereinigt. Die Aufreinigung erfolgte nach Angaben des Herstellers. 


\subsubsection{Integrations-PCR}

Zur Herstellung der speziellen DNA-Produkte mit Überhängen zur Integration in Hefegenome wurde eine spezielle PCR-Reaktion nach Angaben von JANKE et al. 2004 eingesetzt. Folgender Ansatz wurde erstellt:

$\begin{array}{ll}10 \%(\mathrm{~m} / \mathrm{v}) & 10 \times \text { Puffer (s. unten) } \\ 1 \mathrm{mmol} & \text { dNTPs } \\ 0,1 \mu \mathrm{mol} & \text { spezifische Oligonukleotide (sense/antisense) } \\ 200 \mathrm{ng} & \text { DNA-Matritze } \\ 2 \mathrm{U} & \text { Taq-Polymerase } \\ 0,4 \mathrm{U} & \text { Vent-Polymerase } \\ \text { Endvolumen } & 50 \mu 1 .\end{array}$

10 X Puffer:

$\begin{array}{ll}500 \mathrm{mM} & \text { Tris-HCl, } \mathrm{pH} 9,2 \\ 22,5 \mathrm{mM} & \text { Magnesiumchlorid } \\ 160 \mathrm{mM} & \text { Ammoniumsulfat } \\ 20 \% & \text { DMSO } \\ 1 \% & \text { Triton-X100. }\end{array}$

\begin{tabular}{|l|l|l|}
\hline \multicolumn{1}{|c|}{ Reaktion } & \multicolumn{1}{c|}{ Zeit } \\
\hline 1 Denaturierung & $97^{\circ} \mathrm{C}$ & $3 \mathrm{Min}$. \\
\hline 2 Denaturierung & $97^{\circ} \mathrm{C}$ & $1 \mathrm{Min}$. \\
\hline 3 Hybridisierung & $54^{\circ} \mathrm{C}$ & 30 Sek. \\
\hline 4 Amplifikation & $68^{\circ} \mathrm{C}$ & 2 Min. 40 Sek. \\
\hline 5 Denaturierung & $97^{\circ} \mathrm{C}$ & 1 Min. \\
\hline 6 Hybridisierung & $54^{\circ} \mathrm{C}$ & 30 Sek. \\
\hline 7 Amplifikation & $68^{\circ} \mathrm{C}$ & 2 Min. 40 Sek. \\
\hline 8 Kühlen & $4^{\circ} \mathrm{C}$ & Unendlich \\
\hline
\end{tabular}

Tabelle 11: $\quad$ PCR-Programm für Integrations-PCR.

Die Schritte von zwei bis vier wurden zehnmal, und die Schritte von fünf bis sieben wurden 20 Mal wiederholt, wobei die Zeit des Schritts sieben in jeder Runde um 20 Sekunden verlängert wurde. 


\subsubsection{Amplifikation von DNA-Fragmenten aus einem Hefestamm (Kolonie PCR)}

Zur Fragestellung, ob die genomische Integration in der Hefe-DNA erfolgreich war, wurde ein bestimmter Genabschnitt eines Hefestamms amplifiziert. Hierbei wurde eine PCR mit genomischer DNA aus S. cerevisiae als Matrize eingesetzt. Die Reaktion erfolgte ebenso in einem T3 Thermocycler (Biometra) nach folgendem Reaktionssatz:

$$
\begin{array}{ll}
10 \%(\mathrm{~m} / \mathrm{v}) & \text { CL-Puffer } \\
0,187 \mathrm{mM} & \text { dNTPs } \\
100 \mathrm{pmol} & \text { Spezifische Oligonukleotide (sense/antisense) } \\
1 \%(\mathrm{v} / \mathrm{v}) & \text { Triton X-100 } \\
1,5 \mathrm{U} & \text { Taq-Polymerase } \\
\text { Endvolumen } & 18 \mu \mathrm{l} .
\end{array}
$$

Die Hefezellen wurden in den Reaktionssatz direkt zugegeben (ca. $2 \mu 1$ ).

\begin{tabular}{|l|l|l|}
\hline \multicolumn{1}{|c|}{ Reaktion } & \multicolumn{1}{c|}{ Temperatur } \\
\hline 1 Denaturierung & $95^{\circ} \mathrm{C}$ & 4 Min. \\
\hline 2 Denaturierung & $95^{\circ} \mathrm{C}$ & 45 Sek. \\
\hline 3 Hybridisierung & $\begin{array}{l}\text { Oligonukleotid-Primer- } \\
\text { abhängig }\end{array}$ & 50 Sek. \\
\hline 4 Amplifikation & $72{ }^{\circ} \mathrm{C}$ & Produktgrößenabhängig \\
\hline 5 Amplifikation & $72{ }^{\circ} \mathrm{C}$ & 5 Min. \\
\hline 6 Kühlen & $4{ }^{\circ} \mathrm{C}$ & Unendlich \\
\hline
\end{tabular}

Tabelle 12: $\quad$ PCR-Programm für Kolonie-PCR.

Die Schritte von zwei bis vier wurden 30 Mal wiederholt.

Der gesamte Ansatz wurde mittels Agarose-Gelelektrophorese analysiert. 


\subsubsection{DNA-Sequenzierung}

Zuerst wurde die Sequenzierungsreaktion durchgeführt. Die Zusammensetzung des Ansatzes und des Cyclerprogramms ist im Folgenden dargestellt.

Sequenzierungsreaktion:

$\begin{array}{ll}600 \mathrm{ng} & \text { DNA zum Sequenzieren } \\ 5 \mathrm{pM} & \text { Primer } \\ 20 \%(\mathrm{v} / \mathrm{v}) & \text { BigDye Puffer } \\ 10 \%(\mathrm{v} / \mathrm{v}) & \text { BigDye. }\end{array}$

\begin{tabular}{|l|l|l|}
\hline \multicolumn{1}{|c|}{ Reaktion } & \multicolumn{1}{c|}{ Temperatur } & \multicolumn{1}{c|}{ Zeit } \\
\hline Denaturierung 1 & $96{ }^{\circ} \mathrm{C}$ & 10 Sek. \\
\hline Amplifikation 2 & $60^{\circ} \mathrm{C}$ & 4 Min. \\
\hline Ende 3 & $4{ }^{\circ} \mathrm{C}$ & Unendlich \\
\hline
\end{tabular}

Tabelle 13: Sequenzierungsprogramm.

Die Schritte 1-2 wurden 27 Mal wiederholt.

Zur Aufreinigung der amplifizierten DNA wurde zuerst folgender Fällungmix zusammengestellt:

Fällungsmix:

$$
\begin{aligned}
22 \%(\mathrm{v} / \mathrm{v}) & \text { Ethanol } \\
3 \%(\mathrm{v} / \mathrm{v}) & \text { Natriumacetat. }
\end{aligned}
$$

Dazu wurde das Sequenzierungsprodukt gegeben, und gut gemischt (Vortex). Nach 15minütiger Inkubation bei RT wurde die Probe bei $14.000 \mathrm{rpm} 30$ Minuten bei RT zentrifugiert. Nach dem Verwerfen des Überstandes wurde $300 \mu 1$ 70\%iges Ethanol zugegeben. Die Probe wurde weiter 10 Minuten bei $14.000 \mathrm{rpm}$ zentrifugiert. Nach dem Abziehen des Überstands wurde das Pellet mit offenem E-Cup bei $37^{\circ} \mathrm{C}$ getrocknet. Danach wurde das Pellet in $10 \mu 1$ Formamin resuspendiert und auf dem 3100 Avant Genetik Analyzer analysiert. 


\subsection{Klonierungen}

\subsubsection{Plasmid pKO-003 - yECitrine mit CUP1prom}
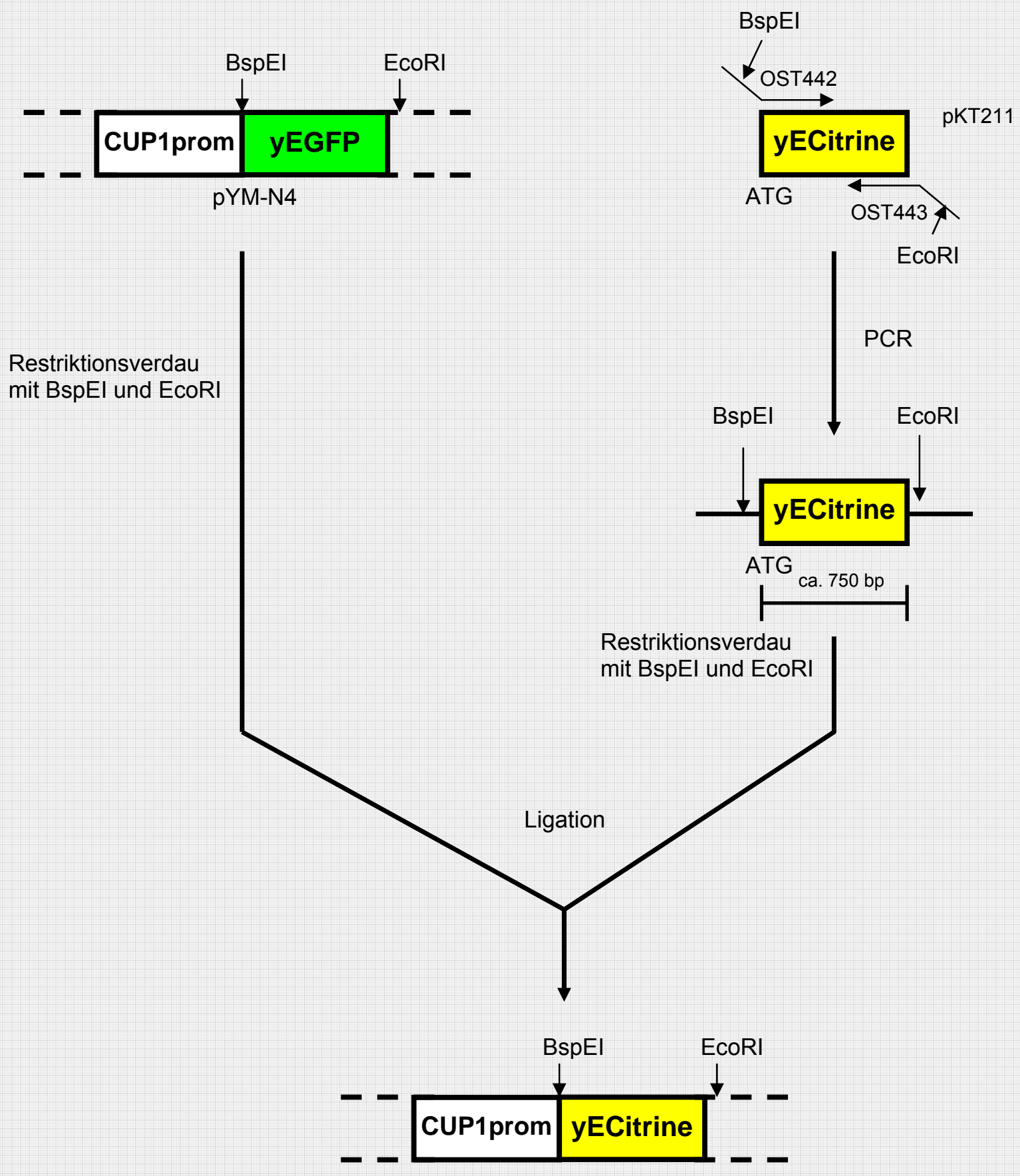

pKO-003

Abbildung 4: Übersicht für das Klonierungskonstrukt von pKO-003.

In Abbildung 4 ist das Konstrukt zur Klonierung von Plasmid pKO-003 dargestellt. Zuerst wurde das Gen für gelbfluoreszierendes Protein (yECitrine) aus dem Plasmid pKT211 durch eine PCR mit den Oligonukleotiden OST442 und OST443 amplifiziert, wodurch der DNA- 
Abschnitt mit den Schnittstellen von BspEI sowie EcoRI versehen wurden. Für diese PCR wurden Taq- und Vent-Polymerasen zur möglichst korrekten Amplifikation der DNA eingesetzt. In der Agarosegel-Analyse des PCR-Produktes war eine Bande bei ca. 750 bp zu sehen, was auf eine erfolgreiche PCR hinwies.

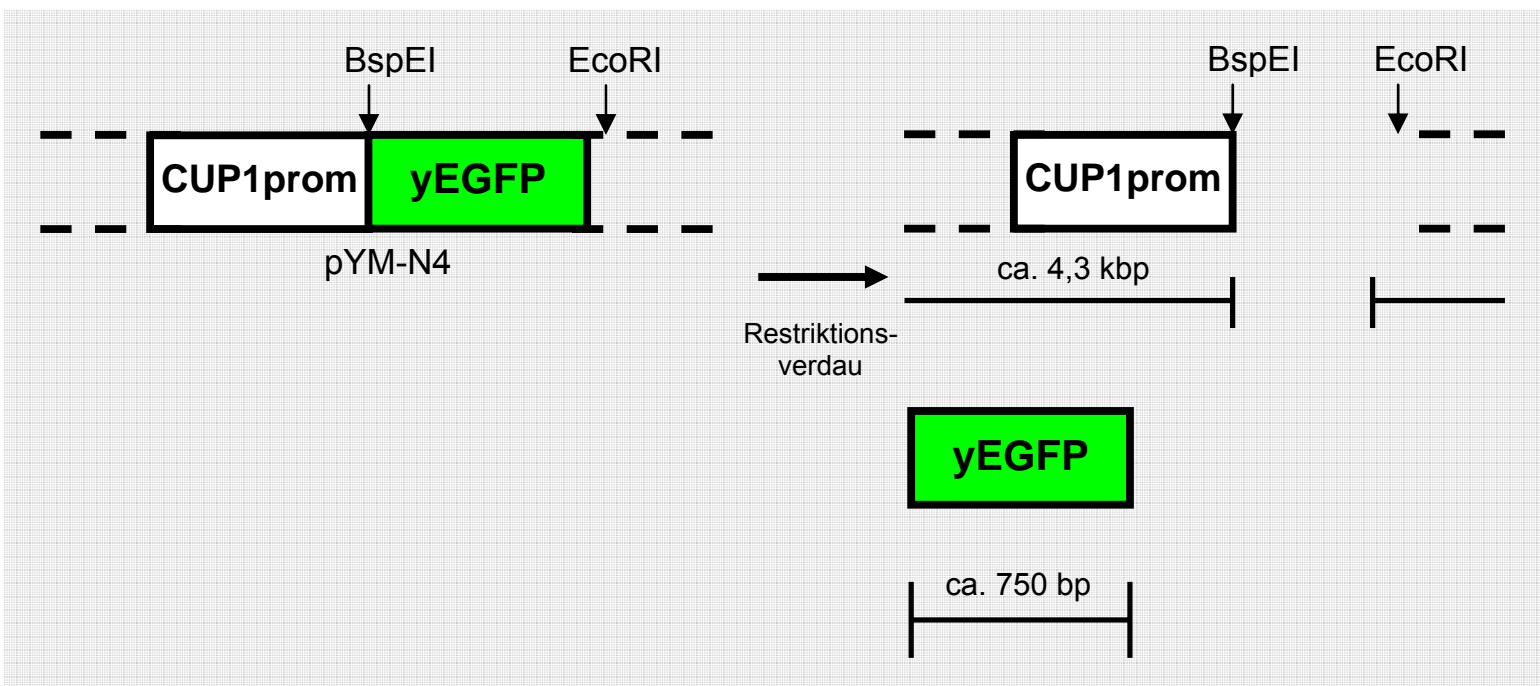

Abbildung 5: Restriktionsverdau von Vektor pYM-N4 mit EspEI und EcoRI.

Dann wurde ein Restriktionsverdau von Vektor pYM-N4 und dem amplifizierten yECitrine über Nacht mit den Restriktionsenzymen BspEI und EcoRI durchgeführt. In Abbildung 5 ist das Konstrukt des Restriktionsverdaus von Vektor pYM-N4 dargestellt.

Nach dem Restriktionsverdau waren auf dem Agarosegel zwei Banden bei ca. 4,3 kbp und bei ca. 750 bp zu erkennen, die der Größe von geöffnetem Vektor, sowie von yEGFP aus dem Vektor entsprachen. Die Bande bei ca. 4,8 kbp wurde zur weiteren Klonierung ausgeschnitten und mit dem Nucleospin Extract II Kit aufgereinigt. Nach dem Restriktionsverdau des Inserts war keine andere Bande außer einer bei ca. 750 bp sichtbar. Dieser wurde mit dem PCRPurification Kit zur weiteren Verarbeitung aufgereinigt. Danach wurden die beiden Fragmente mit Hilfe von Ligate-IT ligiert und in E. coli transformiert.

Nach Isolierung des Plasmids aus E. coli wurde

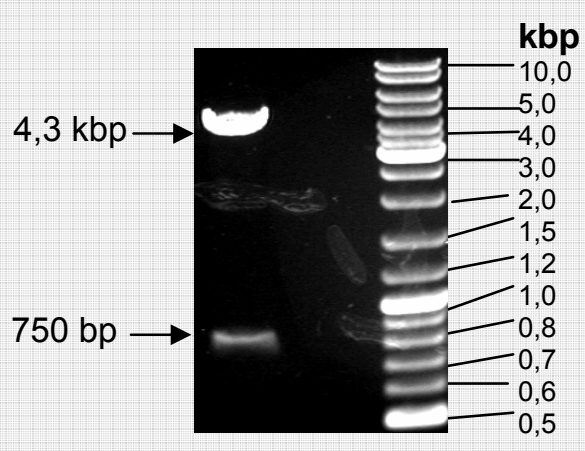
ein Testverdau mit den Restriktionsenzymen BspEI und EcoRI durchgeführt. Der Testverdau

Abbildung 6: Agarosegelanalyse nach dem Testverdau. 
diente zur Prüfung der Richtigkeit des klonierten Plasmids. Wie in Abbildung 6 dargestellt, sind zwei Banden bei 4,3 kbp und 750 bp bei dieser Kolonie zu erkennen, die auf positive Kolonie hinwiesen.

\subsubsection{Plasmid pKO-005 - yECFP mit GAL1prom}
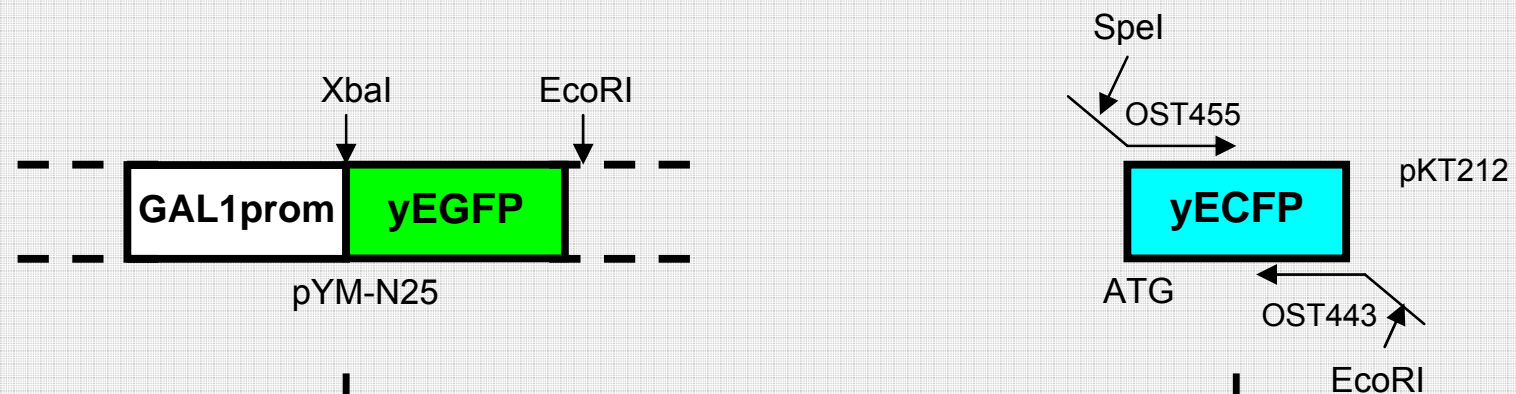

Restriktionsverdau
mit BamHI und EcoR
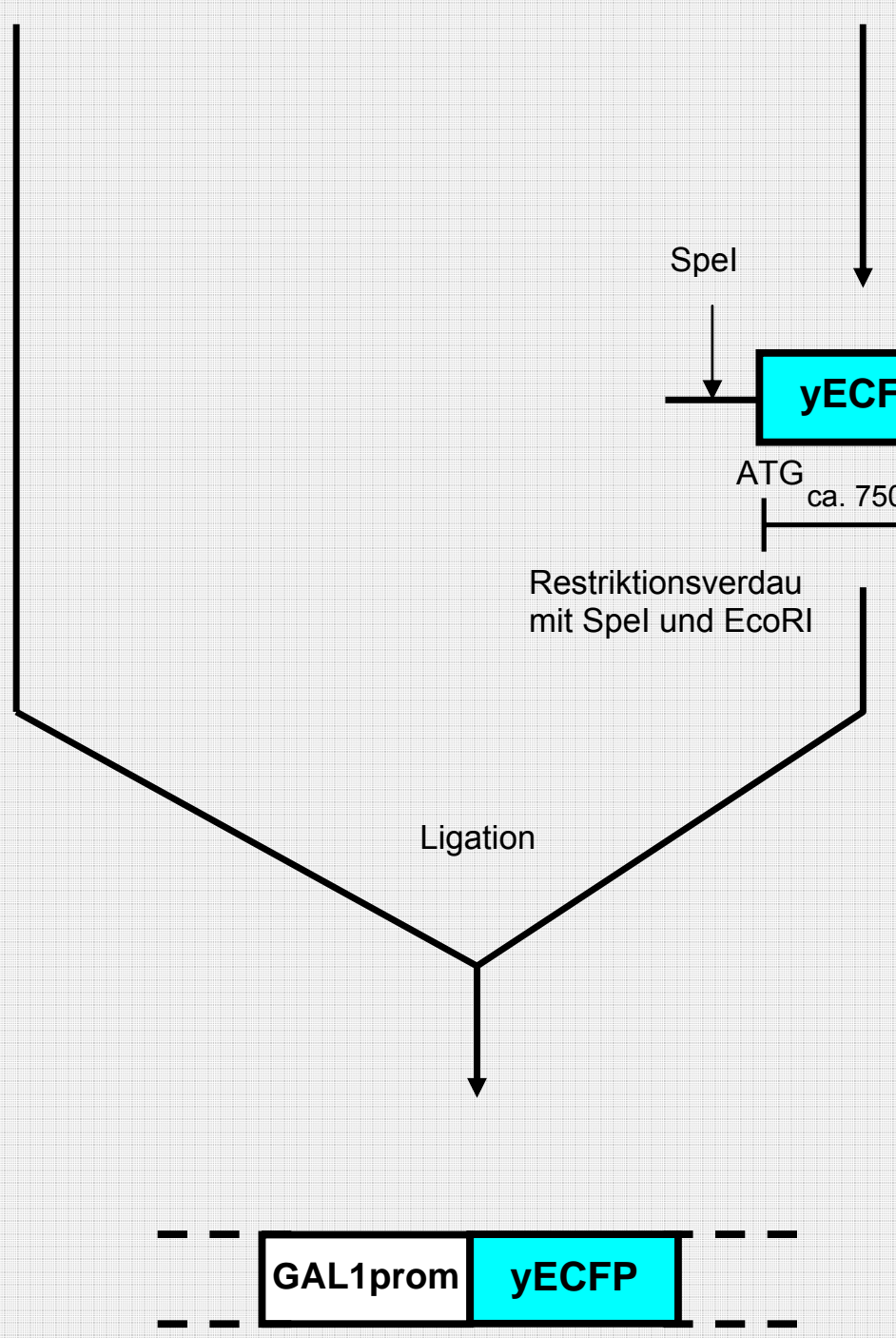

pKO-005

Abbildung 7: $\quad$ Übersicht des Klonierungskonstrukts für das Plasmid pKO-005. 
In Abbildung 7 ist das Konstrukt zur Klonierung von Plasmid pKO-005 dargestellt. Das Grundprinzip der Klonierung ist im vorherigen Abschnitt bereits ausführlich erläutert: Zuerst wurde das Gen für hellblaufluoreszierendes Protein (yECFP) aus dem Plasmid pKT212 durch eine PCR mit Hilfe der Oligonukleotide OST455 und OST443 amplifiziert, damit das PCRProdukt mit den Schnittstellen für SpeI und EcoRI versehen wurden. Dann wurden der Vektor pYM-N25 und das Insert yECFP über Nacht verdaut. Danach wurden die beiden Fragmente mit Hilfe von Ligate-IT ligiert und in E. coli transformiert. Die Besonderheit bei dieser Klonierung bestand in der Auswahl der Restriktionsenzyme: Das Insert, also das ampflizierte yECFP aus pKT212, konnte nicht mit den gleichen Restriktionsenzymen wie der Vektor (XbaI und EcoRI) verdaut werden, denn es waren mehrere Restriktionsstellen für XbaI im Insert vorhanden. Daher wurde der Vektor stattdessen mit den Restriktionsenzymen SpeI und EcoRI verdaut.

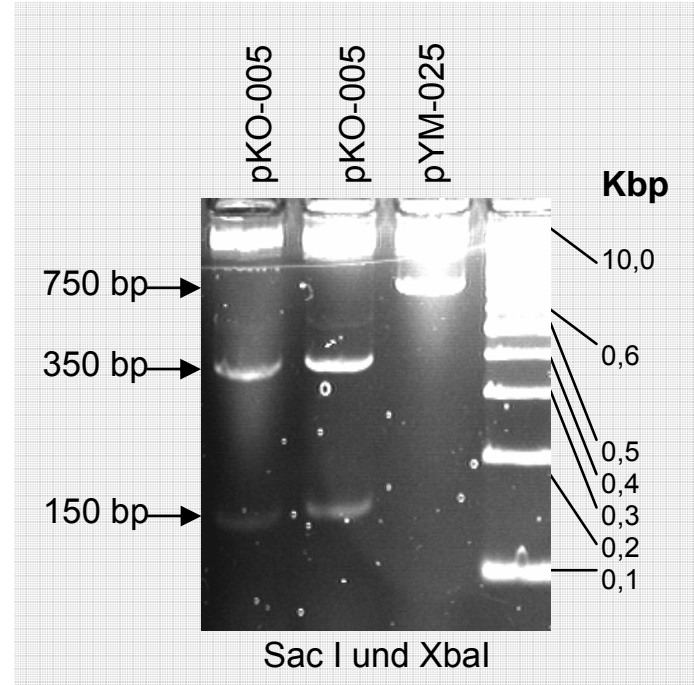

Sac I und Xbal

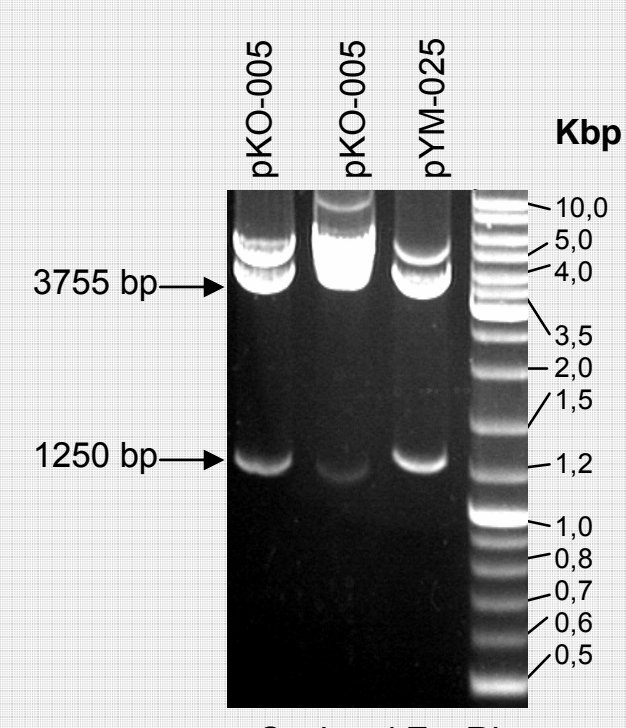

Sacl und EcoRI

Abbildung 8: Agarosegelanalyse des Testverdaus von pKO-005 mit einer Negativ- bzw. Positivkontrolle des Ausgangsplasmids.

Nach der Isolation des Plasmids aus E. coli wurde der Testverdau diesmal nicht mit den gleichen Restriktionsenzymen wie beim vorherigen Restriktionsverdau eingesetzt, da die eigentlichen Restriktionsstellen vor dem Insert für XbaI in Plasmid pKO-005 nicht mehr vorhanden waren. Daher wurden stattdessen zwei verschiedene Testverdauvarianten konstruiert: Die erste Variante bestand aus den Restriktionsenzymen SacI und XbaI und die zweite aus den Restriktionsenzymen SacI und EcoRI. Mit der ersten Variante wurde belegt, dass yECFP im Plasmid vorhanden war. Im Positivfall waren außer einer Bande bei 4,3 kbp zwei Banden bei ca. 350 bp und bei ca. 150 bp auf dem Agarosegel sichtbar, denn mehrere 
XbaI-Schnittstellen im Insert, also dem Genabschnitt von yECFP, waren vorhanden. Waren zwei Banden stattdessen bei 4,3 kbp und ca. $750 \mathrm{bp}$ sichtbar, handelte es sich um das Ausgangsplasmid, denn die Schnittstelle für XbaI lag nicht im yEGFP, sondern ausschließlich einmal vor dem GAL1prom vor. Die SacI-Schnittstelle existierte in beiden Fällen lediglich direkt nach dem yECFP-Genabschnitt.

In der zweiten Variante ging es darum, ob das Plasmid wirklich aus dem Ausgangsplasmid stammt. Hier mussten zwei Banden bei ca. 3,755 kbp und bei ca. 1,25 kbp auf dem Agarosegel sichtbar, und logischerweise mit dem Ausgangsplasmid vergleichbar sein. Bei diesem Testverdau handelte es sich um zwei Schnittstellen außerhalb des klonierten Abschnittes. Die Schnittstellen für beide Enzyme kamen jeweils nur einmal vor. Daher wurden die beiden Plasmide im Positivfall in zwei verschiedene Fragmente geteilt.

In Abbildung 8 ist die Agarosegelanalyse des Testverdaus dargestellt. Die beiden Kolonien von Plasmiden pKO-005 sollten sowohl yECFP-Genabschnitt enthalten sein, als auch aus dem Ausgangsplasmid pYM-N25 stammen.

\subsubsection{Plasmid pKO-012 (TEFprom-YFP-PTS1)}

Das Konstrukt für die Klonierung des Plasmids pKO-012 ist in Abbildung 9 dargestellt. Das Grundprinzip gleicht dem der vorherigen beiden Klonierungen. Bei dieser Klonierung war jedoch zum Beginn keine PCR erforderlich, da sowohl der Vektor als auch das Insert bereits geeignete Restriktionsschnittstellen enthielten.

Zuerst wurde der YFP-PTS1-Genabschnitt aus PST272 mit den Restriktionsenzymen, BamHI und EcoRI, herausgeschnitten. Der Vektor p426TEF wurde mit den gleichen Restriktionsenzymen geöffnet und mit dem Insert ligiert. Dies wurde unmittelbar in E. coli transformiert. Das Plasmid wurde aus E. coli isoliert. Ein Testverdau wurde mit den gleichen Enzymen wie beim Restriktionsverdau durchgeführt. In der Agarosegel-Analyse des Testverdaus zeigten alle geprüften Plasmide zwei Banden bei ca. 5300 bp und bei ca. 750 bp. Die Klonierung war also erfolgreich. 

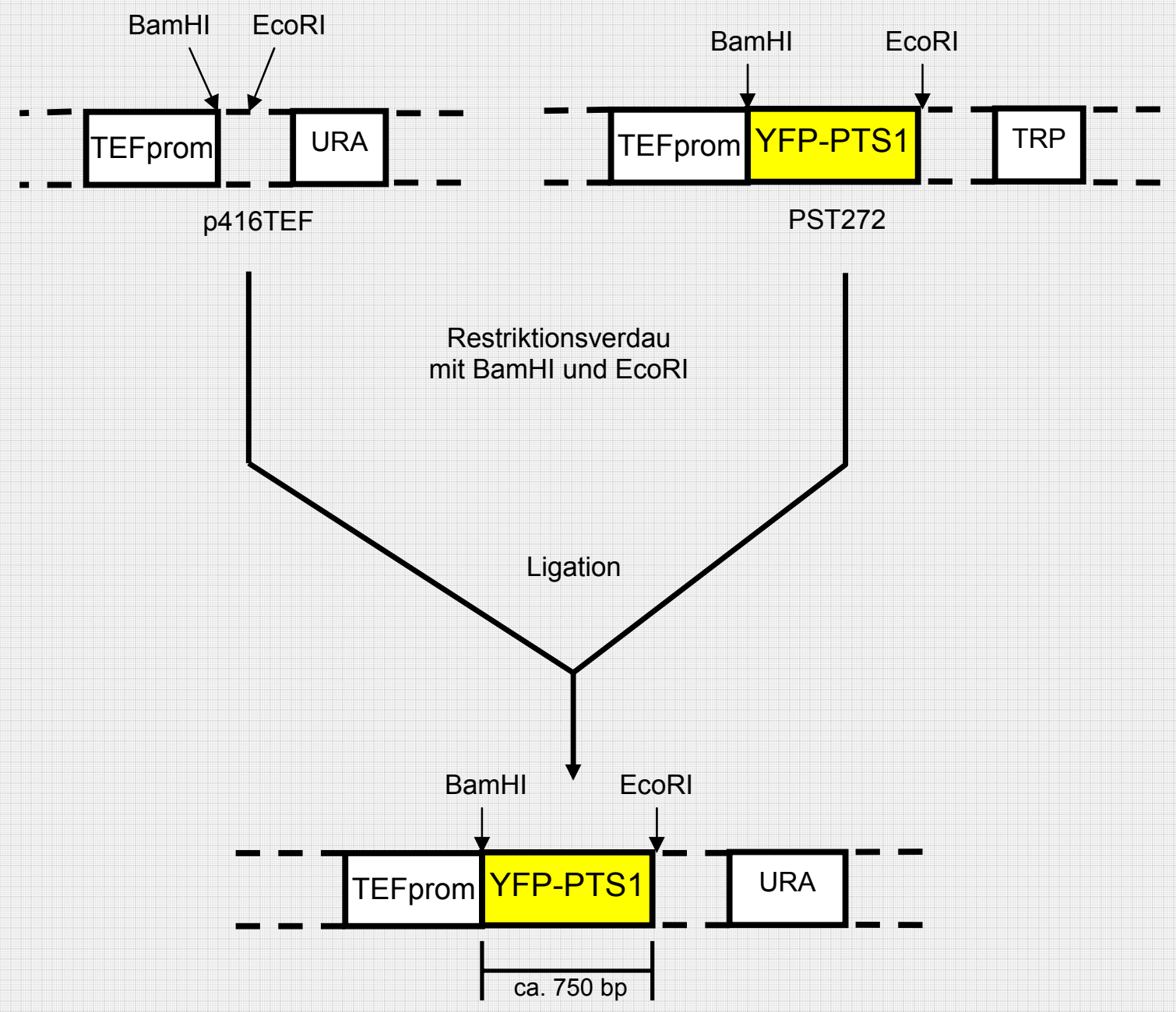

pKO-012

Abbildung 9: Klonierungskonstrukt für das Plasmid pKO-012. 


\subsubsection{Plasmid pKO-008 (TEFprom-Dendra2-Dendra2-PEX3)}
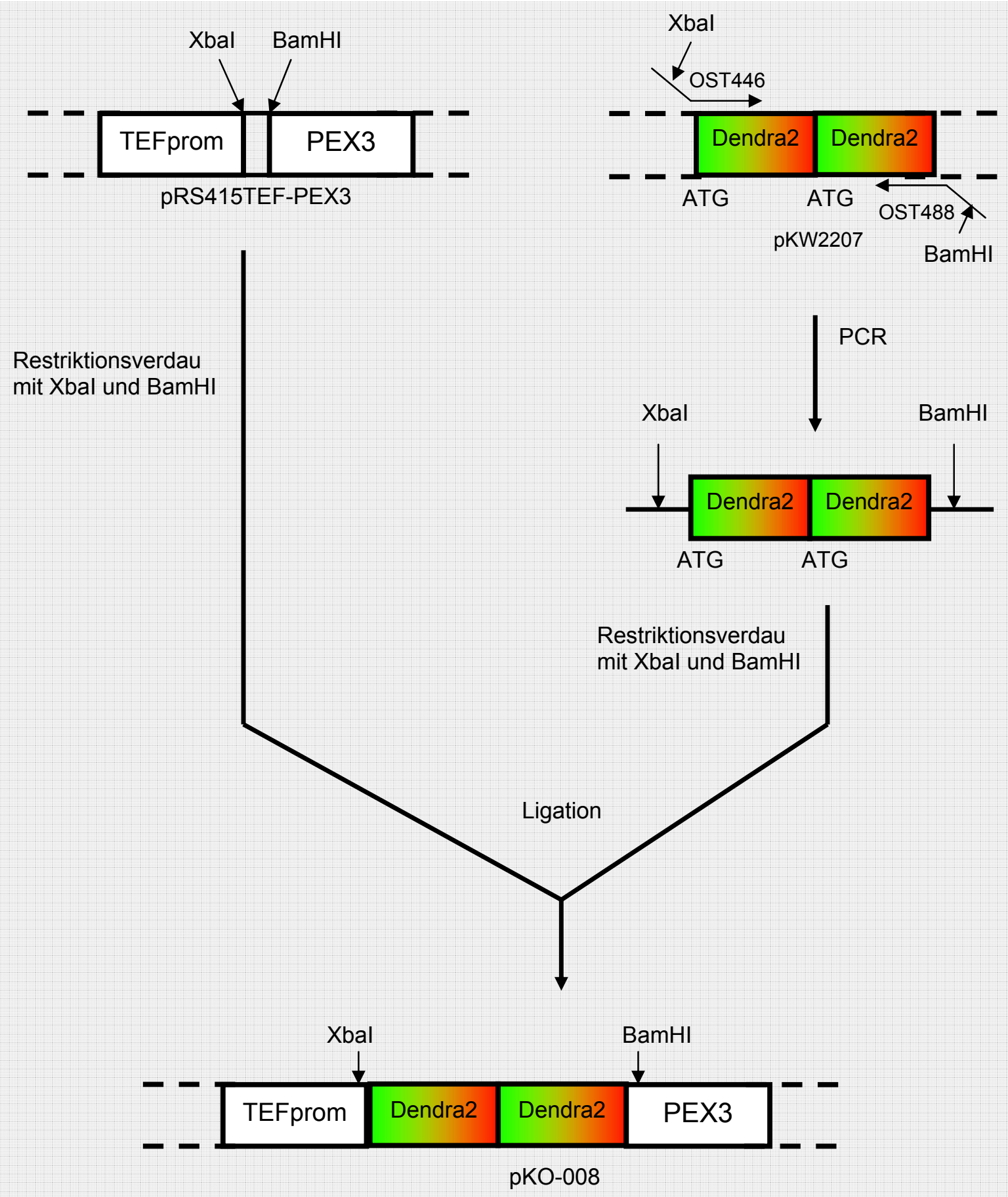

Abbildung 10: Klonierungskonstrukt für das Plasmid pKO-008.

Die Abbildung 10 gibt die Übersicht über die Klonierung für das Plasmid pKO-008.

Zuerst wurde der 2xDendra-Genabschnitt aus dem Plasmid pKW2007 mit Hilfe einer PCR amplifiziert, damit die amplifizierte DNA mit den Schnittstellen für die Restriktionsenzyme 
XbaI und BamHI versehen wurde. Danach wurde ein Restriktionsverdau sowohl des Vektors als auch des Inserts mit den Restriktionsenzymen XbaI und BamHI durchgeführt.

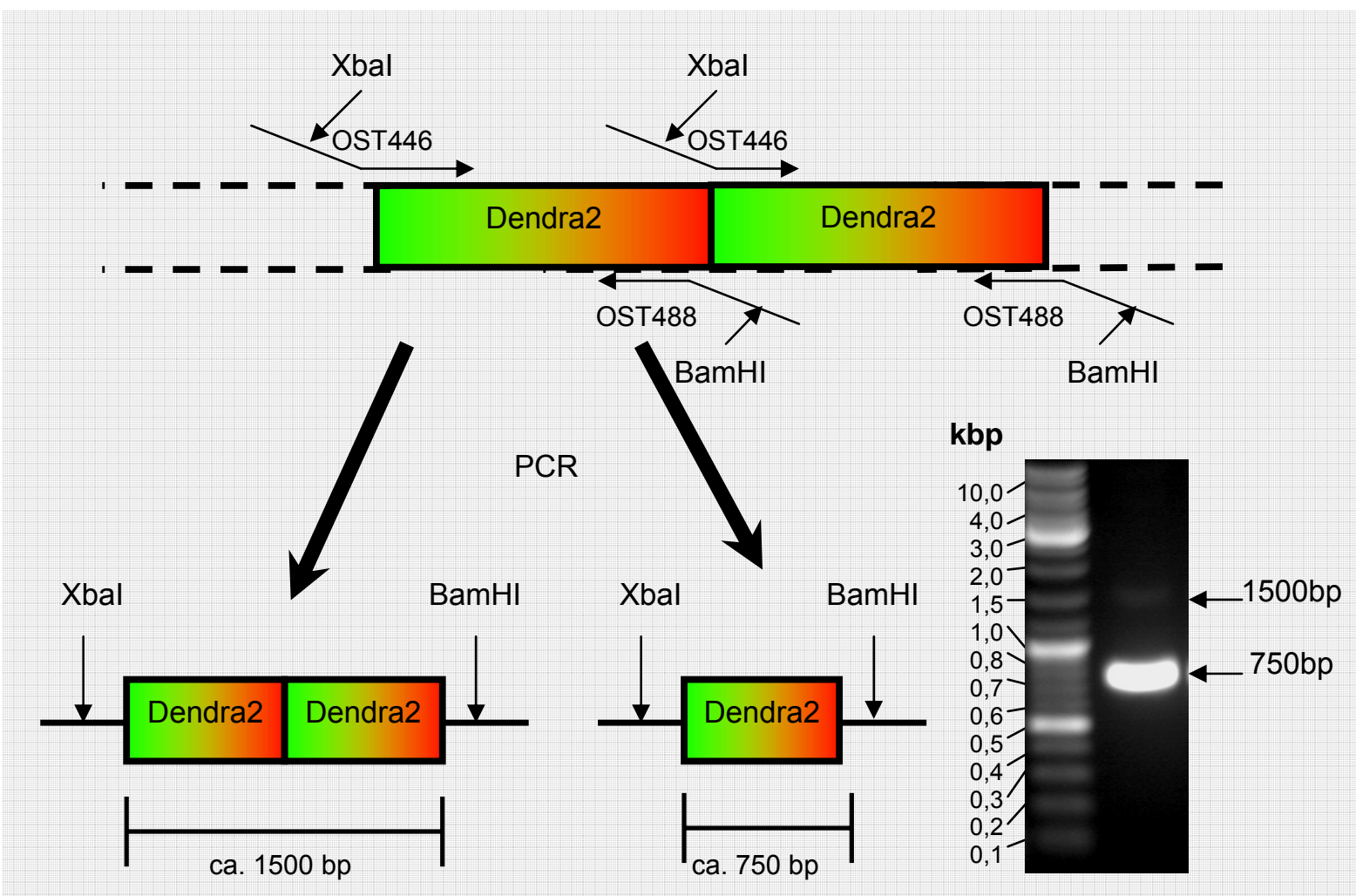

Abbildung 11: Besonderheit bei der Klonierung vom pKO-008. Dargestellt ist das Konstrukt für die PCR zur Amplifikation des Dendra2-Genabschnitts aus dem Plasmid, pKW2207. Die Besonderheit bestand darin, dass sich sowohl einmal als auch zweimal Dendra2 mithilfe von OST 446 und OST488 amplifizieren ließen.

Die Besonderheit dieser Klonierung ist in Abbildung 11 dargestellt: Um eine bessere Darstellung von Pex3p zu ermöglichen, wurde versucht, den Dendra2-Genabschnitt nicht einmal, sondern zweimal hintereinander zu klonieren.

Durch die PCR mit den Oligonukleotiden OST446 und OST448 ließ sich nicht nur zweimal, sondern auch lediglich einmal der Dendra2-Genabschnitt amplifizieren. In der AgarosegelAnalyse waren nicht nur eine kräftige Bande bei ca. 750 bp, sondern auch eine sehr schwache Bande bei ca. 1500 bp zu sehen, die sich in Abbildung kaum darstellen ließ. Es wurden sehr viele Mengen vom 1x Dendra2- und sehr wenige Mengen vom 2x Dendra2-Genabschnitt amplifiziert. Dieses PCR-Produkt wurde zur Klonierung weiter verarbeitet, so dass nicht nur die Plasmide mit 1x Dendra-PEX3, sondern auch die mit 2x Dendra-PEX3 entstehen. 


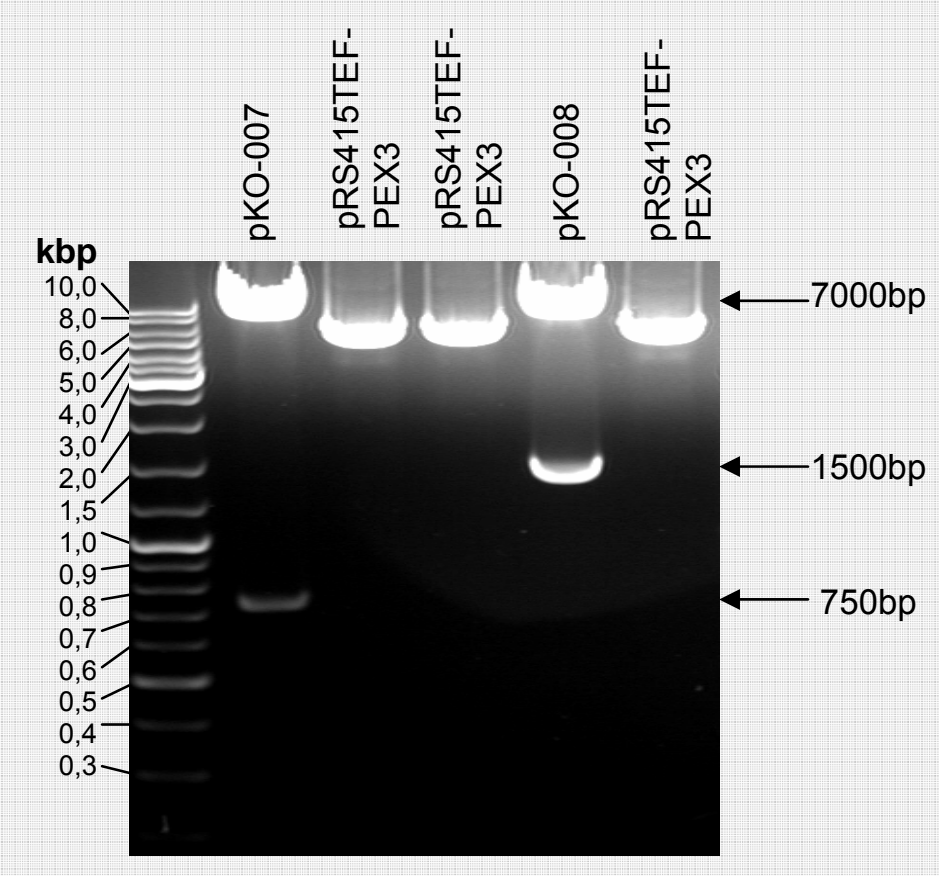

Abbildung 12: Agarosegelanalyse nach dem Testverdau vom pKO-009. Da das Insert nicht nur einmal, sondern zweimal Dendra2 enthielt, ergaben sich aus dieser Klonierung zwei positive Plasmide: pKO-007 besaß einmal und pKO-008 zweimal den Dendra2-Genabschnitt.

Wie in Abbildung $12 \mathrm{zu}$ ersehen, waren zwei Kolonien positiv: In einem Plasmid war eine Bande bei ca. 750 bp auf dem Agarosegel zu ersehen, was der Größe von einmal Dendra2Genabschnitts entsprach. Im anderen Plasmid ist ein DNA-Fragment mit ca. 1500 bp herausgeschnitten entsprechend der Größe von zweimal Dendra2-Genabschnitt.

\subsubsection{Plasmid pKO-010 (GAL1prom-Dendra2-Dendra2-PEX3)}

Die Abbildung 13 gibt die Übersicht dieser Klonierung. Das Plasmid pKO-008 (TEFprom2xDendra-PEX3) wurde zur Herstellung vom Plasmid pKO-010 (GAL1prom-2xDendraPEX3) weiter verarbeitet. Es wurde anstelle des TEF-Promotors der GAL1prom eingefügt. Da die beiden Plasmide die gleichen Restriktionsschnittstellen vor und nach dem Promotorgen besaßen, entfiel die PCR am Beginn.

Zunächst wurden beide Plasmide durch einen Restriktionsverdau mit SacI und XbaI geöffnet. Anschließend wurden der TEF-Promotor aus dem Plasmid pKO-008 und der GAL1-Promotor 
aus dem Plasmid pYM-N25 durch Agarose-Gelelektrophorese getrennt. Dann wurde der GAL1-Promotor mit dem geöffneten Plasmid pKO-008 ligiert.

Ein Testverdau wurde mit den Restriktionsenzymen SacI und XbaI durchgeführt. Von den positiven Plasmiden ließ sich ein Fragment bei ca. 500 bp mittels Agarose-Gelelektrophorese trennen, das der Größe des GAL1-Promotors entsprach.
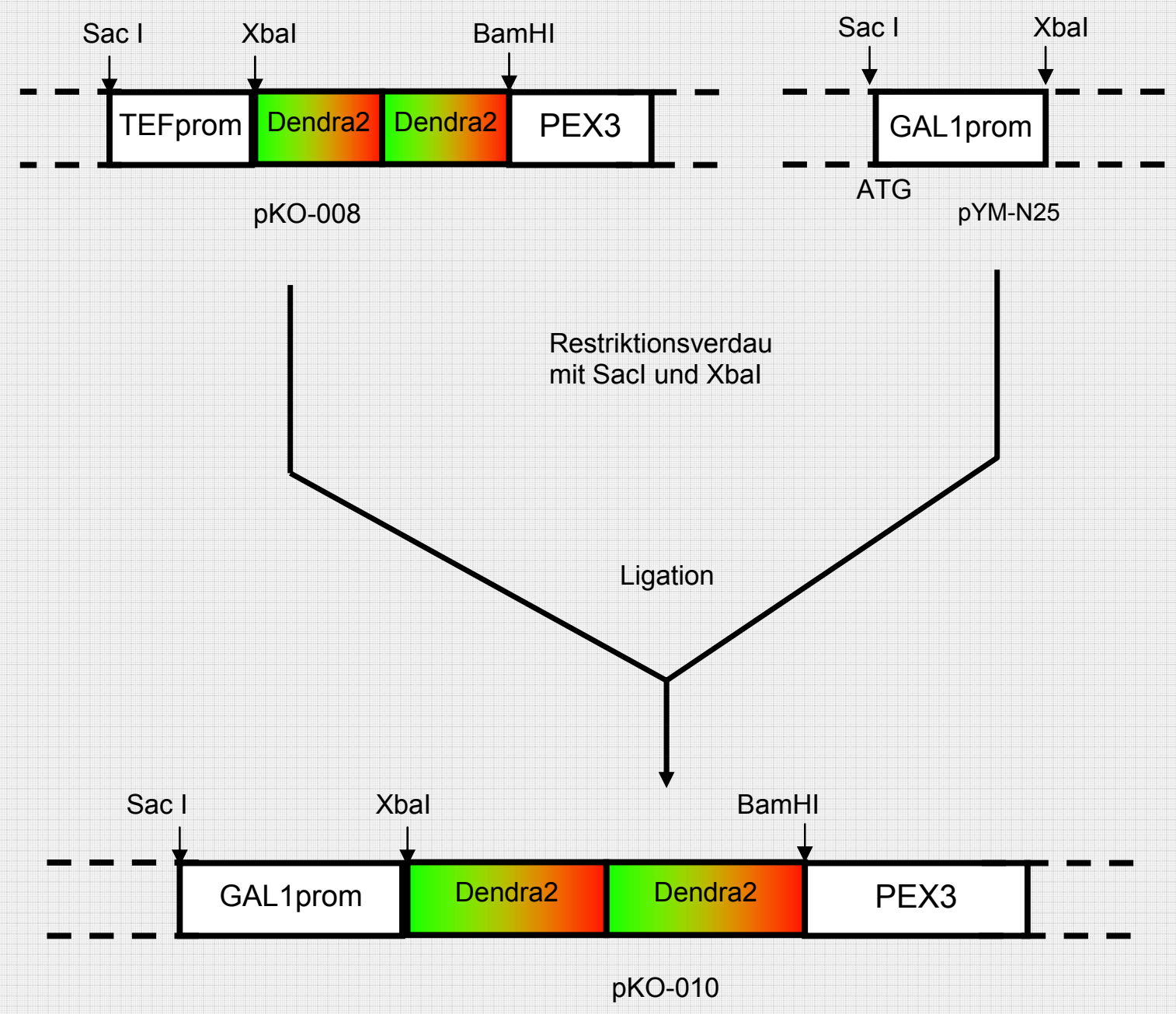

Abbildung 13: Konstrukt für die Klonierung von Plasmid pKO-010. 


\subsection{Kultivierung von E. coli}

Zur Anzucht von Bakterien auf Festagarplatten und in Submerskulturen wurde folgendes Medium verwendet. Festagarplatten wurden durch Hinzufügen von 2\% (w/v) Agar erzeugt. Alle Medien wurden bei $121^{\circ} \mathrm{C}$ für 15 Minuten autoklaviert.

LB-Medium:

$$
\begin{array}{ll}
1 \%(\mathrm{w} / \mathrm{v}) & \text { Trypton } \\
0,5 \%(\mathrm{w} / \mathrm{v}) & \text { Hefeextrakt } \\
0,5 \%(\mathrm{w} / \mathrm{v}) & \text { Natriumchlorid. }
\end{array}
$$

Bei Kultivierung unter selektiven Bedingungen wurden $100 \mu \mathrm{g} / \mathrm{ml}$ Ampicillin (Amp) aus einer sterilfiltrierten Stammlösung zum autoklavierten Medium hinzugesetzt.

\subsection{DNA-Transformation in E. coli und Isolation von Plasmiden}

In dieser Arbeit wurden CH3-Blue kompetente Zellen (Bioline) verwendet. 2,2 - $3 \mu 1$ des Ligationssatzes wurde in $25 \mu \mathrm{l}$ von E. coli Zellen zugegeben. Nach 30-minütiger Inkubation auf Eis erfolgte eine Hitzeschockreaktion für 30 Sekunden bei $42{ }^{\circ} \mathrm{C}$. Danach wurde die Probe für fünf Minuten wiederum auf Eis inkubiert. Die Zellen wurden in $200 \mu 1$ LB-Medium aufgenommen und für 30 Minuten bei $37^{\circ} \mathrm{C}$ im Schüttler bei $200 \mathrm{rpm}$ inkubiert. Dann wurde die Probe auf Selektivagarplatten (LB mit Amp) ausplattiert, und bei $37^{\circ} \mathrm{C}$ für ca. 16 Stunden inkubiert. Jede Kolonie auf Selektivagarplatten wurde in $2 \mathrm{ml}$ flüssigem Selektivmedium (LB mit Amp) über Nacht bei $200 \mathrm{rpm}$ im Schüttler inkubiert. Am nächsten Tag wurde das Plasmid mit Hilfe des Nucleospin Plasmids (Macherey-Nagel) isoliert. Der Vorgang der Isolierung von Plasmiden entsprach der Angabe des Herstellers.

\subsection{Kultivierung von Saccharomyces cerevisiae}

Die Kultivierung von S. cerevisiae auf Agarplatten bzw. im flüssigen Medium erfolgte bei $30^{\circ} \mathrm{C}$. Geschah diese auf Agarplatten, so wurden die Agarplatten in einem Brutschrank inkubiert. Im Falle einer Inkubation im flüssigen Medium wurde die Probe, sofern nicht anders angegeben, in $10 \mathrm{ml}$ flüssigem Medium im Schüttler bei $200 \mathrm{rpm}$ inkubiert. Je nach Fragestellung bzw. genetischen Bedingung des Hefestamms variierten die zugesetzten Kohlenstoffquellen und Aminosäurenzusammensetzungen. Für die Standardinkubation wurde häufig das yeast extract peptone (YP) -Medium verwendet.

Der pH-Wert des SD-Mediums wurde stets auf 6,5 eingestellt. Yeast-Nitrogen-Base (YNB) wurde als Konzentrat zur SD-Vorkultur hinzugefügt. Zusätzlich wurde in dieser Arbeit ein YNB mit einer kupferfreien Zusammensetzung selbst hergestellt. In dieser Arbeit erscheint 
das SD-Medium mit selbst hergestelltem YNB als SD1-Medium, das mit dem YNB im Handel als SD2-Medium bezeichnet. Feste Agarplatten wurden durch Hinzufügen von 2\% (w/v) Agar zu den Medien hergestellt wird.

Die Medien wurden bei $120^{\circ} \mathrm{C}$ für 15 Minuten autoklaviert.

YP:

$\begin{array}{ll}1 \%(\mathrm{w} / \mathrm{v}) & \text { Hefeextrakt } \\ 2 \%(\mathrm{w} / \mathrm{v}) & \text { Pepton. }\end{array}$

Zusätzlich Kohlenstoffquelle: 3\% (w/v) Glucose / 4\% (w/v) Raffinose / 2\% (w/v) Galactose je nach Fragestellung. YP-Medium mit Glucose wird als YPDMedium bezeichnet.

SD:

$$
\begin{array}{ll}
0,17 \%(\mathrm{w} / \mathrm{v}) & \text { YNB } \\
0,8 \%(\mathrm{w} / \mathrm{v}) & \text { Aminosäuremischung. }
\end{array}
$$

Zusätzlich Kohlenstoffquelle: 3\% (w/v) Glucose / 4\% (w/v) Raffinose / 2\% (w/v) Galactose je nach Fragestellung.

YNB (für SD1):

Salze:

$\begin{array}{ll}4,7 \mathrm{mM} & \text { Kaliumphosphat } \\ 4,2 \mathrm{mM} & \text { Magnesiumsulfat } \\ 1,7 \mathrm{mM} & \text { Natriumchlorid } \\ 1,7 \mathrm{mM} & \text { Calciumsulfat. }\end{array}$

Vitamin B:

$\begin{array}{ll}0,82 \mu \mathrm{M} & \text { Biotin } \\ 1,8 \mu \mathrm{M} & \text { Pantothensäure } \\ 11,2 \mu \mathrm{M} & \text { Inositol } \\ 3,2 \mu \mathrm{M} & \text { Niacin } \\ 1,5 \mu \mathrm{M} & \text { p-Aminobenzoesäure } \\ 2,4 \mu \mathrm{M} & \text { Pyridoxin-HCl } \\ 1,2 \mu \mathrm{M} & \text { Thiamin-HCl. }\end{array}$

Spurenelemente:
$8,1 \mu \mathrm{M}$
Borsäure
$0,6 \mu \mathrm{M}$
Kaliumiodid 


$\begin{array}{ll}1,6 \mu \mathrm{M} & \text { Eisenchlorid } \\ 2,6 \mu \mathrm{M} & \text { Magnesiumsulfat } \\ 1,0 \mu \mathrm{M} & \text { Natriummolybdat } \\ 2,5 \mu \mathrm{M} & \text { Zinksulfat. }\end{array}$

Aminosäuremischung:

$\begin{array}{ll}2 \mathrm{~g} & \text { Adenin-hemisulfat } \\ 2 \mathrm{~g} & \text { L-Arginin-HCl } \\ 2 \mathrm{~g} & \text { L-Histidin-HCl } \\ 2 \mathrm{~g} & \text { L-Isoleucin } \\ 2 \mathrm{~g} & \text { L-Leucin } \\ 2 \mathrm{~g} & \text { L-Lysin-HCl } \\ 2 \mathrm{~g} & \text { L-Methionin } \\ 3 \mathrm{~g} & \text { L-Phenylalanin } \\ 2 \mathrm{~g} & \text { L-Threonin } \\ 2 \mathrm{~g} & \text { L-Serin } \\ 3 \mathrm{~g} & \text { L-Tryptophan } \\ 2 \mathrm{~g} & \text { L-Tyrosin } \\ 1,2 \mathrm{~g} & \text { Uracil } \\ 9 \mathrm{~g} & \text { L-Valine. }\end{array}$

Für die Selektionsmedien wurden die betroffenen Aminosäuren weggelassen.

\subsection{Hocheffiziente Hefe-DNA-Transformation durch LiAc-Methode}

Die hocheffiziente Hefe-DNA-Transformation erfolgte nach GIETZ und ScHIESTL (2007). Zuerst wurden die Hefezellen für 18 Stunden im YPD-Medium, wie im vorherigen Abschnitt beschrieben, kultiviert. Danach wurde die Zelldichte mithilfe eines Photometers bestimmt. Die Zellen wurden auf einen OD-Wert von $0,5 \mathrm{im} 50 \mathrm{ml}$ bei $30^{\circ} \mathrm{C}$ vorgewärmten YPDMedium verdünnt, und weiter für vier Stunden inkubiert. $500 \mathrm{mg}$ der Lachsspermien als Träger der Einzelstrang-DNA wurde in $100 \mathrm{ml}$ TE (10mM Tris-HCl, 1mM EDTA bei pH von 8.0) zugegeben. Dies wurde 10 Minuten bei $95^{\circ} \mathrm{C}$ inkubiert, und anschließend sofort auf Eis gebracht.

Nach vierstündiger Inkubation wurden die Zellen bei $3000 \mathrm{rpm}$ für fünf Minuten bei RT zentrifugiert, und danach zweimal mit bei $30{ }^{\circ} \mathrm{C}$ vorgewärmtem Wasser mit gleicher Zentrifugationsgeschwindigkeit und -zeit gewaschen. Nach dem Abziehen des Überstandes 
wurde das Pellet in $1 \mathrm{ml}$ Wasser resuspendiert, und in einen E-Cup gebracht, noch einmal durch eine Zentrifugation bei $13000 \mathrm{rpm}$ bei RT für eine Minute gewaschen, und wieder in 1 ml Wasser resuspendiert. $100 \mu \mathrm{l}$ davon wurden in E-Cups zugegeben, und für eine Minute bei $13000 \mathrm{rpm}$ bei RT zentrifugiert. Zu den jeweiligen Zellen wurde folgender Reaktionssatz hinzugefügt:

$\begin{array}{ll}33 \%(\mathrm{v} / \mathrm{v}) & \text { PEG } 3350 \\ 36 \mu \mathrm{mol} & \text { Lithiumacetat } \\ 500 \mu \mathrm{g} & \text { Lachsspermien-DNA } \\ 4-5 \mu \mathrm{g} & \text { DNA zur Transformation } \\ \text { Endvolumen } & 360 \mu \mathrm{l} .\end{array}$

Unmittelbar erfolgte eine Hitzeschockreaktion bei $42{ }^{\circ} \mathrm{C}$ für 40 Minuten. Die Probe wurde danach bei 13000 rpm für eine Minute bei RT zentrifugiert.

Erfolgte die Selektion durch Aminosäurekarenz, so wurde das Pellet in $1 \mathrm{ml}$ Wasser resuspendiert, und $200 \mu 1$ davon auf eine Selektionsplatte ausplattiert.

Im Falle einer Selektion mit einem Antibiotikum wurde das Pellet in $1 \mathrm{ml}$ YPD-Medium resuspendiert, und für drei Stunden inkubiert, um eine bessere Wachstumsbedingung zu ermöglichen. Dann wurden $200 \mu 1$ davon auf eine Selektionsagarplatte ausplattiert. Die Inkubation bei $30^{\circ} \mathrm{C}$ erfolgte bis zu vier Tage.

\subsubsection{Anwendung der hocheffizienten Hefe-DNA-Transformation}

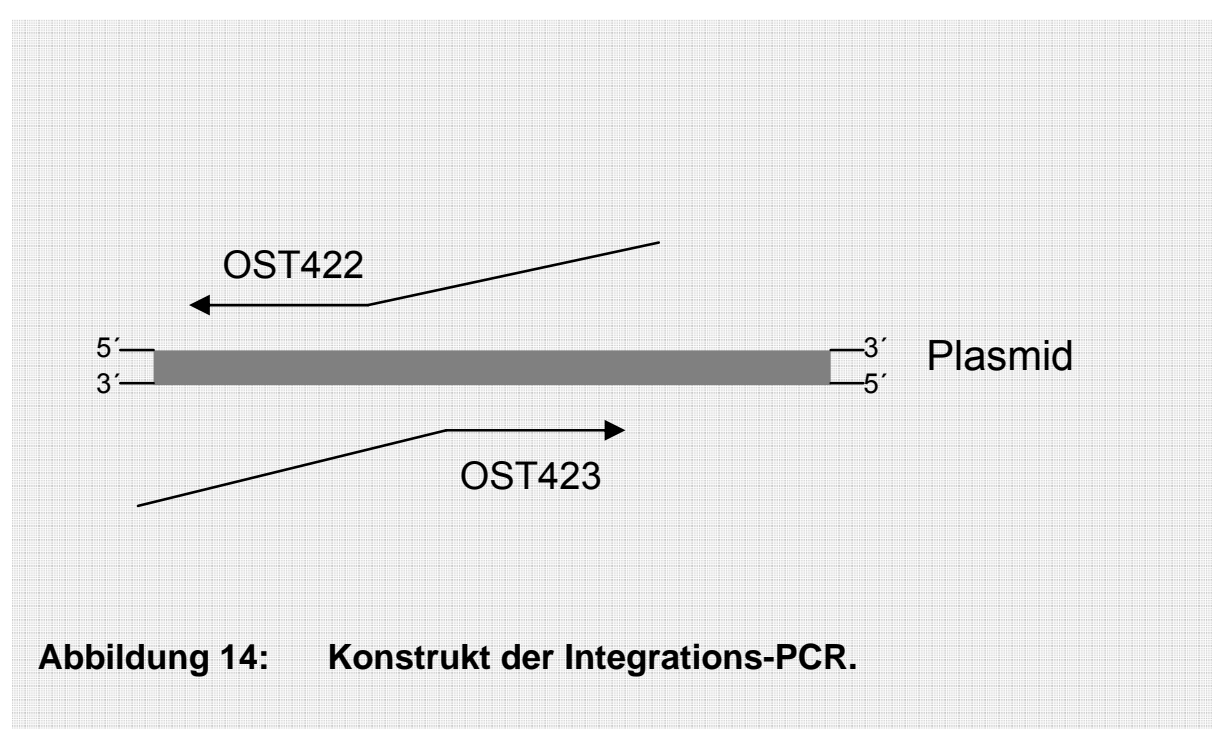

Mit der hocheffizienten Hefe-DNA-Transformation wurden zunächst folgende Hefestämme hergestellt: YKO-006 (CUP1prom-yECitrine-PEX3) und YKO-026 (GAL1prom-yECFPPEX3) 
Für diesen Zweck wurden zwei Plasmide pKO-003 (CUP1prom-yECitrine) und pKO-005 (GAL1prom-yECFP) wie in diesem Kapitel beschrieben, hergestellt. Um die Transformation der DNA in das Hefegenom vor dem PEX3-Gen zu ermöglichen, musste eine IntegrationsPCR durchgeführt werden, da die beiden Plasmide sowohl nicht geöffnet waren, als auch keinen Überhang für das PEX3-Gen besaßen.

Das Konstrukt der Integrations-PCR ist in Abbildung 14 dargestellt. Die Oligonukleotiden OST422 und OST423 waren nach JANKE et al. (2004) so konstruiert, dass sie sich sowohl für pKO-003 (CUP1prom-yECitrine) als auch für pKO-005 (GAL1prom-yECFP) verwenden ließen. 8-10 $\mu \mathrm{g}$ der amplifizierten DNA mit ca. 1,6 kbp wurde nach Aufreinigung mit High Pure PCR Product Purification Kit in das Genom der Wildtyp-Hefestämme BY4741 sowie BY4742 integriert. Das Konstrukt ist in Abbildung 15 veranschaulicht. Für die Selektion wurde clonNAT in YPD-Medium so zugegeben, dass sich die Endkonzentration von 0,1 $\mu \mathrm{g} / \mathrm{ml}$ ergab.

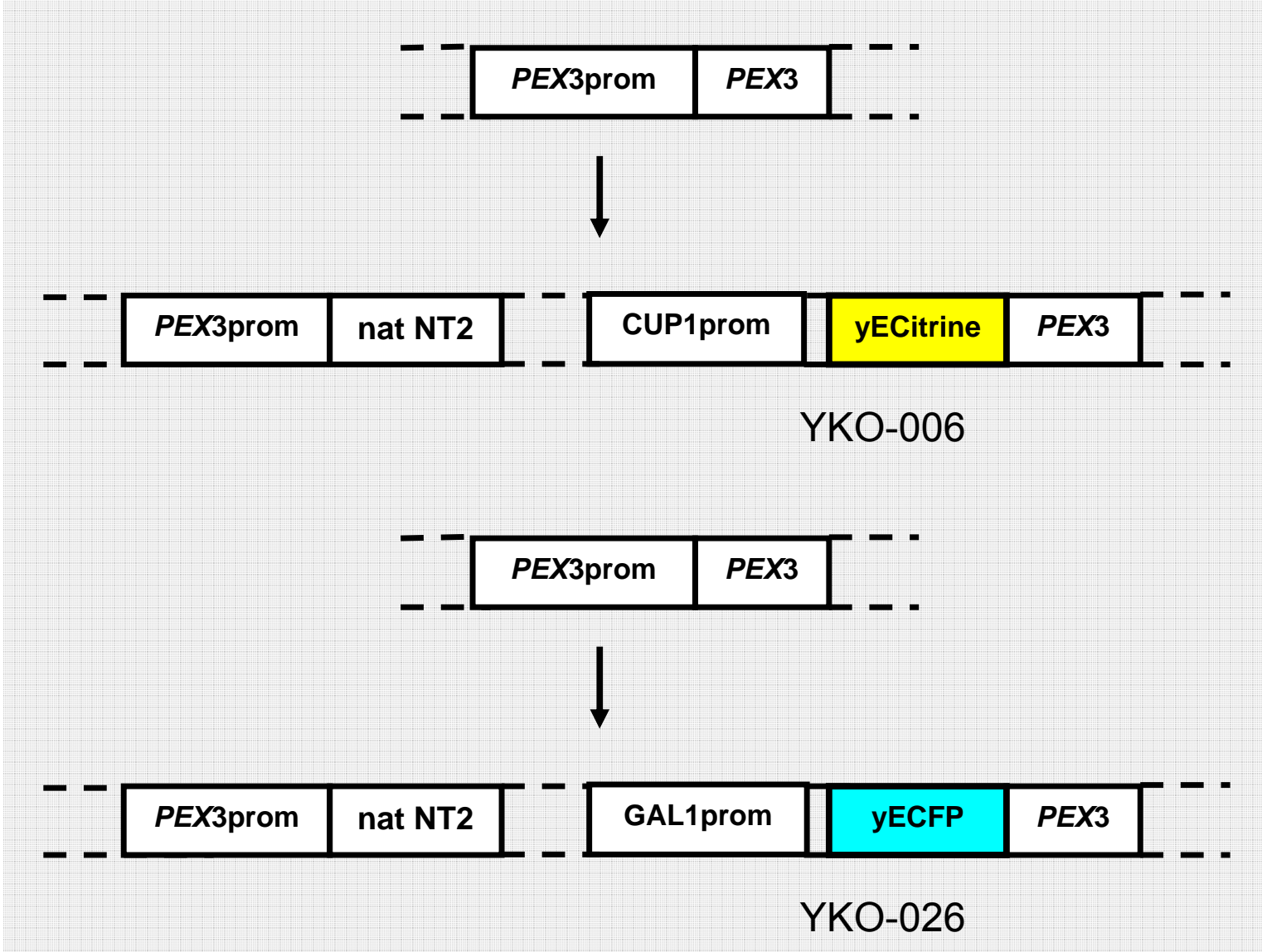

Abbildung 15: Zielkonstrukt von YKO-006 und YKO-026. 
Die hocheffiziente Hefe-DNA-Transformation wurde ebenso zur Herstellung von YKO-026 (GAL1p-yECFP-PEX3 mit dsRED-ER) angewandt: Das Plasmid dsREDER wurde für 20 Stunden durch den Restriktionsverdau mit EcoRV linealisiert. $15 \mu \mathrm{g}$ davon wurde in das Genom von YKO-026 integriert.

\subsection{Niedereffiziente Hefe-DNA-Transformation durch LiAc-Methode}

Die Hefezellen wurden in YPD Medium für 18 Stunden inkubiert. Nach der Bestimmung des OD-Wertes wurden die Zellen auf einen OD-Wert von 0,3 in $50 \mathrm{ml}$ bei $30^{\circ} \mathrm{C}$ vorgewärmtem YPD- Medium verdünnt. Die Probe wurde weiter für vier Stunden inkubiert.

Die Lachsspermien als Träger der Einzelstrang-DNA wurden, wie im vorherigen Abschnitt beschrieben, behandelt.

Die Zellen wurden bei 3.000 rpm für drei Minuten bei RT zentrifugiert. Nach dem Verwerfen des Überstandes wurde das Pellet in $300 \mu 1 \mathrm{1M}$ LiAc resuspendiert, in einen E-Cup gebracht, und unmittelbar bei 15000 rpm für zwei Minuten bei RT zentrifugiert. Der Überstand wurde verworfen, und das Pellet wurde wiederum in $300 \mu 11 \mathrm{M} \mathrm{LiAc}$ resuspendiert.

Danach wurde folgende Zusammensetzung erstellt:

$\begin{array}{ll}100 \mu \mathrm{l} & \text { Zellsuspension } \\ 100 \mu \mathrm{g} & \text { Lachsspermien-DNA } \\ 0,25-0,5 \mu \mathrm{g} & \text { DNA } \\ 500 \mu 150 \%(\mathrm{~m} / \mathrm{v}) & \text { PEG } \\ \text { Endvolumen } & 630 \mu \mathrm{l} .\end{array}$

Unmittelbar wurde die Probe für 30 Minuten auf dem Drehrad bei RT unter leichter Drehung inkubiert. Nach Zugabe von $50 \mu \mathrm{l}$ DMSO erfolgte eine Hitzeschockreaktion bei $42{ }^{\circ} \mathrm{C}$ für zehn Minuten.

Die Probe wurde bei 3000 rpm für 30 Sekunden bei RT zentrifugiert. Nach dem Verwerfen des Überstandes wurde das Pellet in $50 \mu 1$ Wasser resuspendiert. Die Probe wurde auf eine Selektionsagarplatte ausplattiert, und bis zu drei Tage inkubiert.

\subsubsection{Anwendung der niedereffizienten Hefe-DNA-Transformation}

Dieses Verfahren wurde in dieser Arbeit nur dann angewandt, wenn ein ganzes Plasmid in die Hefezellen transformiert werden, und hierbei keine genomische Integration in die Hefe-DNA erfolgen sollte. Die mit diesem Verfahren hergestellten Hefestämme mussten daher stets in einem Selektionsmedium gehalten werden, damit diese das transformierte Plasmid nicht verloren. Folgende Hefestämme wurden mit Plasmiden transformiert: 
- YKO-012 (CUP1prom-yECitrine-PEX3 mit TEFprom-eqFP611-PTS1)

- YKO-021 (GAL1-prom-yECFP-PEX3 mit TEFprom-YFP-PTS1)

- YKO-025 (GAL1prom-Dendra2-Dendra2-PEX3).

\subsection{Paarungsmethode (Mating)}

Zwei haploide Hefezellen mit unterschiedlichen Paarungstypen lassen sich paaren. Nach der Paarung besitzt das Hefegenom eine diploide Eigenschaft. Zunächst wurden zu paarende Hefestämme für 18 Stunden in $10 \mathrm{ml}$ YPD-Medium kultiviert. Die Zellen wurden auf einen OD-Wert von 0,3 in $10 \mathrm{ml}$ YPD-Medium verdünnt, und weiter für vier Stunden inkubiert.

Nach einer Zelldichtemessung wurden in einen E-Cup die Zellen jedes Paarungstyps mit der gleichen Zelldichte zugegeben. Als Negativkontrolle wurde $1 \mathrm{ml}$ Zellsuspension eines Hefestamms in einen E-Cup zugegeben.

Die Proben wurden bei 13000 rpm für zwei Minuten bei RT zentrifugiert. Nach Verwerfen des Überstandes wurde das Pellet auf ein YPD-Festmedium gebracht, und über Nacht inkubiert.

Am Folgetag wurden die Proben auf eine Selektionsagarplatte ausgestrichen und bis zu vier Tagen bei $30{ }^{\circ} \mathrm{C}$ inkubiert.

\subsubsection{Anwendung der Paarungsmethode}

Folgende diploide Hefestämme wurden so hergestellt:

- YKO-028 (CUP1prom-yECitrine-PEX3 und GAL1prom-yECFP-PEX3)

- YKO-029 (CUP1prom-yECitrine-PEX3 und GAL1prom-yECFP-PEX3 mit dsREDER).

Das Ziel der Paarung bestand darin, einen Hefestamm herzustellen, der sich sowohl mit Kupfersulfat yEYFP-Pex3p, als auch mit Galactose yECFP-Pex3p induzieren lässt. Für die beiden Hefestämme wurde als Selektionsmedium das SD-Medium ohne Lysin und Methionin verwendet.

\subsection{Einzel-Pulse-Chase-Experiment mit einem haploiden Hefestamm}

Dieses Experiment wird deswegen Pulse-Chase-Experiment bezeichnet, weil nach einer einmaligen Induktion (Einzel-Pulse) die Veränderung in Zellen verfolgt (Chase) wird.

Die Zellen wurden in $10 \mathrm{ml}$ Medium kultiviert. Für die Hefestämme mit einem GAL1Promotor wurde hierbei YP Medium mit 4\% (w/v) Raffinose, für die Hefestämme mit einem 
CUP1-Promotor kupferfreies SD1-Medium dazu verwendet. Nach 16-stündiger Inkubation erfolgte eine einstündige Induktion (Pulse Phase). Hierfür wurden die Zellen auf einen ODWert von 1,0 in $10 \mathrm{ml}$ Medium verdünnt. Für den Hefestamm mit einem GAL1-Promotor wurde das YP Medium mit 2\% (w/v) Galactose, und für den Hefestamm mit einem CUP1Promotor das SD1 Medium mit Zusatz von $10 \mu 100 \mu \mathrm{M}$ Kupfersulfat pro $10 \mathrm{ml}$ verwendet. Nach einer Stunde bzw. 90 Minuten wurden die Proben in Falconröhrchen gebracht, und bei 3000 rpm für fünf Minuten bei RT zentrifugiert. Nun erfolgte ein Waschschritt, um Galactose bzw. Kupfersulfat vollständig zu entfernen. Nach dem Abziehen des Überstandes wurde das Pellet einmal bei $300 \mathrm{rpm}$ für fünf Minuten bei RT mit bei $30^{\circ} \mathrm{C}$ vorgewärmtem Wasser gewaschen. Nun begann die sog. Chase Phase: Die Zellen wurden unmittelbar danach in 10 $\mathrm{ml} \mathrm{Medium} \mathrm{mit} \mathrm{4 \%} \mathrm{(w/v)} \mathrm{Glucose} \mathrm{gebracht.} \mathrm{Die} \mathrm{Peroxisomenbiogenese} \mathrm{wurde} \mathrm{für} \mathrm{weitere}$ fünf Stunden verfolgt.

Je nach Fragestellung wurden Proben mit Medium zu bestimmten Zeitpunkten zum Mikroskopieren bzw. für Western Blots genommen.

\subsection{Doppel-Pulse-Chase-Experiment mit einem diploiden Hefestamm}

Das Experiment bestand aus zwei aufeinander folgenden Pulse-Chase-Phasen und wurde deswegen als Doppel-Pulse-Chase-Experiment bezeichnet.

Die Zellen wurden am Vortag im SD1-Medium mit 4\% (w/v) Raffinose kultiviert. Nach 16stündiger Inkubation wurden die Zellen auf einen OD-Wert von 1,0 in $10 \mathrm{ml}$ Medium verdünnt. Nun begann die erste Induktionsphase mit Galactose (erste Pulse). Hierfür wurde das SD1-Medium 2\% (m/v) mit Galactose verwendet. Nach einer Stunde wurde die Probe ins Falconröhrchen gebracht, und bei $3000 \mathrm{rpm}$ für fünf Minuten bei RT zentrifugiert. Danach wurden diese einmal bei $3000 \mathrm{rpm}$ für fünf Minuten mit bei $30^{\circ} \mathrm{C}$ vorgewärmten Wasser gewaschen. Die Zellen wurden unmittelbar danach in $10 \mathrm{ml}$ SD1 Medium mit 4\% (w/v) Glucose weiter für drei Stunden inkubiert (erste Chase Phase).

Dann erfolgte die zweite Induktion (zweite Pulse Phase). Dafür wurde $10 \mu 1 \quad 100 \mu \mathrm{M}$ Kupfersulfatlösung in $10 \mathrm{ml}$ Probe zugegeben. Nach einer Stunde wurde die Probe in Falconröhrchen gebracht, und bei 3000 rpm für fünf Minuten bei RT zentrifugiert. Danach wurden sie einmal bei $3000 \mathrm{rpm}$ für fünf Minuten mit bei $30{ }^{\circ} \mathrm{C}$ vorgewärmtem Wasser gewaschen. 
Die Zellen wurden unmittelbar danach im $10 \mathrm{ml}$ SD1 Medium mit 4\% (w/v) Glucose weiter drei Stunden inkubiert (zweite Chase Phase). Je nach Fragestellung wurden die Proben zu den bestimmten Zeitpunkten zum Mikroskopieren bzw. für Western Blots genommen.

\subsection{Batch-Umwandlung (Fluoreszenzkonversion durch UV-Licht) des Dendra2- Proteins}

Das Dendra-Protein ist ein Fluoreszenzprotein, dessen Fluoreszenzeigenschaft sich unter Einwirkung von UV-Licht mit Wellenlänge von $365 \mathrm{~nm}$ von GFP zu RFP umwandeln lässt [GURSKAYA et al. 2006]. Die Fluoreszenzkonversion durch eine externe UV-Lichtquelle ist als Batch-Umwandlung bezeichnet.

Im Rahmen dieser Arbeit wurde ein Verfahren zur UV-Licht-Dendra-Protein-Umwandlung etabliert. Eine kleine Petrischale wurde auf eine UV-Lampe gebracht. Die restliche Fläche wurde mit Aluminiumfolie dicht bedeckt. Der Deckel der Petrischale wurde ebenso mit einer Aluminiumfolie dicht zugedeckt. Diese „Batch-Umwandlung“ erfolgte nach der Induktion des Dendra-Proteins. $10 \mathrm{ml}$ der Probe wurde für fünf Minuten bei $5.000 \mathrm{rpm}$ bei RT zentrifugiert, nach Verwerfen des Überstandes mit $1 \mathrm{ml}$ bei $30{ }^{\circ} \mathrm{C}$ vorgewärmten Wasser resuspendiert, und möglichst dicht auf die Petrischale der UV-Licht-Dendra-Protein-Umwandlungsanlage gebracht. Die Bestrahlung durch UV-Licht erfolgte für eine Stunde bei $365 \mathrm{~nm}$.

\subsection{Doppel-Pulse-Chase-Experiment mit einer Batch-Umwandlung}

Mit dem Hefestamm YKO-025 (GAL1p- 2xDendra2-PEX3) wurde ein Doppel-Pulse-ChaseExperiment mit einer Batch-Umwandlung von $2 x$ Dendra-Pex3p durchgeführt. Das Grundprinzip entsprach dem des Doppel-Pulse-Chase-Experimentes mit einem diploiden Hefestamm.

Der Hefestamm YKO-025 wurde wie oben beschrieben durch eine Plasmid-DNATransformation in das Genom des PEX3-deletierten Stamm hergestellt, und musste daher in einem leucinfreien Medium gehalten werden. Die gesamte Inkubation erfolgte daher im SD2Medium ohne Leucin.

Die Hefezellen wurden im $10 \mathrm{ml}$ Medium mit 4\% (m/v) Raffinose inkubiert. Nach 16stündiger Inkubation wurde die Probe auf einen OD-Wert von 1,0 in 10 ml Medium mit 2\% $(\mathrm{w} / \mathrm{v})$ Galactose gebracht. Nun begann die erste Induktionsphase: Die Inkubationsdauer mit Galactose betrug zwei Stunden (Erste Chase Phase). Danach wurden die Zellen bei $5000 \mathrm{rpm}$ für fünf Minuten bei RT zentrifugiert. Nach Verwerfen des Überstandes wurden die Zellen 
mit bei $30{ }^{\circ} \mathrm{C}$ vorgewärmtem Wasser zum Waschen resuspendiert, und wiederum bei 5000 rpm für fünf Minuten bei RT zentrifugiert.

Nun wurden die Zellen im Medium mit 4\% (m/v) Glucose für eine Stunde inkubiert. Dann erfolgte die Batch-Umwandlung, wie im vorherigen Abschnitt beschrieben. Nachdem die nahezu vollständige Batch-Umwandlung mikroskopisch festgestellt wurde, erfolgte die zweite Induktion in $2 \%(\mathrm{~m} / \mathrm{v})$ Galactose für zwei Stunden (Zweite Pulse Phase).

Danach wurden die Zellen bei $5000 \mathrm{rpm}$ für fünf Minuten bei RT zentrifugiert. Nach Verwerfen des Überstandes wurden die Zellen in bei $30{ }^{\circ} \mathrm{C}$ vorgewärmtem Wasser zum Waschen resuspendiert, und wiederum bei $5000 \mathrm{rpm}$ für fünf Minuten bei RT zentrifugiert. Nun wurden die Zellen wiederum in Medium mit 4\% (m/v) Glucose für drei Stunden inkubiert. Je nach Fragestellung wurden die Proben zu den bestimmten Zeitpunkten zum Mikroskopieren bzw. für den Western Blot genommen.

\subsection{Aufschluss von S. cerevisiae-Zellen - Erstellung von Proteinproben}

Zur Erstellung von Proteinproben für Western Blots wurden die Hefezellen folgendermaßen behandelt. Zuerst wurde zwei Lösungen in folgender Zusammensetzung hergestellt. Die Lösungen wurden stets auf Eis gehalten:

TE (Tris-EDTA) -Puffer:

$$
\begin{array}{ll}
10 \mathrm{mM} & \text { Tris- } \mathrm{HCl}(\mathrm{pH}=8) \\
1 \mathrm{mM} & \text { EDTA. }
\end{array}
$$

Zytolyselösung:

$\begin{array}{ll}1,85 \mathrm{M} & \mathrm{NaOH} \\ 7,4 \%(\mathrm{v} / \mathrm{v}) & \beta \text {-Mercaptoethanol } \\ 0,1 \mathrm{mM} & \text { PMSF } \\ 0,5 \mathrm{mM} & \text { EDTA. }\end{array}$

Die Hefezellen wurden im $10 \mathrm{ml}$ Medium, wie bereits beschrieben, gezüchtet. Die Zelldichte von einem OD-Wert von 2,5 wurde entnommen, und für 30 Sekunden bei $17000 \mathrm{rpm}$ bei $4{ }^{\circ} \mathrm{C}$ zentrifugiert. Dann wurde die Probe in $500 \mu 1$ Tris-EDTA-Puffer resuspendiert, und für 30 Sekunden bei $17000 \mathrm{rpm}$ bei $4{ }^{\circ} \mathrm{C}$ zentrifugiert. Der Überstand wurde vorsichtig abgezogen. Nach Resuspension in gekühltem $500 \mu 1$ Wasser wurde $75 \mu 1$ Zytolyselösung zugegeben. Der Reaktionssatz wurde für zehn Minuten bei $4{ }^{\circ} \mathrm{C}$ gemischt (Vortex). Danach wurde auf Eis vorgekühlte $280 \mu 172 \%(\mathrm{w} / \mathrm{v})$ TCA zugegeben, und für fünf Minuten bei $0{ }^{\circ} \mathrm{C}$ inkubiert. Nach zwölfminütiger Zentrifugation bei $17.000 \mathrm{rpm}$ bei $4{ }^{\circ} \mathrm{C}$ wurde der Überstand vorsichtig 
abgenommen. Dann wurde $500 \mu 1$ bei $-20{ }^{\circ} \mathrm{C}$ vorgekühlte Aceton zugegeben. Die Probe wurde für zehn Minuten bei maximaler Geschwindigkeit bei $4{ }^{\circ} \mathrm{C}$ zentrifugiert.

Zum Trocknen wurde der Deckel des E-Cup geöffnet, und die Probe für 10 Minuten bei RT inkubiert. Nach Zugabe von $40 \mu 12$ X SDS-Ladepuffer wurde die Probe bei $4{ }^{\circ} \mathrm{C}$ zehn Minuten gemischt (Vortex). Die Probe wurde bei $95{ }^{\circ} \mathrm{C}$ für 2 Minuten erhitzt, und ummittelbar danach auf das PAGE-Gel aufgetragen.

\subsection{Protein-Biochemische Methoden}

\subsubsection{SDS-PAGE}

Zur elektrophoretischen Trennung von Proteinen unter denaturierenden Bedingungen wurden diskontinuierliche SDS-Polyacrylamidgele verwendet. Das 10\%ige Trenngel wurde in folgender Zusammensetzung hergestellt.

10\% Trenngel:

$\begin{array}{ll}10 \%(\mathrm{v} / \mathrm{v}) & \text { Rotiphorese Gel } \\ 0,38 \mathrm{M} & \text { Tris-HCl }(\mathrm{pH}=8,8) \\ 0,1 \%(\mathrm{v} / \mathrm{v}) & \text { SDS } \\ 0,1 \%(\mathrm{v} / \mathrm{v}) & \text { APS } \\ 0,04 \%(\mathrm{v} / \mathrm{v}) & \text { TEMED. }\end{array}$

Es wurde mit Isopropanol benetzt, und ca. 30 Minuten bis zur Polymerisation bei RT inkubiert. Das Sammelgel wurde währenddessen in folgender Zusammensetzung hergestellt: Sammelgel:

$\begin{array}{ll}5,1 \%(\mathrm{v} / \mathrm{v}) & \text { Rotiphorese Gel } \\ 0,13 \mathrm{M} & \text { Tris-HCl }(\mathrm{pH}=6,8) \\ 0,1 \%(\mathrm{v} / \mathrm{v}) & \text { SDS } \\ 0,1 \%(\mathrm{v} / \mathrm{v}) & \text { APS } \\ 0,1 \%(\mathrm{v} / \mathrm{v}) & \text { TEMED. }\end{array}$

Isopropanol wurde abgezogen. Das Sammelgel wurde zugegeben. Es wurde für ca. 30 Minuten zur Polymerisierung bei RT inkubiert.

Die Elektrophorese eines Gels (Dimension: $8 \mathrm{~cm}$ x $10 \mathrm{~cm}$ x 0,075 cm) mit einer Polyacrylamidkonzentration des Trenngels von 10\% erfolgte in einer Mini-PROTEAN Tetra-Cell (BioRad Laboratories) für ca. eine Stunde bei $25 \mathrm{~mA}$. 
10x Laufpuffer (PAGE):

$\begin{array}{ll}1,9 \mathrm{M} & \text { Glycin } \\ 0,25 \mathrm{M} & \text { Tris } \\ 0,5 \%(\mathrm{w} / \mathrm{v}) & \text { SDS. }\end{array}$

Als Molekulargewichts-Standard wurde der ProSieve Color Protein Marker (Lonza) benutzt. Der Marker enthält Proteine mit den Molekulargewichten 190 kDa, 127 kDa, 77 kDa, 49 kDa, $38 \mathrm{kDa}, 25 \mathrm{kDa}, 18 \mathrm{kDa}, 12 \mathrm{kDa}$ und $9 \mathrm{kDa}$.

\subsubsection{Western Blot und Immundetektion}

Der Transfer der mittels SDS-Polyacrylamid-Gelelektrophorese aufgetrennten Proteine auf eine Nitrocellulose-Membran (Porengröße: 0,45 $\mu \mathrm{m}$ ) erfolgte in einer Fastblot B43 (Biometra) bei einer konstanten Stromstärke von $60 \mathrm{~mA}$ für eine Stunde. Um freie Proteinbindungsstellen abzusättigen, wurde die Membran anschließend für eine Stunde in 5\% $(w / v)$ Magermilch inkubiert. Die darauf folgende Immundetektion erfolgte mittels eines entsprechenden Antikörpers, und anschließend mit Hilfe des zweiten Antikörpers: Nach einstündiger Inkubation mit Blocking-Puffer wurde der Blot über Nacht mit dem in 5\% (w/v) Magermilch verdünnten ersten Antikörper inkubiert. Die Konzentration der Antikörper wurde bereits im Abschnitt 2.6 aufgelistet.

Am nächsten Tag wurde der Blot dreimal innerhalb von 30 Minuten mit TBST-Puffer gewaschen. Danach wurde für eine Stunde in 1:10000 mit einem Blocking-Puffer-verdünnten zweiten Antikörper inkubiert.

Anschließend wurde der Blot in die Lumi-Light Western Blotting Substrate (Roche) getaucht, und entwickelt.

Blotpuffer, $\mathrm{pH} 9,0$ :

$\begin{array}{ll}20 \mathrm{mM} & \text { Tris } \\ 150 \mathrm{mM} & \text { Glycin } \\ 0,05 \%(\mathrm{w} / \mathrm{v}) & \text { SDS } \\ 20 \%(\mathrm{w} / \mathrm{v}) & \text { Methanol. }\end{array}$

TBST-Puffer:

$\begin{array}{ll}150 \mathrm{mM} & \mathrm{NaCl} \\ 20 \mathrm{mM} & \text { Tris-HCl }(\mathrm{PH}=7,5) \\ 0,01 \%(\mathrm{w} / \mathrm{v}) & \text { Tween } 20 .\end{array}$

Blocking-Puffer:

TBST mit 5\% (w/v) Magermilch. 


\subsection{Kultivierung der Fibroblasten}

Die Zellen wurden in DMEM (Dulbecco's modified Eagle's medium) high glucose (4,5 g/l) mit 10\% FKS (fötalem Kälberserum), Glutamin (2 mM) und für Wildtyp-Zellen zusätzlich mit Puromycin $(10 \mathrm{mg} / \mathrm{ml})$ in $650 \mathrm{ml}$ Zellkulturflaschen bei $37{ }^{\circ} \mathrm{C}$ und mit $5 \%(\mathrm{v} / \mathrm{v}) \mathrm{CO}_{2}$ kultiviert.

Um eine starke Abnahme der Proliferationsrate bzw. ein Absterben der Kultur zu verhindern, mussten die Fibroblasten nach erreichter Maximaldichte ,passagiert“ werden, indem sie unter Verdünnung von der alten Zellkulturflasche in eine neue überführt wurden.

Das alte Medium wurde aus der alten Zellkulturflasche abgesaugt. Die Zellen wurden mit 5 ml PBS (Phosphate Buffered Saline)-Puffer gewaschen, nach Zugabe von $5 \mathrm{ml}$ Trypsin für ca. fünf Minuten in den Brutschrank gestellt, bis sich die Fibroblasten von der Unterlage ablösten und abgerundet in der Trypsinierungslösung schwammen. Dieser Vorgang wurde mit Nährmedium gestoppt.

\subsection{Probenvorbereitung zur Immunfluoreszenz von Fibroblasten}

Am Vortag wurden Fibroblasten für die indirekte Immunfluoreszenzmikroskopie zu einer 3050\%-igen Konfluenz auf der Oberfläche von Deckgläschen $(18 \mathrm{~mm})$ in Kulturschalen angezogen. Am nächsten Tag wurden die Zellen einmal kurz mit PBS gewaschen. Dann wurden sie mit 4\% (m/v) Paraformaldehyd (PFA) zur Fixierung für 20 Minuten bei RT inkubiert. Dann wurden die Zellen dreimal mit PBS-Puffer gewaschen. Zur Permeabilisierung wurde $0,1 \%(\mathrm{~m} / \mathrm{v})$ Triton X-100 in PBS-Puffer zugegeben. Nach fünfminütiger Inkubation bei RT wurden die Proben dreimal für fünf Minuten mit PBS-Puffer gewaschen. Der erste Antikörper wurde verdünnt auf Parafilm in feuchter Kammer gegeben. Die Deckgläser mit Proben wurden darauf gelegt, und über Nacht bei $4{ }^{\circ} \mathrm{C}$ inkubiert.

Dann wurden die Proben dreimal fünf Minuten mit PBS gewaschen. Der zweite Antikörper wurde verdünnt auf Parafilm in feuchter Kammer gegeben. Die Deckgläser mit Proben wurden darauf gelegt, und für eine Stunde bei RT in Dunkelheit inkubiert. Die Proben wurden wiederum dreimal für fünf Minuten gewaschen. Die Verdünnung von Antikörpern ist im Abschnitt 2.6 bereits erläutert.

Mit $8 \mu$ ProLong Gold wurden die Proben auf dem Objektträger eingebettet, und über Nacht bei $4{ }^{\circ} \mathrm{C}$ inkubiert. Am Folgetag wurden die Proben mikroskopisch untersucht. 


\subsection{Fluoreszenzmikroskopie}

\subsubsection{Einbettung von Hefezellen}

Für die mikroskopischen Analysen wurde zunächst 1\%-ige LMP-Agarose geschmolzen, und auf ca. $40^{\circ} \mathrm{C}$ abgekühlt. Das Zellmaterial wurde zu gleichem Anteil mit der warmen $1 \%$ (w/v) Agarose vermischt, sofort auf Objektträger aufgetragen, und mit einem Deckglas abgeschlossen. So konnten die lebenden Hefezellen schonend fixiert werden, ohne dass eine Beeinflussung der Fluoreszenz stattfand.

\subsubsection{Mikroskopische Analyse}

Die mikroskopischen Untersuchungen wurden an einem AXIO-Mikroskop (Zeiss) durchgeführt, und mit einer AXIO CAM HR (Zeiss) fotodokumentiert.

Die Bearbeitung der entsprechenden Bildausschnitte erfolgte mit Hilfe des Bildbearbeitungsprogramms Axiovision (Zeiss) und Microsoft Photo Editor.

\subsection{Verfahren zur Quantifizierung von mikroskopischen Bildern}

\subsubsection{Quantifizierung der Fluoreszenzkonversion}

Zur quantitativen Messung der Effektivität von Konvertierung von Fluoreszenzprotein durch das UV-Licht wurde eine Grauwertbestimmung mit Axiovisionprogramm durchgeführt. Dann wurden die Messwerte mit EXEL-Programm (Microsoft) weiter verarbeitet. Es wurden zwei mikroskopische Schwarz-Weiß-Bildgruppen vor und nach der Bestrahlung folgendermaßen verglichen: Zuerst wurden jeweils 20 beliebige Stellen im Hintergrund als Hintergrundwert gemessen. Daraus wurde ein Mittelwert berechnet (mittlerer Hintergrundwert). Dann wurde eine Grauwertmessung von 20 verschiedenen Peroxisomen im GFP- sowie im RFP-Kanal durchgeführt. Vom jeweiligen Grauwert wurde der mittlere Hintergrundwert im jeweiligen Kanal abgezogen. Somit wurden die Rohwerte errechnet. Aus den Rohwerten des gleichen Peroxisoms im GFP- und RFP-Kanal wurden folgende Quotienten für jedes Peroxisom berechnet: Rohwert (GFP) : Rohwert (RFP) sowie Rohwert (RFP) : Rohwert (GFP)

Ein Mittelwert von 20 Quotientenwerten wurde für jeden Kanal berechnet. Diese Mittelwerte wurden in Form eines Balkendiagrams dargestellt. Ersichtlich darin waren zuerst die Quotienten vor der Bestrahlung (I: Intensität):

- $\mathrm{I}_{\text {vor der Bestrahlung }}(\mathrm{GFP})$ : $\mathrm{I}_{\text {vor der Bestrahlung }}$ (RFP)

- $\mathrm{I}_{\text {vor der Bestrahlung }}(\mathrm{RFP}): \mathrm{I}_{\text {vor der Bestrahlung }}(\mathrm{GFP})$

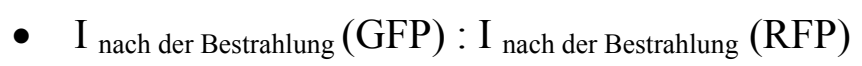


- $\mathrm{I}_{\text {nach der Bestrahlung }}$ (RFP) : I nach der Bestrahlung (GFP).

\subsubsection{Messung von Abstand zwischen Peroxisomen und Zellrand}

Um quantitativ darzustellen, dass Peroxisomen während der Reifung vom zellkernnahen Bereich zum peripheren Bereich der Zellen gelangen, wurde der Abstand zwischen Peroxisomen und dem nächsten Zellrand mit Hilfe des Axiovisionprogramms gemessen. Dies wurde für 100 Peroxisomen durchgeführt. Die Messwerte wurden mit Hilfe des EXELProgramms folgendermaßen weiter verarbeitet: Zunächst wurden Mittelwert und Standardabweichung daraus errechnet. Dann wurden diese mit einem Balkendiagramm dargestellt. Aus den Messwerten wurde die Irrtumswahrscheinlichkeit mit Hilfe des t-Tests berechnet. 


\section{ERGEBNISSE}

\section{1 Übersicht}

In dieser Arbeit soll zum Verständnis der Peroxisomenbildung zuerst die Frage geklärt werden, ob Vorstufen von Peroxisomen entstehen und zu reifen Peroxisomen werden (Reifungsmodell), oder ob Vorstufen von Peroxisomen miteinander fusionieren (Fusionsmodell). In einer Reihe von Hefestämmen wurde das in die frühen Schritte der Peroxisomenbildung involvierte $P E X 3-G e n$ manipuliert, um diese Fragestellungen zu klären. Anschließend wurden, um eine mögliche Beteiligung des ER zu prüfen, Untersuchungen hinsichtlich der räumlichen Beziehung zwischen ER und Peroxisomen durchgeführt. Hierzu wurden zunächst die Immunfluoreszenz mit menschlichen Zellen sowie Pulse-ChaseExperimente mit Hefestämmen durchgeführt, indem Peroxisomen und das ER mit verschiedenen Fluoreszenzfarben markiert wurden.

\subsection{Experimente zur Peroxisomenbiogenese}

In dieser Arbeit wurde zur Klärung der Peroxisomenbiogenese versucht, das PEX3-Gen zu manipulieren. Dies war deswegen sinnvoll, weil die Abschaltung des PEX3-Gens zur Abwesenheit von Peroxisomen, und dessen Anschaltung zur Peroxisomenneubildung führt.

Außerdem liegt Pex3p an der peroxisomalen Membran vor, und dessen Markierung führt somit zur Markierung von Peroxisomen. Deshalb wurde zur mikroskopischen Darstellung von Peroxisomen eine Fluoreszenzmarkierung von Pex3p angewandt.

Durch die Manipulation des PEX3-Gens sollten die folgenden Ziele erreicht werden: Erstens sollte die willkürliche Steuerung der Induktion von Pex3p erfolgen. Zweitens sollte die Darstellung von Peroxisomen unter dem Fluoreszenzmikroskop ermöglicht werden.

Dazu wurde zunächst ein regulierbarer Promotor vor das PEX3-Gen eingefügt. Der CUP1Promotor ermöglicht eine regulierbare Induktion des Proteins durch Kupfersulfat. Der GAL1Promotor funktioniert nach einem gleichen Prinzip: Die Anwesenheit von Galactose führt zur Induktion des Proteins.

Darüber hinaus wurde ein Gen für ein fluoreszierendes Protein zwischen dem regulierbaren Promotor und dem PEX3-Gen eingefügt, welches den Hefezellen die Synthese eines Fusionsproteins von Pex3p mit einem Fluoreszenzprotein, und somit eine Darstellung von Peroxisomen mit Fluoreszenz ermöglicht. Für diese Arbeit werden folgende fluoreszierende 
Proteine verwendet: Gelbfluoreszierendes Protein yECitrine, welches in dieser Arbeit YFP genannt wird, und hellblaufluoreszierendes Protein yECFP, sowie Dendra2-Protein, dessen Fluoreszenzeigenschaft sich unter Einwirkung von UV-Licht konvertieren lässt.

Aus diesen beiden Konstrukten werden drei Hefestämme mit folgendem Genotyp konstruiert:

- YKO-006 (CUP1prom-YFP-PEX3)

- YKO-026 (GAL1-prom-CFP-PEX3)

- YKO-025 (GAL1 prom-Dendra2-Dendra2-PEX3).

Zuerst werden die Experimente mit den oberen beiden Hefestämmen erläutert.

\subsubsection{Experiment mit einem diploiden Hefestamm}

Die Hefestämme YKO-006 und YKO-026 sollten miteinander gepaart werden. Die Paarung beider Hefestämme bedeutet, dass der gepaarte Hefestamm YKO-028 aufgrund seines diploiden Genotyps in der Lage ist, gelbfluoreszierendes Pex3p (YFP-Pex3p) in Anwesenheit von Kupfersulfat und hellblaufluoreszierendes Pexp3p (CFP-Pex3p) in Anwesenheit von Galactose zu induzieren. Hierdurch soll ermöglicht werden, ein Experiment zu konstruieren, in dem zweimal Pex3p induziert wird. Pex3p von der ersten und zweiten Induktion soll unterschieden werden. Dies soll dadurch ermöglicht werden, dass dieser Hefestamm zuerst mit Galactose, und dann mit Kupfersulfat inkubiert wird. So soll sich prüfen lassen, ob die erneute Induktion von Peroxisomen zur Neubildung von unabhängigen Peroxisomen oder zur Fusion von Vorstufen von Peroxisomen mit bereits vorhandenen Peroxisomen führt. Sollte die erste Variante der Fall sein, würde man in den Zellen sowohl nur hellblau als auch nur gelbfluoreszierende Peroxisomen sehen, die voneinander unabhängig sind. Im Falle der zweiten Variante würde man eine Kolokalisation beider Farben sehen.

Bevor diese beiden Hefestämme gepaart werden, wurde eine Reihe von Experimenten mit den haploiden Hefestämmen durchgeführt, um die erfolgreiche Manipulation des Hefegenoms nachzuweisen, und eine optimale Experimentsbedingungen heraus zu finden.

\subsubsection{Nachweisexperimente der haploiden Hefestämme und Optimierung der Experimentbedingung}

Zuerst wurde durch das Ergebnis der Kolonie-PCR dargelegt, dass die genetische Manipulation erfolgreich war. Zweitens werden die Ergebnisse in Bezug auf eine Qualitätssicherung der Experimentbedingung erörtert. Erstens wird das Ergebnis der 
Bestimmung des Kupfergehalts im Nährmedium für die CUP1-Promotor tragenden Hefestämme erläutert, da Kupferfreiheit für den CUP1-Promotor ein wichtiger Aspekt war. Drittens wird hier in Form einer mikroskopischen Analyse sowie Western Blotting veranschaulicht, dass sich die Proteininduktion des haploiden Hefestamms mit Kupfersulfat bzw. mit Galactose anschalten lässt. Dies war eine sehr wichtige Voraussetzung für die Hauptexperimente in dieser Arbeit. Viertens wurde durch eine Kolokalisation von Pex3p mit fluoreszierendem PTS1 belegt, dass es sich bei den fluoreszierenden vesikelförmigen Strukturen mit XFP-Pex3p in den Zellen tatsächlich um Peroxisomen handelt.

\subsection{Kolonie-PCR}

War die die genomische Integration im Genom der Wildtyp-Hefestämme durch Hefe-DNATransformation zur Herstellung von YKO-006 (CUPprom-YFP-PEX3) und YKO-026 (GAL1 prom-CFP-PEX3) erfolgreich?

Um diese Frage sicher zu beantworten, wurde eine Kolonie-PCR durchgeführt. Durch dieses Verfahren wurde ein Teil der essentiellen Hefe-DNA amplifiziert, der durch die genomische Integration verändert wurde. Die Agarosegelanalyse der amplifizierten DNA gab einen Anhalt dafür, dass die Hefe-DNA den transformierten DNA-Abschnitt besaß und somit die genetische Integration erfolgreich war. In dieser Arbeit wurde die Kolonie-PCR in folgenden drei Varianten durchgeführt: Die erste Variante zielte darauf $a b$, den Genabschnitt des Fluoreszenzproteins zu detektieren. Die zweite Variante wies Anwesenheit von einem Teil des PEX3-Promotors mit einem natNT2-Abschnitt nach, der ebenso bei der genomischen Integration eingefügt wurde. Mit der dritten Variante wurde die Anwesenheit des GAL1Promotors nachgewiesen.

\subsection{1 Überprüfung der Anwesenheit des XFP-Genabschnitts}

Die Kolonie-PCR-Reaktionen mit den Oligonukleotiden OST442 und OST443 wurden, wie in Abbildung $16 \mathrm{zu}$ ersehen, konstruiert: OST442 und OST443 binden in den Genabschnitt für Fluoreszenzprotein jeweils stromaufwärts und stromabwärts.

War der Genabschnitt für Fluoreszenzprotein im Hefegenom vorhanden, so war die Bande bei ca. 750 bp auf dem Agarosegel zu sehen. Das Ergebnis ist ebenso in Abbildung 16 ausgeführt. Eine Bande bei ca. 750 bp war bei den beiden Hefestämmen zu erkennen. Wildtyp (BY4741) wurde als Negativkontrolle mit aufgetragen. Es war keine Bande zu erkennen. 

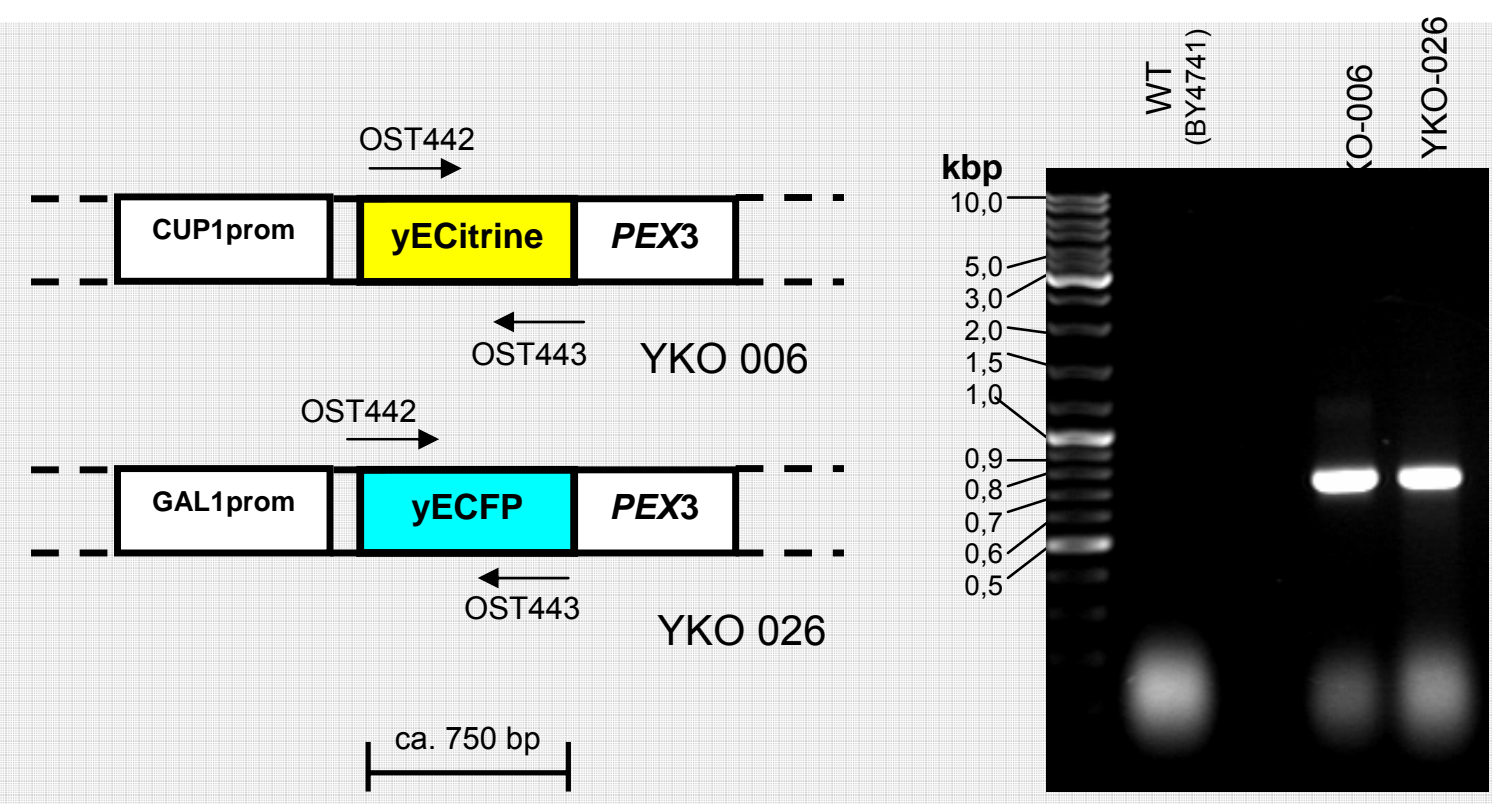

Abbildung 16: Konstrukt und Ergebnis der Kolonie-PCR zum Nachweis eines Genabschnittes von Fluoreszenzproteinen. Die PCR mit den genannten Oligonukleotiden ermöglichte die Amplifikation des Genabschnitts von Fluoreszenzproteinen. In der Agarosegel-Analyse war eine Bande bei ca. 750 bp bei den Hefestämmen YKO-006 und YKO-026 sichtbar, die der Größe des Fluoreszenzproteins entsprach. Im WT war dieser Genabschnitt nicht nachzuweisen.

\subsection{2 Überprüfung der Anwesenheit des nat NT2-Genabschnitts}

Diese Kolonie PCR wies die Anwesenheit des Genabschnitts nat NT2 nach, der für die Resistenzbildung gegen clonNAT verantwortlich ist, und somit für die Selektion bei der Herstellung dieser beiden Hefestämme. Dieser Genabschnitt wurde ebenso bei der genomischen Integration ins Hefegenom eingefügt. Das Konstrukt der PCR ist in Abbildung 17 dargestellt: OST425 bindet in den Abschnitt von nat NT2. OST424 bindet in den Genabschnitt von PEX3prom. Existierte der nat NT2 im Hefegenom, war eine Bande bei ca. 527 bp auf dem Agarosegel zu sehen. Das Ergebnis ist ebenso in Abbildung 17 dokumentiert: Bei den beiden Hefestämmen YKO-006 und YKO-026 zeigen sich eine Bande bei ca. 530 bp, die auf die Anwesenheit von nat NT2-Gen, und somit auf eine erfolgreiche genetische Integration hinwies. Jedoch war dies bei den Wildtyp-Hefestämmen nicht der Fall. Dieser Befund korrelierte ebenso mit der Tatsache, dass die beiden Hefestämme in der Lage waren, in einem clonNAT-haltigen Medium zu wachsen, und sich somit selektieren ließen. 


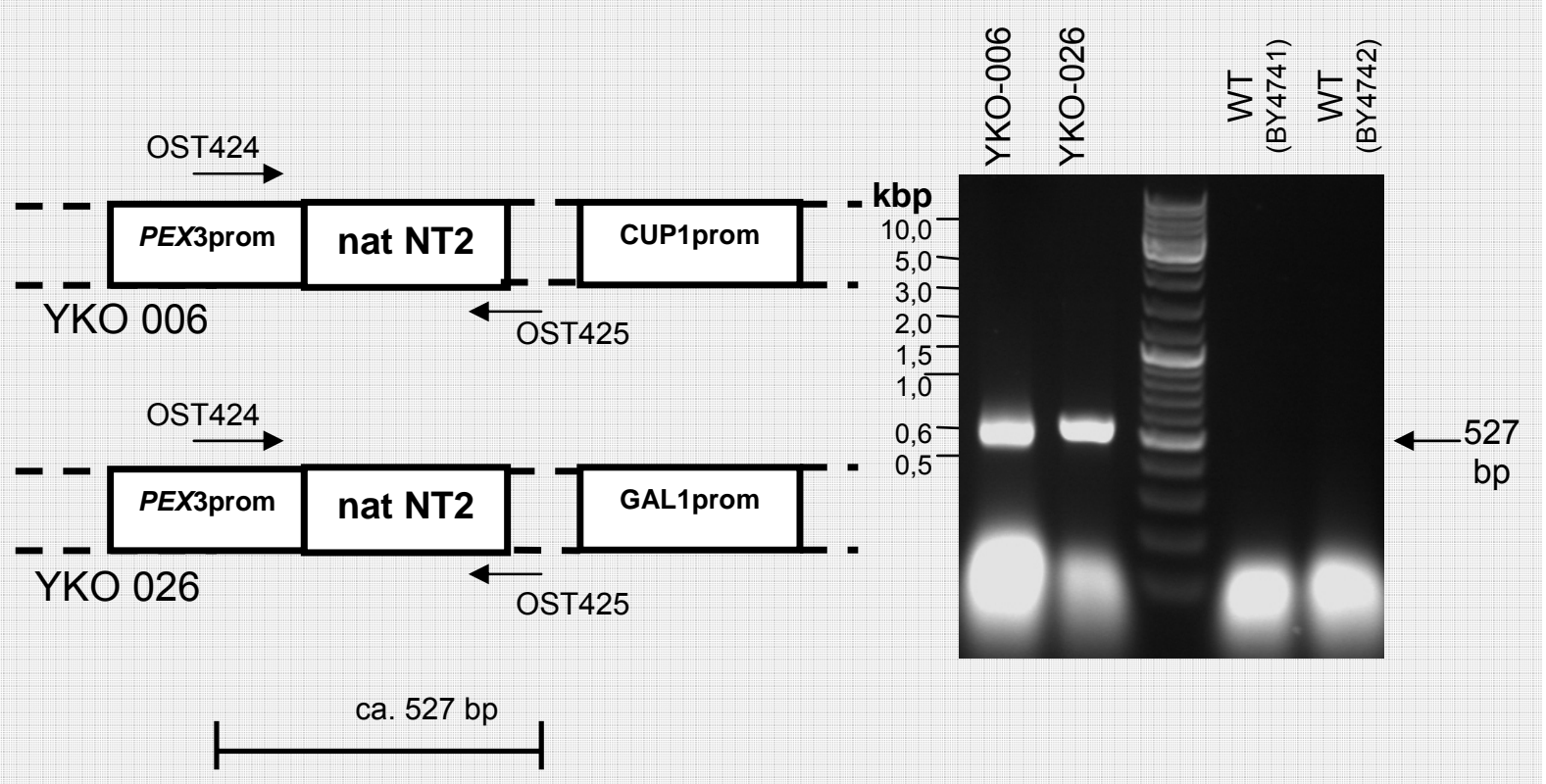

Abbildung 17: Konstrukt und Ergebnis der Kolonie-PCR zum Nachweis der Anwesenheit des natNT2-Genabschnittes. Die PCR mit oben genannten Oligonukleotiden führte zur Amplifikation des Teils des PEX3-Promotors sowie des nat NT2Genabschnittes mit insgesamt ca. 527 bp. In der Agarosegel-Analyse wurde dies bei den Hefestämmen YKO-006 und YKO-026 nachgewiesen. Jedoch bei den Wildtypen war dies nicht der Fall.

\subsection{3 Überprüfung der Anwesenheit des GAL1prom-XFP-PEX3-Genabschnitts}

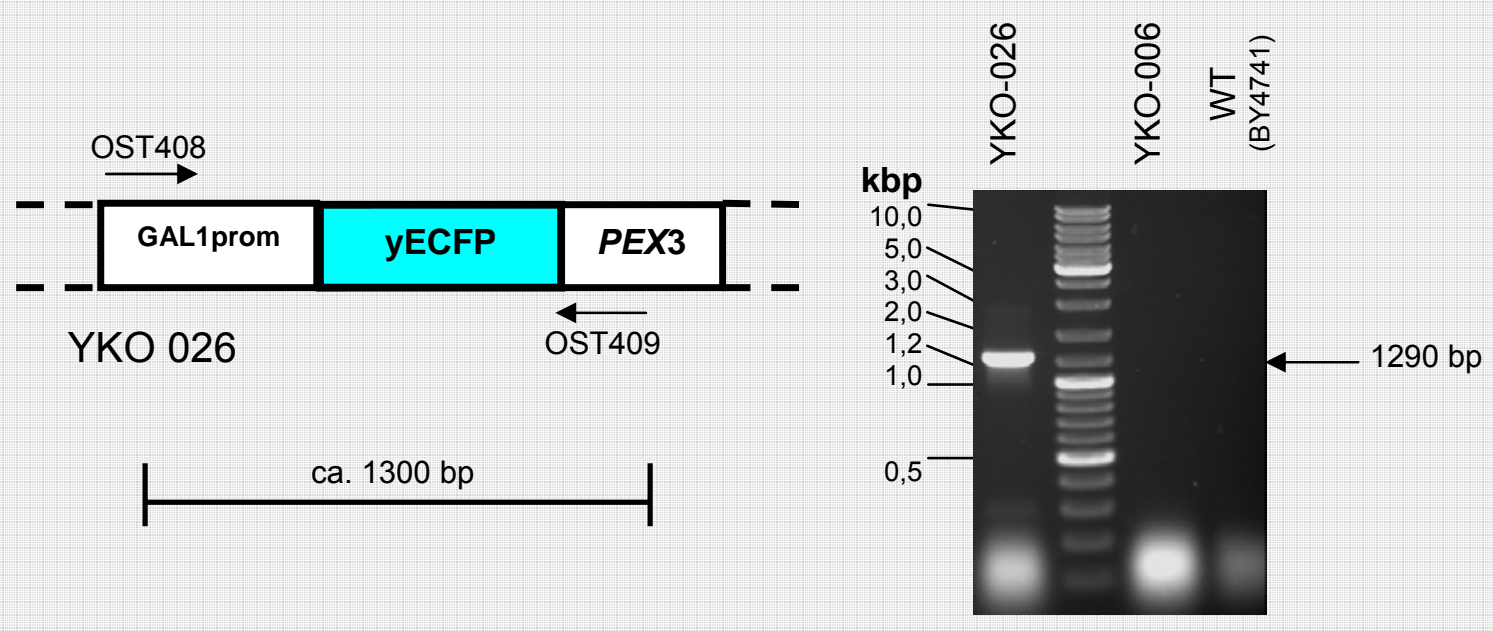

Abbildung 18: Konstrukt und Ergebnis von Kolonie-PCR zum Nachweis von GAL1prom-CFP-Genabschnitt. Die Kolonie-PCR mit OST408 und OST409 ermöglichte die Amplifikation des GAL-Promotor-Genabschnittes und eines Teils des PEX3-Gens, was insgesamt ca. 1290 bp enthielte. Beim Hefestamm YKO-026 zeigte sich dieser Genabschnitt. Beim Hefestamm YKO-006 sowie Wildtyp wurde keine amplifizierte DNA nachgewiesen. 
Mit dieser Kolonie-PCR wurde die Anwesenheit von GAL1prom-CFP nachgewiesen. Das Konstrukt dieser Kolonie-PCR ist in Abbildung 18 dargestellt: OST408 bindet in einem Genabschnitt von GAL1 prom, OST409 bindet in einem Genabschnitt des PEX3-Gens.

War GAL1prom-CFP sowie PEX3-Gen im Hefegenom vorhanden, war eine Bande bei ca. 1290 bp zu sehen. Das Ergebnis ist in Abbildung 18 gezeigt. Eine Bande bei ca. 1290 bp war bei YKO-026 zu erkennen und wies somit die Anwesenheit von GAL1prom-CFP-PEX3 nach. Bei den Negativkontrollen mit Wildtyp und YKO-006 (CUP1p-YFP-PEX3) war aufgrund des fehlenden GAL1Promotors keine Bande zu erkennen.

\subsection{Bestimmung der Kupferkonzentration}

\begin{tabular}{|c|c||c|c|}
\hline Medium & $\begin{array}{c}\text { Messwert } \\
{[\mu \mathrm{M}]}\end{array}$ & Kohlenstoffquelle & $\begin{array}{c}\text { Messwert } \\
{[\mu \mathrm{M}]}\end{array}$ \\
\hline YP & 0,6 & $3 \%(\mathrm{~m} / \mathrm{v})$ Glucose & 0,4 \\
\hline $\begin{array}{c}\text { SD mit YNB1 } \\
\text { ohne Kupfer } \\
\text { ohne Zucker }\end{array}$ & 0 & $4 \%(\mathrm{~m} / \mathrm{v})$ Raffinose & 0,3 \\
\hline $\begin{array}{c}\text { SD mit YNB2 } \\
\text { ohne Zucker }\end{array}$ & 1 & $2 \%(\mathrm{~m} / \mathrm{v})$ Galactose & 0,2 \\
\hline $\begin{array}{c}\text { SD mit YNB1 } \\
\text { SM Kupfersulfat ohne } \\
\text { Zucker }\end{array}$ & 114 & & \\
\hline SD mit YNB1 mit einem \\
$\begin{array}{c}\text { Zusatz: } \\
+2 \% \text { (m) Pepton }\end{array}$
\end{tabular}

Tabelle 14: Ergebnis der Konzentrationsbestimmung von Kupfersulfat im Medium und in Kohlenstoffquellen. In SD1-Medium, das für diese Arbeit extra hergestellt wurde, wurde kein Kupfersulfat detektiert. Die restlichen Nährmedien enthielten stets Kupfersulfat. In der Zuckerlösung wurde eine geringe Konzentration von Kupfersulfat detektiert. (YNB1: selbst hergestellt; YNB2: YNB von Fa. Sigma-Aldrich).

Es war für die Untersuchung mit dem Hefestamm mit einem CUP1prom primär nicht unerheblich, ein Nährmedium herzustellen, das möglichst kein Kupfersulfat enthält, um eine mögliche Induktion durch eine geringe Menge von Kupfersulfat im Medium zu vermeiden. Alle handelsüblichen Medienzutaten enthielten eine geringe Menge von Kupferionen. Daher wurde in dieser Arbeit eine Hefestickstoffbasis (YNB) ohne Zusatz von Kupfersulfat, wie im Kapitel, Material und Methoden, beschrieben, hergestellt. Diese ist in dieser Arbeit als YNB1 bezeichnet. Die Kupferkonzentration der Medien, die in dieser Arbeit verwendet wurden, 
wurde ohne Zusatz einer Kohlenstoffquelle gemessen. Daher wurde die Kupferkonzentration von verschiedenen Zuckerlösungen zusätzlich gemessen. Um die Wachstumsbedingung zu optimieren, wurde ein weiteres Medium mit folgender Zusammensetzung hergestellt: $\mathrm{Zu}$ SD1-Medium wurden 2\% (m/v) Pepton sowie 0,5\% (w/v) Ammoniumsulfat zu gegeben, welches als SD1 mit einem Zusatz bezeichnet ist. Das Messungsergebnis ist in Tabelle 14 aufgelistet. Im Medium mit dem selbst hergestellten YNB wurde kein Kupfer detektiert.

Überraschenderweise hatte die Kohlenstoffquelle einen geringen Anteil von Kupfer. Jedenfalls konnte die Konzentration von Kupfersulfat letztendlich mit dem SD1 in viel geringerer Menge gehalten werden, als die in den Medien, wie YPD- sowie SD2-Medium.

\subsection{Optimale Konzentration des Kupfersulfats}

Der Hefestamm YKO-006 (CUP1prom-YFP-PEX3) besaß einen CUP1-Promotor, der die Induktion von YFP-Pex3p in Anwesenheit von Kupfersulfat ermöglicht. YFP-Pex3p ist ein Fusionsprotein von Pex3p mit einem gelbfluoreszierenden Protein. In der Literatur wurde jedoch noch nicht beschrieben, welche Konzentration von Kupfersulfat eine optimale Bedingung darstellt. Um die optimale Konzentration von Kupfersulfat für die Anschaltung von Induktion von YFP-Pex3p herauszufinden, wurde ein Experiment durchgeführt, in dem der Hefestamm YKO-006 in folgender Konzentrationsreihe von Kupfersulfat für sechs Stunden inkubiert und mikroskopisch analysiert wurde.

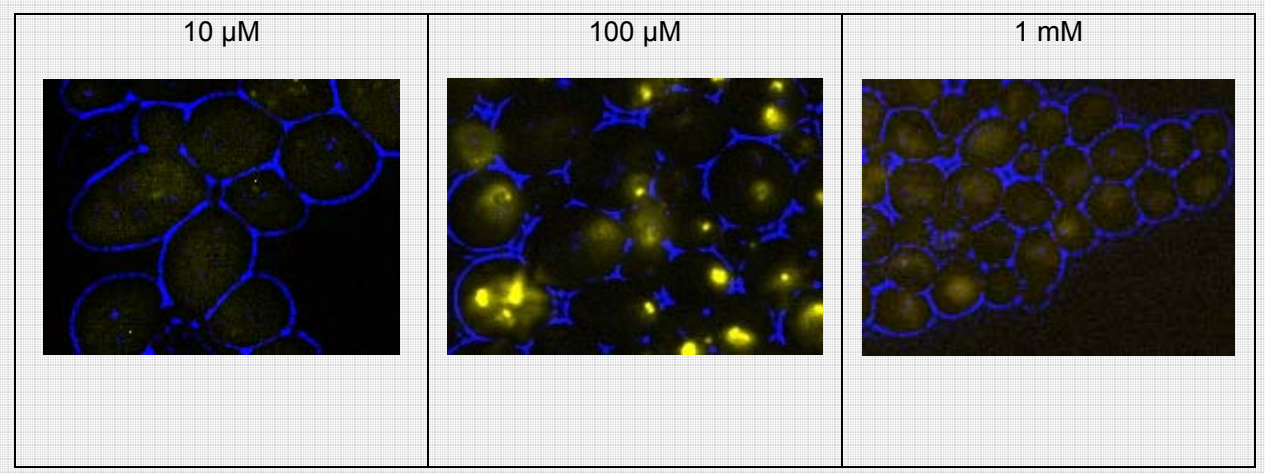

Abbildung 19: Induktion vom yEYFP-Pex3p in unterschiedlicher Kupferkonzentration. Die Inkubation in $100 \mu \mathrm{M}$ Kupfersulfat erbrachte eine optimale Bedingung. Lag die Konzentration von Kupfersulfat 10fach darüber bzw. darunter, war die Induktion nicht gut sichtbar. Bei $1 \mathrm{mM}$ Kupfersulfat waren die Zellen in Vergleich mit anderen Bedingungen deutlich verkleinert. 
Die mikroskopischen Bilder sind in Abbildung 19 mit dem gleichen Vergrößerungsfaktor dargestellt. Es ließ sich feststellen, dass die Induktion von YFP-Pex3p bei der Konzentration von $100 \mu \mathrm{M}$ optimal zu beobachten war. Die Zellmorphologie war intakt und somit mit den Zellen vergleichbar, die in YPD-Medium gezüchtet wurden. Das Zellwachstum war ebenfalls nicht gestört. Bei einer Konzentration bei $1 \mathrm{mM}$ waren die Zellen deutlich verkleinert. Es wurde YFP-Pex3p nur gering induziert. Es fand offensichtlich eine Wachstumsstörung sowie eine Zytolyse statt. Die Inkubation in $10 \mu \mathrm{M}$ Kupfersulfat erbrachte eine kaum sichtbare Induktion von YFP-Pex3p.

\subsection{Fluoreszenzmikroskopie}

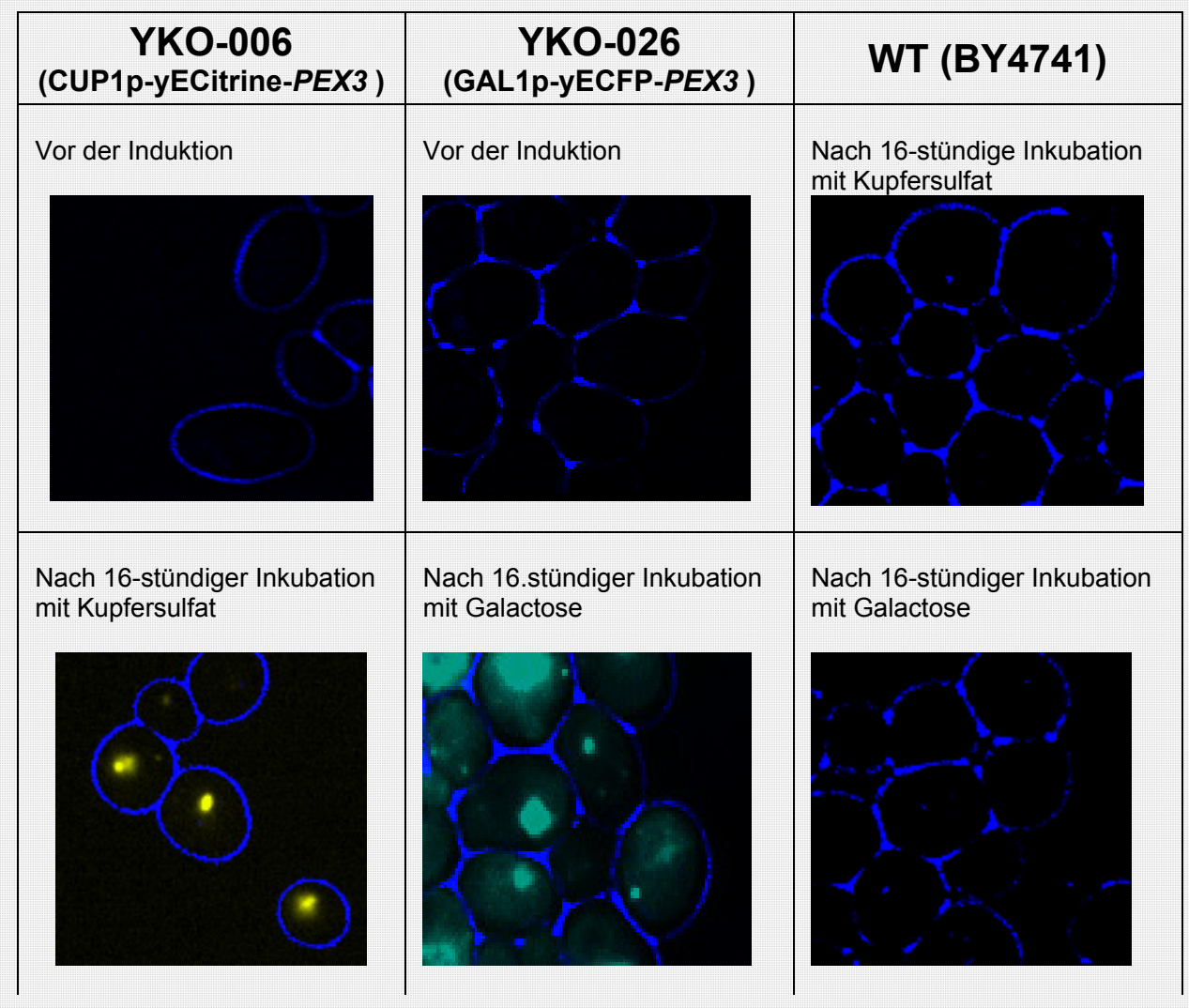

Abbildung 20: 16-stündige Induktion mit Negativkontrolle mit WT (BY4741). Wie zu erwarten, war vor der Induktion kein Fluoreszenzprotein zu erkennen. Nach 16-stündiger Inkubation mit Kupfersulfat bzw. Galactose entstanden fluoreszierende auffällig große vesikelförmige Strukturen. In YKO-026 war auf dem Nativbild zusätzlich eine ringförmige Struktur schwach sichtbar. Im gleich behandelten WT-Hefestamm war zu diesem Zeitpunkt kein Fluoreszenzprotein sichtbar. 
Um zu testen, ob die Induktion überhaupt stattfand, wurde der Hefestamm YKO-006 (CUPprom-YFP-PEX3) in glucosehaltigem SD1-Medium mit Zusatz von Kupfersulfat und YKO-026 (GAL1prom-CFP-PEX3) in galactosehaltigem YP-Medium für 16 Stunden inkubiert. Als Negativkontrolle wurde pararell auch der Wildtyp (BY4741) gleichermaßen behandelt. Wie in Abbildung 20 dargestellt, wurden nach 16-stündiger Kupfer- bzw. Galactose-Inkubation jeweils in YKO-006 YFP-Pex3p und in YKO-026 CFP-Pex3p vesikelförmige Strukturen sichtbar. Jedoch war dies im Wildtyp (BY4741) nicht der Fall. Eine Auffälligkeit bestand jedoch darin, dass die Induktion von Pex3p in dieser Bedingung zur Bildung von Vesikeln führte, die übermäßig vergrößert waren.

\subsection{Einzel-Pulse-Chase-Experiment}

Läßt sich die Induktion von Pex3p wirklich durch Galactose bzw. Kupfersulfat anschalten? Führt die darauf folgende Abwesenheit von Galactose bzw. Kupfersulfat zur Abnahme von Pex3p? Wird wirklich XFP-Pex3p induziert?

Um diese Fragen zu klären, wurde ein Pulse-Chase-Experiment durchgeführt. Die Hefezellen wurden durch mikroskopische Untersuchung und Western Blotting zu mehreren Zeitpunkten analysiert. Durch mikroskopische Analyse zu verschiedenen Zeitpunkten wurde die Induktion von XFP-Pex3p auf optischer Ebene untersucht. Mit dem Western Blot wurde belegt, dass es sich bei den induzierten Proteinen wirklich um XFP-Pex3p handelt, und dass sich die Proteininduktion an- und ausschalten lässt. Es wurden der Anti-Pex3p- sowie der Anti-GFPAntikörper eingesetzt.

\subsection{YKO-006 (CUP1prom-YFP-PEX3)}

An dieser Stelle wird zuerst das Ergebnis des Pulse-Chase-Experiments mit YKO-006 (CUP1prom-YFP-PEX3) erläutert. Die Proben wurden vor der Induktion, direkt nach zweistündiger Induktion mit Kupfersulfat und dann jeweils nach einer Stunde, zwei Stunden sowie vier Stunden nach der Induktion analysiert. Da der Anti-GFP-Antikörper auch auf YFP reagiert, wurde dieser verwendet, um die Induktion von YFP zu testen. Das Ergebnis ist in Abbildung 21 veranschaulicht. Pex3p aber nicht YFP war bereits vor der Induktion im Western Blot zu detektieren. Die zweistündige Inkubation von YKO-006 mit Kupfersulfat führte zu einer guten Induktion von YFP-Pex3p. Die Proteinmenge klang bis zwei Stunden nach der Induktion kaum ab. Erst vier Stunden nach der Induktion nahmen die beiden Proteine ab, waren jedoch noch detektierbar. Die mikroskopische Analyse wies ein ähnliches 
Bild auf. Es war vor der Induktion kein YFP-Pex3p zu erkennen. Der restliche Befund am Mikroskop war mit dem Ergebnis des Western Blots vereinbar: YFP-Pex3p war bis zwei Stunden nach der Induktion nahezu gleich stark sichtbar. Vier Stunden nach der Induktion klang die Fluoreszenzintensität ab, war jedoch noch mäßig erkennbar. Als Kontrolle wurde der Wildtyp-Hefestamm geprüft, wobei Pex3p jedoch kein YFP zu detektieren war.

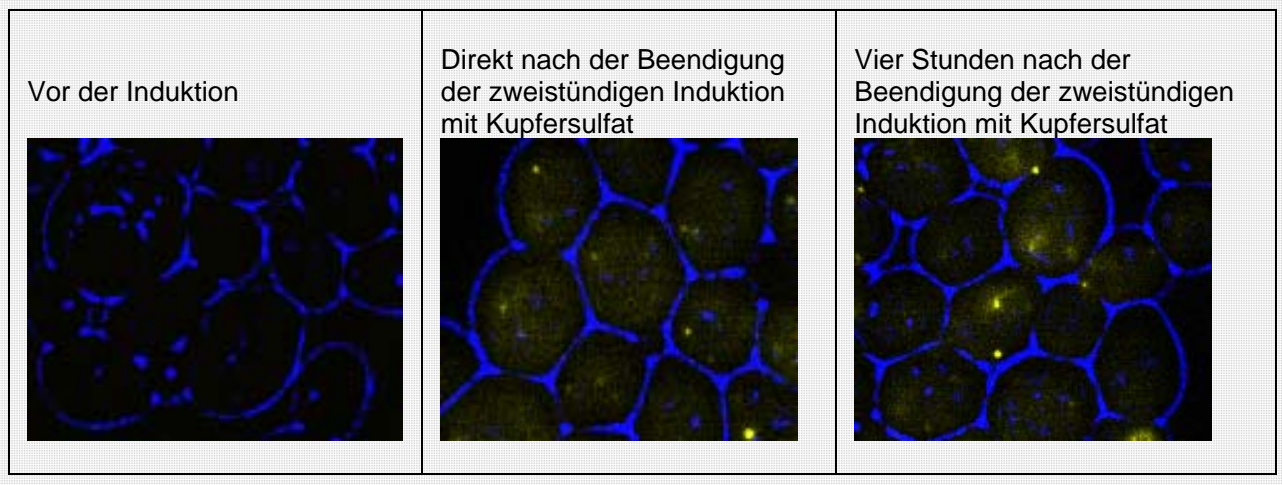

\begin{tabular}{|c|c|c|c|c|c|c|}
\hline & \multirow{2}{*}{$\begin{array}{l}\text { Vor der } \\
\text { Induktion }\end{array}$} & \multicolumn{4}{|c|}{$\begin{array}{l}\text { Nach der Beendigung der zweistündigen } \\
\text { Induktion mit Kupfersulfat }\end{array}$} & \multirow{2}{*}{$\begin{array}{c}\text { Wildtyp } \\
\text { (BY4741) }\end{array}$} \\
\hline & & Sofort & $1 \mathrm{Std}$. & 2 Std. & 4 Std. & \\
\hline \multicolumn{7}{|l|}{ Pex3p } \\
\hline GFP & & & & & & \\
\hline
\end{tabular}

Abbildung 21: Analyse von Einzel-Pulse-Chase-Experiment mit dem Hefestamm, YKO-006. Vor der Induktion war keinerlei Fluoreszenzprotein in der mikroskopischen Analyse sichtbar. YFP-Pex3p war sowohl direkt als auch vier Stunden nach der Beendigung der zweistündigen Induktion gut als vesikelförmig sichtbar. Im Western Blot war bereits vor der Induktion Pex3p aber nicht YFP zu detektieren. Beide Proteine waren bis vier Stunden nach Beendigung der Induktion detektierbar. Als Kontrolle mit dem Wildtyp war Pex3p aber nicht YFP unabhängig von der Inkubation mit Kupfersulfat detektierbar.

\subsection{YKO-026 (GAL1prom-CFP-PEX3)}

Die Analyse des Einzel-Pulse-Chase-Experiments mit dem Hefestamm YKO-026 wird nun erläutert. $\mathrm{Zu}$ den Zeitpunkten, vor der Induktion, direkt nach einstündiger Induktion mit Galactose sowie nach Abschluss der einstündigen Induktion jeweils nach 60 Minuten, nach 120 Minuten sowie nach 240 Minuten wurden die Proben analysiert. Zur Kontrolle wurde ebenso der Wildtyp (BY4741) mit aufgetragen. In Abbildung 22 ist das Ergebnis dargestellt: 
Es war im Western Blot zu erkennen, dass vor der Inkubation mit Galactose weder CFP noch Pex3p zu detektieren waren. Direkt nach einstündiger Induktion war bereits eine mäßige Menge von beiden Proteinen zu detektieren. Jedoch erreichte die Induktion von CFP-Pex3p erst 60 Minuten nach der einstündigen Induktion das Maximum. Danach nahm diese ab. Zum Zeitpunkt zwei Stunden nach der Induktion ergab sich ein interessantes Bild: Pex3p wurde kaum detektiert, wohingegen CFP mäßig zu sehen war. Nach 300 Minuten war etwa die gleiche Proteinmenge erreicht, wie bei Wildtyp-Pex3p, wobei das CFP nur in geringer Menge detektiert wurde. Die mikroskopische Analyse zeigte folgenden Verlauf: Vor der Induktion war kein CFP-Pex3p zu erkennen. Direkt nach der Induktion war CFP-Pex3p als vesikelförmige Strukturen gut sichtbar. Danach nahm die Intensität der Fluoreszenz von Peroxisomen kontinuierlich ab. Jedoch war CFP-Pex3 vier Stunden nach der Induktion noch sehr gut zu sehen.

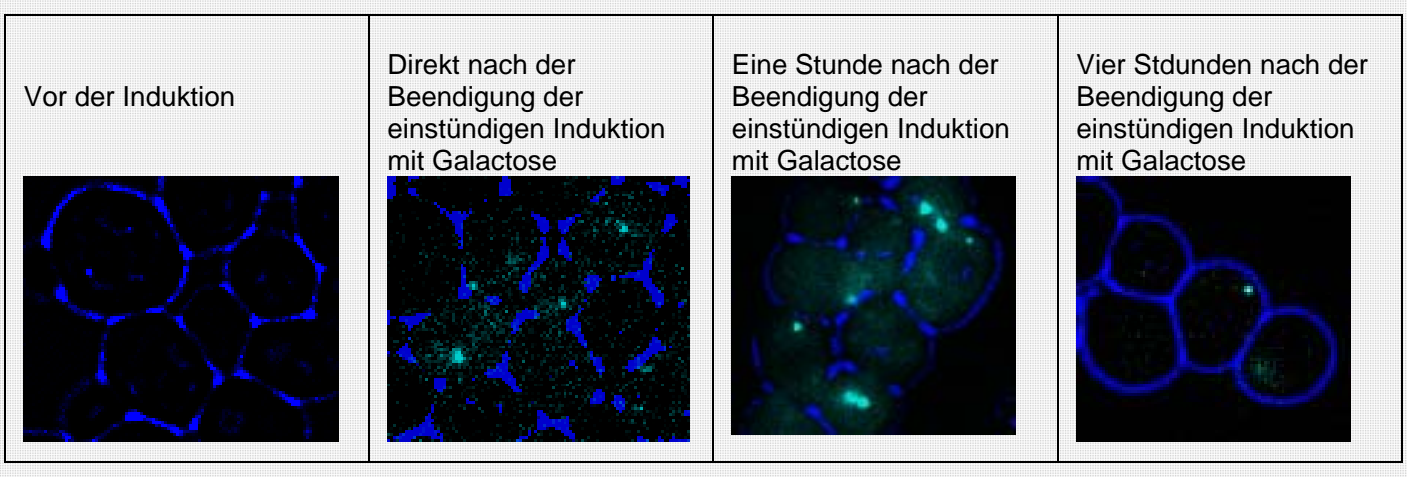

\begin{tabular}{|c|c|c|c|c|c|c|}
\hline \multirow{2}{*}{$\begin{array}{c}\text { Vor der } \\
\text { Induktion }\end{array}$} & \multicolumn{3}{|c|}{$\begin{array}{c}\text { Nach der Beendigung der einstündigen } \\
\text { Induktion mit Galactose }\end{array}$} & Wildtyp \\
\cline { 2 - 5 } & & Sofort & 1 Std. & 2 Std. & 4 Std. & (BY4741) \\
\hline Pex3p & & & & & & \\
\hline GFP & & & & & & \\
\hline
\end{tabular}

Abbildung 22: Analyse von Einzel-Pulse-Chase-Experiment mit dem Hefestamm YKO026. Vor der Induktion war keinerlei Fluoreszenzprotein in der mikroskopischen Analyse sichtbar. CFP-Pex3p war sowohl direkt als auch vier Stunden nach der Beendigung der zweistündigen Induktion gut als vesikelförmige Struktur sichtbar. Im Western Blot war vor der Induktion weder Pex3p noch CFP zu detektieren. Beide Proteine waren bis vier Stunden nach Beendigung der Induktion detektierbar, wobei die beiden Proteine nach einer Stunde nach Beendigung der Induktion das Maximum erreichten. Interessanterweise nahm die Menge von Pex3p zwei Stunden nach der Induktion deutlich ab aber zwischen zwei und vier Stunden leicht zu. Beim Wildtyp war Pex3p aber nicht YFP detektierbar. 


\subsection{Nachweis von Peroxisomen durch Kolokalisation von fluoreszierendem Pex3p und PTS1}

\begin{tabular}{|c|c|c|c|}
\hline & YFP-PTS1 & CFP-Pex3p & überlappt \\
\hline 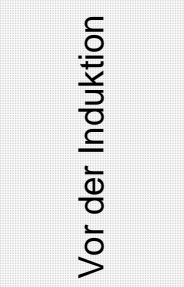 & & & \\
\hline 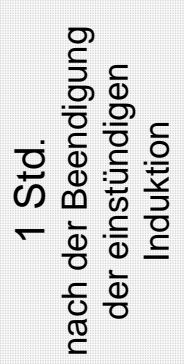 & & & \\
\hline 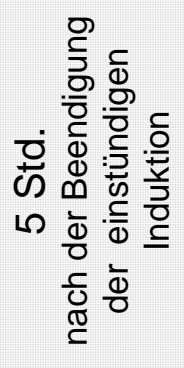 & & & \\
\hline
\end{tabular}

Abbildung 23: Mikroskopische Analyse von Pulse-Chase-Experiment mit YKO-025 (GAL1prom-CFP-PEX3 mit YFP-PTS1). Vor der Induktion war kein CFP-Pex3p sichtbar. YFP-PTS1 war ubiquitär in Zellen verteilt. Eine Stunde nach der Beendigung der einstündigen Induktion waren Vesikeln mit CFP-Pex3p nachweisbar. Jedoch zeigte YFP-PTS1 weiterhin eine ubiquitäre Verteilung in Zellen, was auf das Nicht-Vorhandensein von reifen Peroxisomen hinwies. Erst nach fünf Stunden nach der Beendigung der Induktion waren beide Farben miteinander kolokalisiert.

Handelt es sich bei den von XFP-Pex3p markierten Vesikeln in der mikroskopischen Analyse wirklich um Peroxisomen?

Um dieser Frage zu beantworten, wurde ein weiterer Peroxisomenmarker angewandt: mit Fluoreszenz markiertes PTS1. YKO-006 (CUP1prom-YFP-PEX3) wurde mit dem rotfluoreszierenden PTS1 eqFP611-PTS1 und YKO-026 (GAL1prom-CFP-PEX3) mit gelbfluoreszierenden PTS1, YFP-PTS1 kombiniert. Die beiden Hefestämme wurden nun 
jeweils YKO-017 und YKO-021 genannt. Es wurde ein Einzel-Pulse-Chase-Experiment mit diesen beiden Hefestämmen durchgeführt, um durch Kolokalisation der fluoreszierenden Peroxisomen mit Pex3p mit fluoreszierenden PTS1-Peroxisomen nachzuweisen, dass es sich bei fluoreszierendem Pex3p wirklich um Peroxisomen handelt.

Die Bilddokumentation der mikroskopischen Analyse bei YKO-021 (GAL1prom-CFP-PEX3 mit YFP-PTS1) ist in Abbildung 23 veranschaulicht. Zu beobachten war, dass vor der Induktion und eine Stunde nach der Beendigung der Induktion mit Galactose im YFP-Kanal keinerlei Peroxisomen, sondern lediglich eine ubiquitäre Verteilung von YFP-PTS1 in den Zellen nachweisbar war. Dies deutet auf die Abwesenheit von Peroxisomen hin, obwohl einige wenige Vesikel mit CFP-Pex3p bereits eine Stunde nach der Induktion entstanden waren. Erst sechs Stunden nach der Induktion war eine exakte Kolokalisation der Vesikel mit YFP-PTS1 mit denen von CFP-Pex3p zu dokumentieren, was darauf hinwies, dass CFPPex3p zu diesem Zeitpunkt reife Peroxisomen markierte.

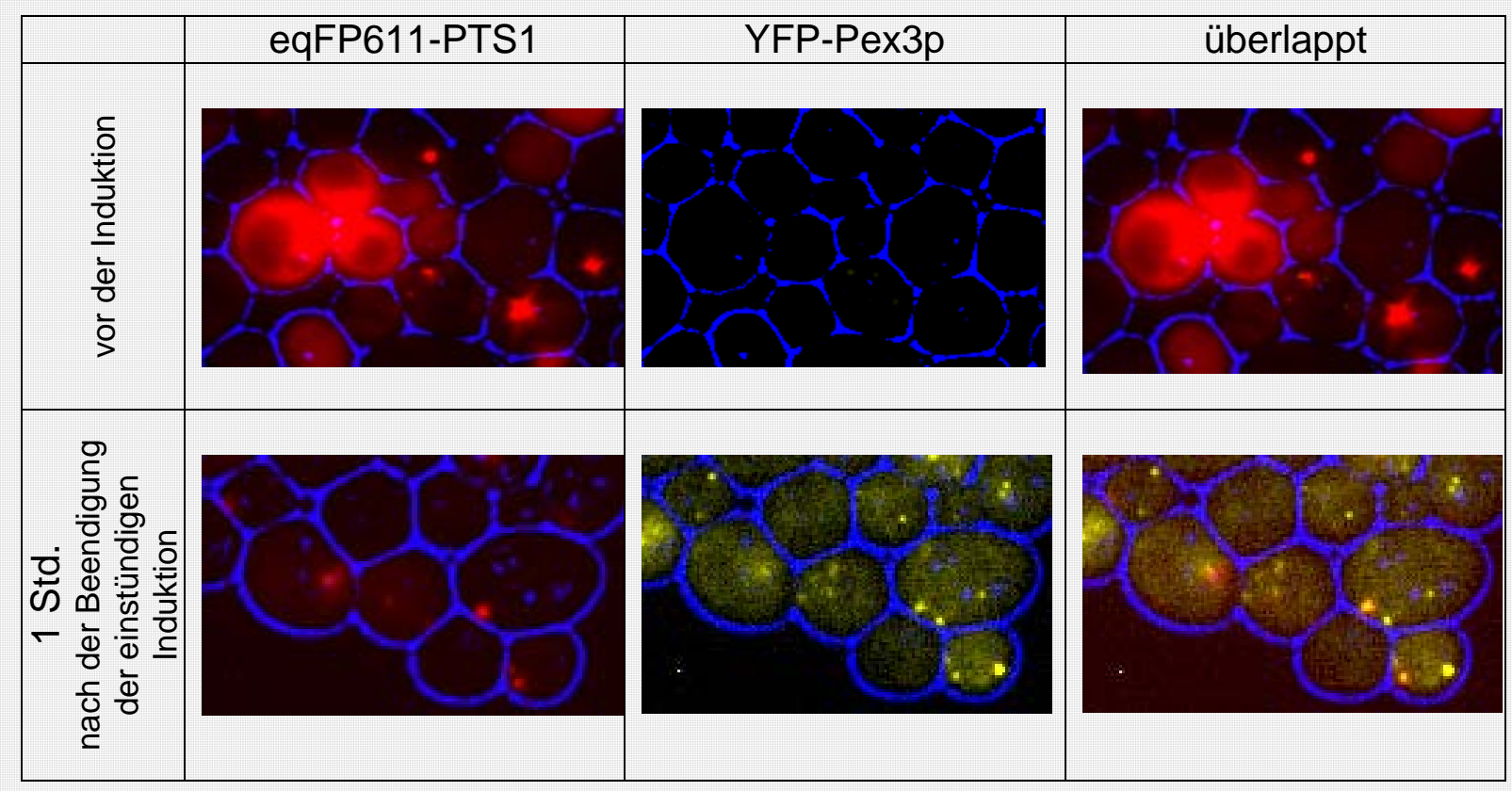

Abbildung 24: Mikroskopische Analyse von Pulse-Chase-Experiment mit YKO-017 (CUP1prom-YFP-PEX3 mit eqFP611-PTS1). Vor der Induktion war kein YFPPex3p sichtbar. Jedoch waren wenige Peroxisomen durch eqFP611-PTS1 bereits $\mathrm{zu}$ diesem Zeitpunkt markiert. Eine Stunde nach Beendigung der Induktion zeigte sich teilweise eine Kolokalisation beider Farben. Einige Peroxisomen waren bereits zu diesem Zeitpunkt reif.

Das Ergebnis bei YKO-017 (CUP1prom-YFP-PEX3 mit eqFP611-PTS1) ist in Abbildung 24 gezeigt. Es waren die Vesikel mit eqFP611 bereits vor der Induktion neben ubiquitär 
verteiltem eqFP611-PTS1 teilweise sichtbar, was darauf hinwies, dass bereits vor der Induktion vereinzelt nicht von YFP-Pex3p dargestellte reife Peroxisomen vorlagen. Nach der Induktion dauerte es nur eine Stunde, bis eine gute Kolokalisation von Vesikeln mit YFPPex3p mit denen von eqFP611-PTS1 festzustellen war.

\subsubsection{7 Überexpression vom Pex3p und Peroxisomenbiogenese}

Im vorherigen Experiment wurde beobachtet, dass eine übermäßige Induktion von Pex3p zu einer Bildung vergrößerter Vesikel führt.

Um die Frage zu klären, ob es sich bei diesen Vesikeln noch um funktionsfähige Peroxisomen handelt, wurde YKO-017 (CUP1prom-YFP-PEX3 mit eqFP611-PTS1) für zwölf Stunden mit Kupfersulfat inkubiert, um die übermäßige Induktion von Pex3p zu erzielen. Wie in Abbildung 25 dargestellt, wiesen die Vesikel von Pex3p und PTS1 eine exakte Kolokalisation auf, wenn die Vesikel noch relativ klein waren, jedoch keine Kolokalisation, wenn die Vesikel mit Pex3p übermäßig vergrößert waren. Die übermäßig vergrößerten Vesikeln konnten also nicht mehr PTS1 importieren.

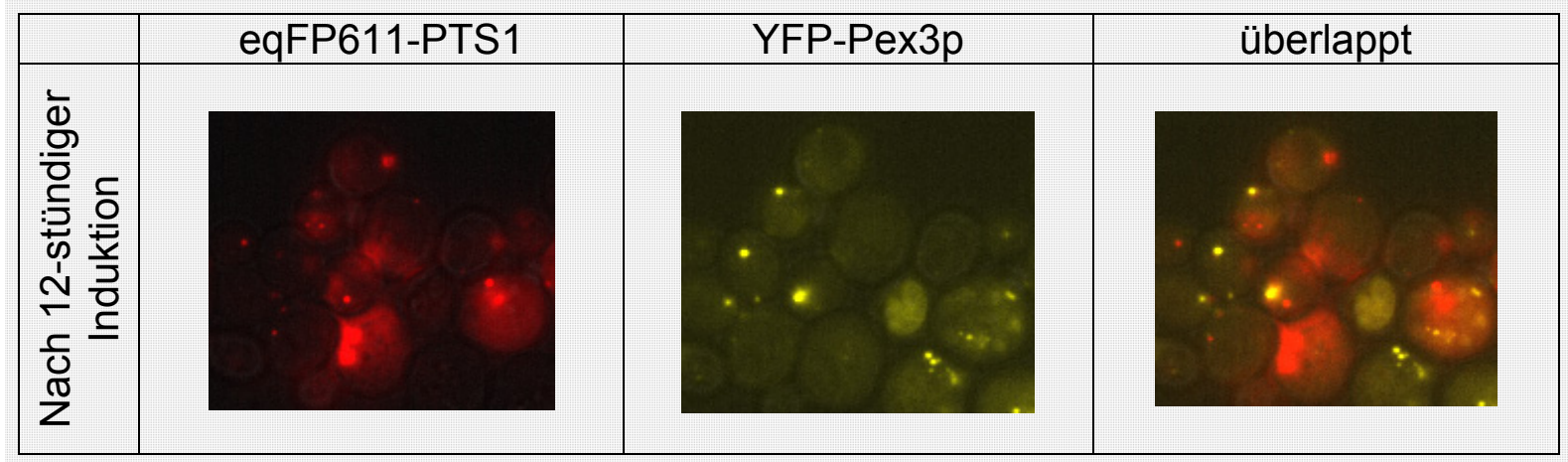

Abbildung 25: Überexpression von Pex3p im Hefestamm YKO-017 (CUPprom-YFP-PEX3 mit YFP-PTS1). Nach Überexpression durch 12-stündige Induktion zeigte sich zum größten Teil keine Kolokalisation beider Farben mehr, wenn die Vesikeln übermäßig vergrößert waren. Waren die Vesikel noch relativ klein, beobachtete man eine Kolokalisation beider Farben. 


\subsubsection{Doppel-Pulse-Chase-Experiment mit einem gepaarten Hefestamm YKO-028}

A
\begin{tabular}{|c|c|c|c|c|}
\hline $\begin{array}{c}\text { Raffinose } \\
16 \text { Std. }\end{array}$ & $\begin{array}{c}\text { Galactose } \\
1 \text { Std. }\end{array}$ & $\begin{array}{c}\text { Glucose } \\
\text { 3 Std. }\end{array}$ & $\begin{array}{c}\text { Kupfersulfat } \\
1 \text { Std. }\end{array}$ & $\begin{array}{c}\text { Glucose } \\
\text { 3 Std. }\end{array}$ \\
\hline
\end{tabular}

B

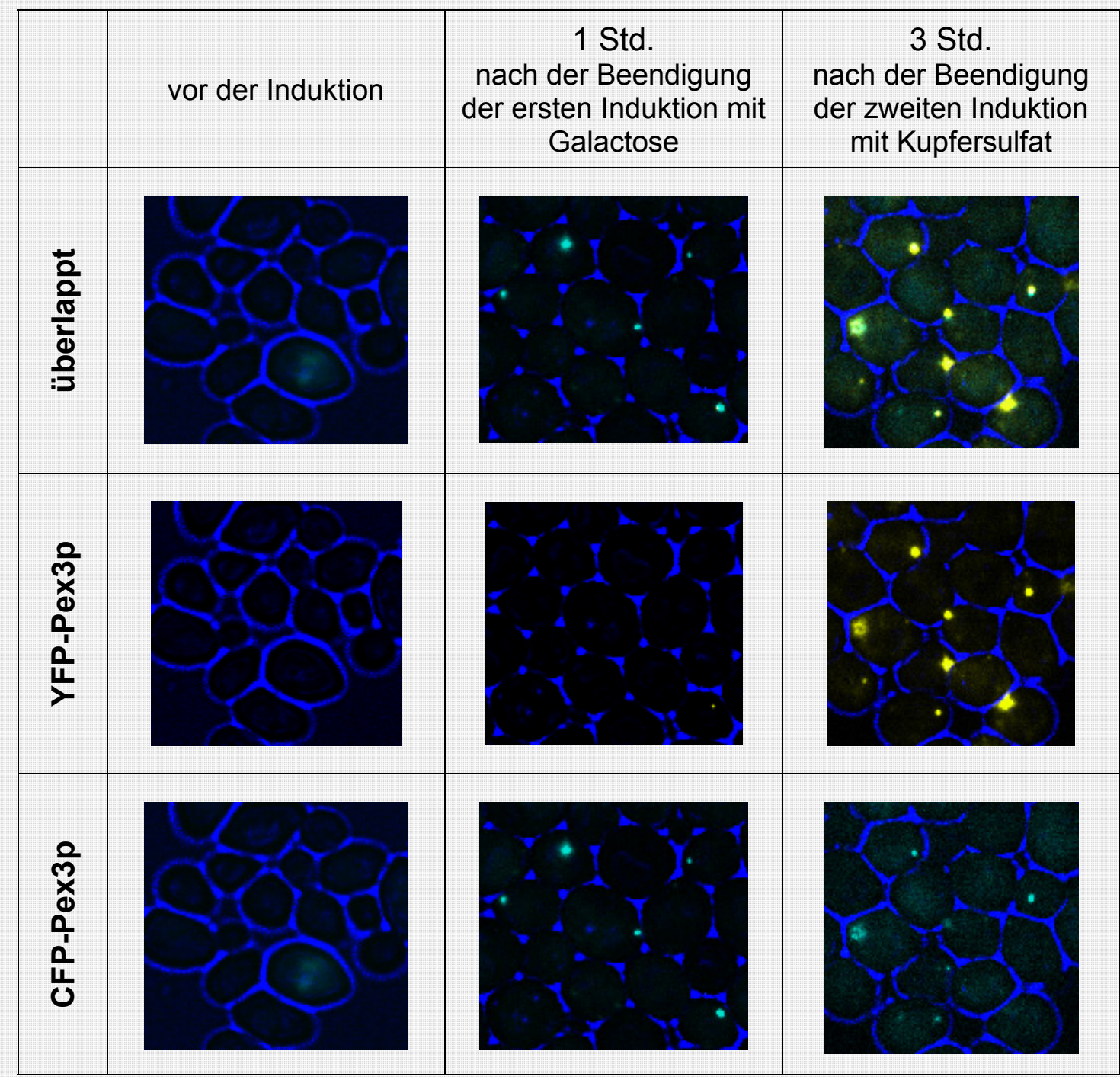

Abbildung 26: Doppel-Pulse-Chase-Experiment mit YKO-028 (CUP1prom-YFP-PEX3 mit GAL1prom-CFP-PEX3). Vor der Induktion war kein Pex3p sichtbar. Nach der Beendigung der ersten Induktion mit Galactose waren mehrere Peroxisomen sichtbar. Drei Stunden nach der zweiten Induktion waren beide Farben exakt miteinander kolokalisiert, was darauf hinwies, dass die zweite Induktion lediglich dazu geführt hat, dass Pex3p zu bereits vorhandenen Peroxisomen gelangte und Peroxisomen nicht mehr neu gebildet wurden, wenn die Zellen bereits Peroxisomen besaßen. (A: Experimentsverlauf, B: Bilddokumentation) 
Nach den erfolgreichen grundlegenden Experimenten wurde dann auf die Frage eingegangen, ob Vorstufen von Peroxisomen entstehen und $\mathrm{zu}$ reifen Peroxisomen werden (Reifungsmodell), oder ob Vorstufen von Peroxisomen miteinander fusionieren (Fusionsmodell). Um diese Frage zu klären, wurde das Verhältnis der Zellen mit bereits existierenden Peroxisomen beobachtet. Hierfür wurde YKO-006 und YKO-026 miteinander gepaart. Der gepaarte Hefestamm YKO-028, war nun diploid mit einem Genotyp CUP1promYFP-PEX3 und GAL1prom-CFP-PEX3. Nach positiven Kontrollexperimenten mit KoloniePCR und Einzelinduktion wurde ein Doppel-Pulse-Chase-Experiment durchgeführt.

Die Bilddokumentation des Experimentes ist in Abbildung 26 dargestellt. Es gab keine sichtbaren Peroxisomen vor der Induktion. Nach zweistündiger Induktion mit Galactose waren unmittelbar nicht viele Peroxisomen zu sehen. Eine Stunde nach der Induktion waren jedoch reichlich Vesikel mit CFP-Pex3p zu erkennen. Nach zweistündiger Inkubation in Glucose erfolgte eine Inkubation mit Kupfersulfat von eine Stunde. Wieder wiesen die Zellen unmittelbar wenig jedoch nach vier Stunden deutlich Vesikel mit YFP-Pex3p auf. 180 Minuten nach der zweiten Induktion waren die Vesikel beider Farben gut sichtbar. Die Vesikel beider Farben zeigten zu diesem Zeitpunkt eine exakte Kolokalisation.

Die zweite Induktion führte dazu, dass die Vesikel mit Pex3p ausschließlich in bereits existierende Peroxisomen gelangten und Peroxisomen nicht neu gebildet wurden, wenn die Zellen bereits Peroxisomen besaßen.

\subsubsection{Untersuchung mit dem Hefestamm YKO-025 (GAL1p-2x Dendra2-Pex3)}

In einem zweiten Verfahren sollte ein Hefestamm YKO-025 (GAL1prom-Dendra2-Dendra2$P E X 3)$ zur Markierung von Peroxisomen mit 2xDendra2-Pex3p konstruiert werden. In diesem Hefestamm wurde 2xDendra-Pex3p in Anwesenheit von Galactose induziert. Das Dendra2Protein ist ein fluoreszierendes Protein, dessen Fluoreszenzeigenschaft sich unter Einwirkung von UV-Licht von grünfluoreszierendem Protein (GFP) nach rotfluoreszierendem Protein (RFP) umwandeln lässt.

Mit diesem Hefestamm wurde ein weiteres Experiment durchgeführt. In der ersten Induktion mit Galactose sollte zunächst grünfluoreszierendes 2x Dendra2-Pex3p induziert werden, was durch das UV-Licht von GFP nach RFP umgewandelt werden sollte. Daraufhin erfolgte die zweite Induktionsphase, in der wiederum grünfluoreszierendes 2x Dendra2-Pex3p induziert werden sollte. Somit sollte es möglich sein, das Pex3p in der ersten und zweiten Induktion voneinander zu unterscheiden. Dadurch sollte versucht werden, die Fragestellung zu klären, 
ob die zweite Induktion von Pex3p zur weiteren Peroxisomenneubildung oder zur Fusion von Vorstufen von Peroxisomen in die bereits existierenden Peroxisomen führt. Im Falle der ersten Variante würde man sowohl nur rot- als auch grünfluoreszierende Peroxisomen am Ende des Experiments sehen. Sollte die zweite Variante der Fall sein, würde man die Kolokalisation beider Farben beobachten.

Bevor dieses Hauptexperiment durchgeführt wurde, wurden die Experimente zum Nachweis der genetischen Manipulation, sowie zur Optimierung der Experimentsbedingungen durchgeführt. Zunächst wurde ein Pulse-Chase-Experiment mit diesem Hefestamm durchgeführt, das mit mikroskopischer Untersuchung und Western Blotting mit einem AntiPex3p-Antikörper analysiert wurde. Dann wurde hinsichtlich der Fluoreszenzkonversion versucht, die externe UV-Licht-Anlage zu optimieren, sowie die optimale UV-LichtEinwirkungszeit herauszufinden. Schließlich wurde ein Doppel-Pulse-Chase-Experiment durchgeführt, um die Fragestellung zu klären.

\subsubsection{Nachweisexperimente und Etablierung der Fluoreszenzumwandlung}

Es werden die Ergebnisse der Experimente zum Nachweis der Induktion von 2x Dendra2Pex3p sowie zur Etablierung der Fluoreszenzumwandlung erläutert.

\subsection{Einzel Pulse-Chase-Experiment mit YKO-025 (GAL1prom- 2x Dendra2- PEX3)}

Lässt sich 2x Dendra2-Pex3p in An- und Abwesenheit von Galactose an- bzw. ausschalten?

Es wurde hierfür ein Einzel-Pulse-Chase-Experiment durchgeführt. Das Ergebnis wurde in Form einer mikroskopischen Analyse, sowie Western Blotting mit einem Anti-Pex3pAntikörper analysiert. Das Ergebnis ist in Abbildung 27 dargestellt: In der mikroskopischen Analyse war die Darstellung von Pex3p deutlich besser, als in YKO-026 (GAL1prom-CFP$P E X 3)$. Es war keine Fluoreszenz vor der Induktion mikroskopisch zu erkennen. Eine Stunde nach der Beendigung der einstündigen Induktion mit Galactose war eine gute Induktion von 2x Dendra2-Pex3p zu erkennen, wobei dies interessanterweise nicht nur als Vesikel im Zytosol, sondern auch am Zellkern lokalisiert war und sich als ringförmige Strukturen darstellte. Dieses Phänomen war ebenso zwei Stunden nach der Induktion teilweise noch zu ersehen. Fünf Stunden nach der Beendigung der Induktion ließ sich 2x Dendra2-Pex3p nicht mehr ringförmig, sondern im größten Teil an Peroxisomen darstellen. 


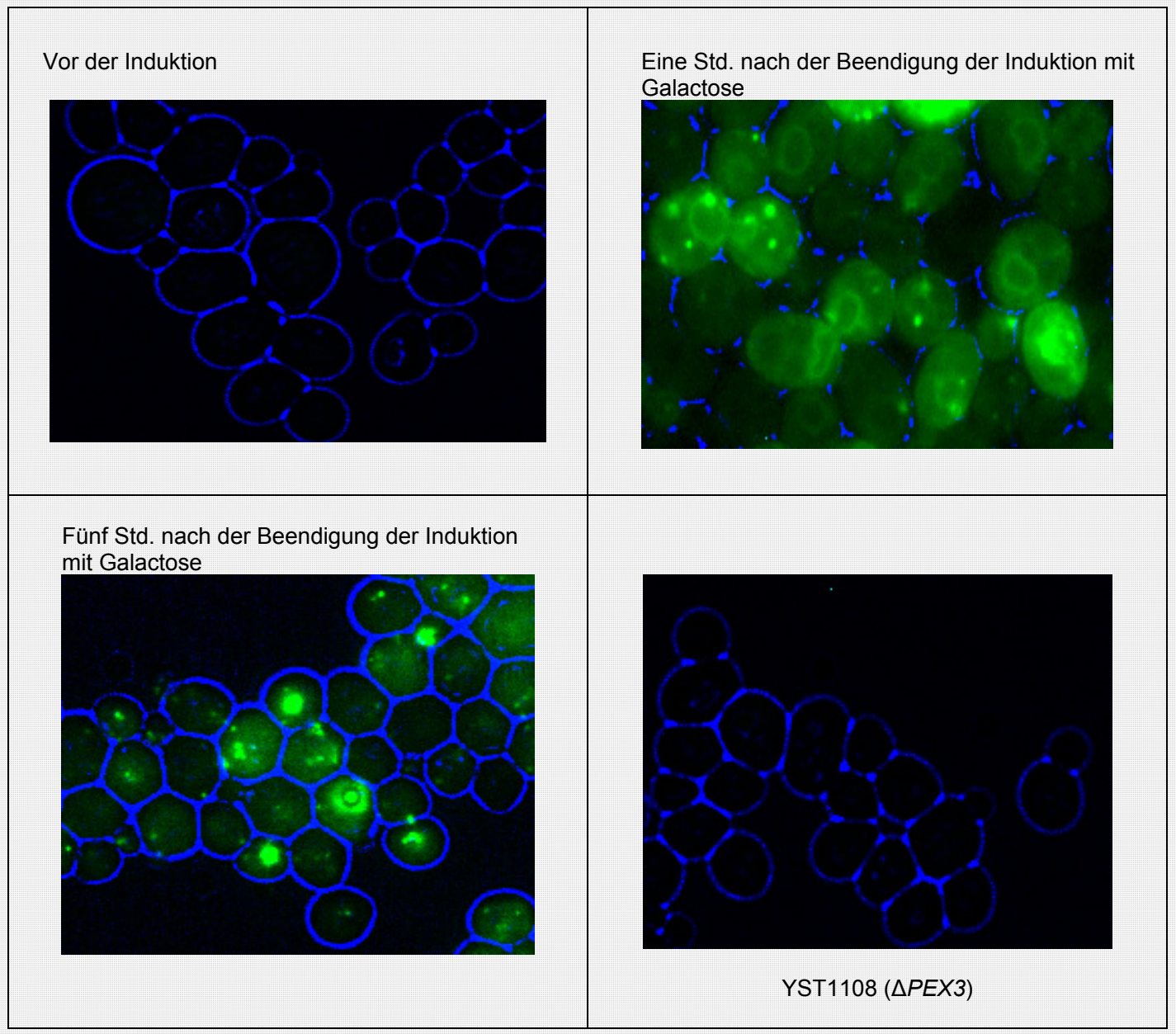

\begin{tabular}{|c|c|c|c|c|c|c|}
\hline & \multirow{2}{*}{$\begin{array}{l}\text { Vor der } \\
\text { Induktion }\end{array}$} & \multicolumn{4}{|c|}{$\begin{array}{l}\text { Nach Beendigung der einstündigen } \\
\text { Induktion mit Galactose }\end{array}$} & \multirow{2}{*}{$\begin{array}{r}\text { YST1108 } \\
(\triangle P E X 3)\end{array}$} \\
\hline & & Sofort & 1 Std. & 2 Std. & 5 Std. & \\
\hline Pex3p & & & & & & \\
\hline
\end{tabular}

Abbildung 27: Ergebnis von Einzel-Pulse-Chase-Experiment mit YKO-025 (GAL1 prom-2x Dendra2-PEX3). In der mikroskopischen Analyse war vor der Induktion kein Fluoreszenzprotein sichtbar. Eine Stunde nach Beendigung der einstündigen Induktion stellte sich $2 x$ Dendra2 als vesikelförmige und ringförmige Strukturen dar. Fünf Stunden nach der Beendigung der Induktion lag dies im größten Teil an Peroxisomen. Es ließ sich gut mikroskopisch darstellen. Im Western Blot ließ sich vor der Induktion eine sehr geringe Menge an Pex3p nachweisen. Eine Stunde nach Beendigung der Induktion erreichte die Menge von Pex3p das Maximum. Danach klang dies ab. Im Gegensatz zur mikroskopischen Analyse wurde fünf Stunden nach Beendigung der Induktion nur eine geringe Menge von Pex3p nachgewiesen. Beim Ausgangshefestamm YST1108 ließ sich sowohl mikroskopisch als auch im Western Blot kein Pex3p detektieren. 
Anders als in YKO-026, der ebenso einen GAL1prom besaß, wurde eine sehr geringe Menge von Pex3p bereits vor der Induktion detektiert, welches am Mikroskop jedoch nicht zu erkennen war. Die restliche Konstellation im Bezug auf den Wester Blot war ähnlich der Konstellation bei YKO-026 (GAL1p-CFP-PEX3): Das Maximum der Induktion von Pex3p wurde nicht direkt nach der Beendigung der Inkubation mit Galactose, sondern erst eine Stunde danach erreicht. Interessanterweise konnte fünf Stunden nach der Induktion im Gegensatz zur mikroskopischen Analyse nahezu kein Pex3p mehr detektiert werden. Als Negativkontrolle wurde der PEX3-defekte Ausgangstamm gleich behandelt, wobei eine Stunde nach der Beendigung der Induktion die Probe für den Western Blot genommen wurde. Es war kein Pex3p zu detektieren.

\subsection{Dendra-Induktionsexperiment und Farbumwandlung mittels des Lichtes durch den DAPI-Filter}

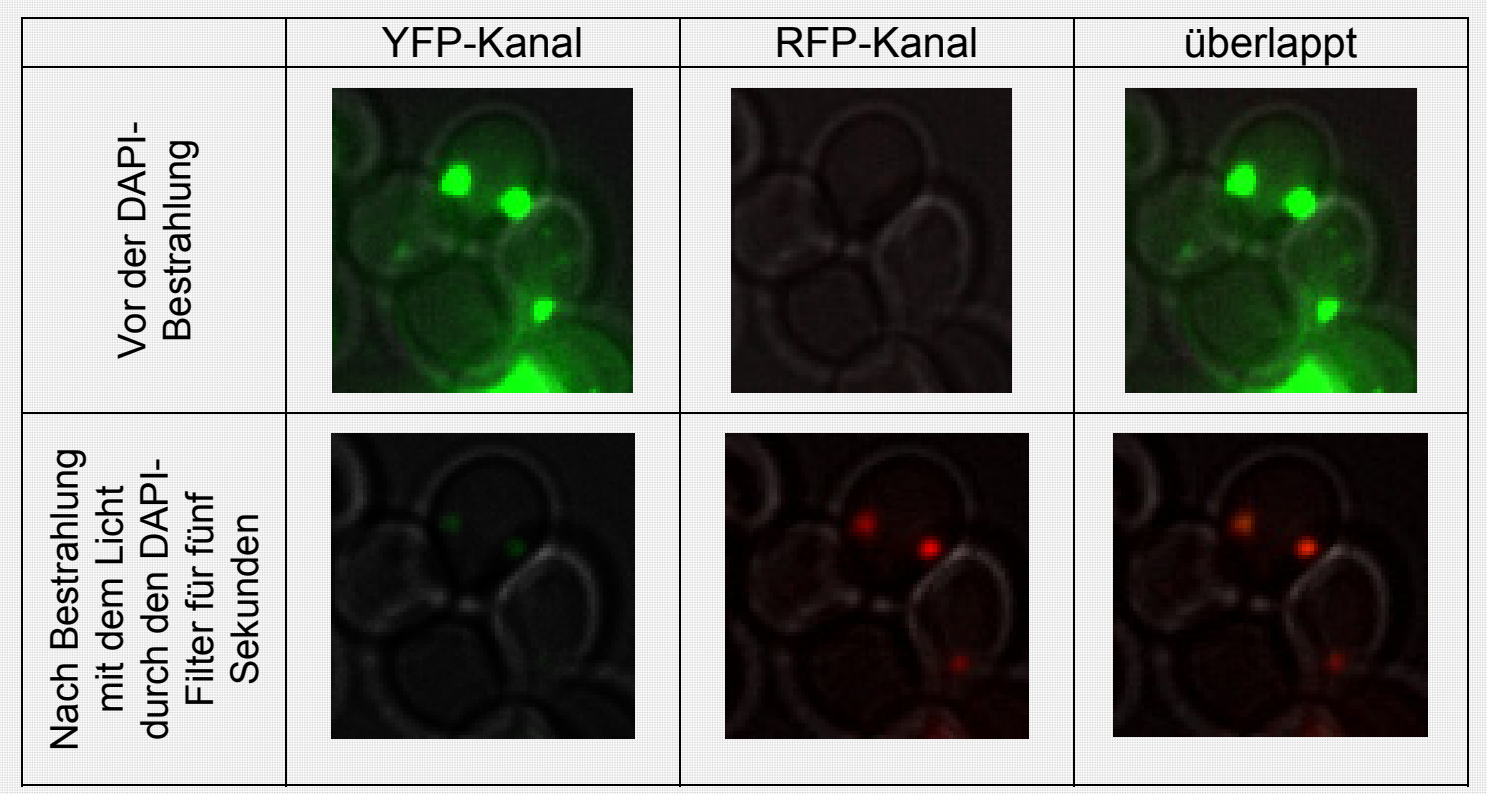

Abbildung 28: Farbumwandlung vom 2x Dendra-Pex3p bei einer Bestrahlung mit dem Licht durch den DAPI-Filter. 2x Dendra2-Pex3p wurde nach Lichtbestrahlung für fünf Sekunden nahezu komplett von GFP nach RFP umgewandelt. Jedoch ist der GFP sehr leicht nach der Umwandlung sichtbar.

Im Folgenden wurde belegt, dass sich die Fluoreszenzeigenschaft von 2x Dendra2-Pex3p unter Einwirkung von UV-Licht konvertieren ließ. YKO-025 (GAL1p-2x Dendra2-PEX3) wurde dafür zunächst über Nacht mit Galactose inkubiert. Am Folgetag wurden die Zellen mikroskopisch untersucht: Wie in Abbildung $28 \mathrm{zu}$ ersehen, war der Hefestamm in der Lage, funktionsfähiges Dendra2-Pex3p zu induzieren. Nach dem Mikroskopieren wurden die Zellen 
mit dem Licht durch den DAPI-Filter für fünf Sekunden bestrahlt. Die Zellen wurden unmittelbar mikroskopiert. Die Fluoreszenz wurde nahezu vollständig von GFP nach RFP umgewandelt. GFP war nach der Umwandlung jedoch sehr leicht noch sichtbar.

\subsection{Etablierung des Verfahrens zur Fluoreszenzkonversion durch eine externe UV-Lichtquelle}

Batch-Umwandlung beinhaltet einen Prozess, der die Fluoreszenzeigenschaft von Dendra2Pex3p durch eine externe UV-Lichtquelle umwandelt. Da die Zellmenge bei der Fluoreszenzkonversion mit dem Licht durch den DAPI-Filter nicht ausreichend für das Doppel-Pulse-Chase-Experiment war, war ein anderes Verfahren erforderlich, welches die Fluoreszenzkonversion der ganzen Zellen im Medium ermöglichte. Dafür wurde zuerst versucht, die ganze Probe direkt mit einer externen UV-Lichtquelle mit einer Wellenlänge von $365 \mathrm{~nm}$ zu bestrahlen: Die Kolben mit der Probe wurden zuerst in den Schüttler gestellt, und mit einem externen UV-Licht bestrahlt.

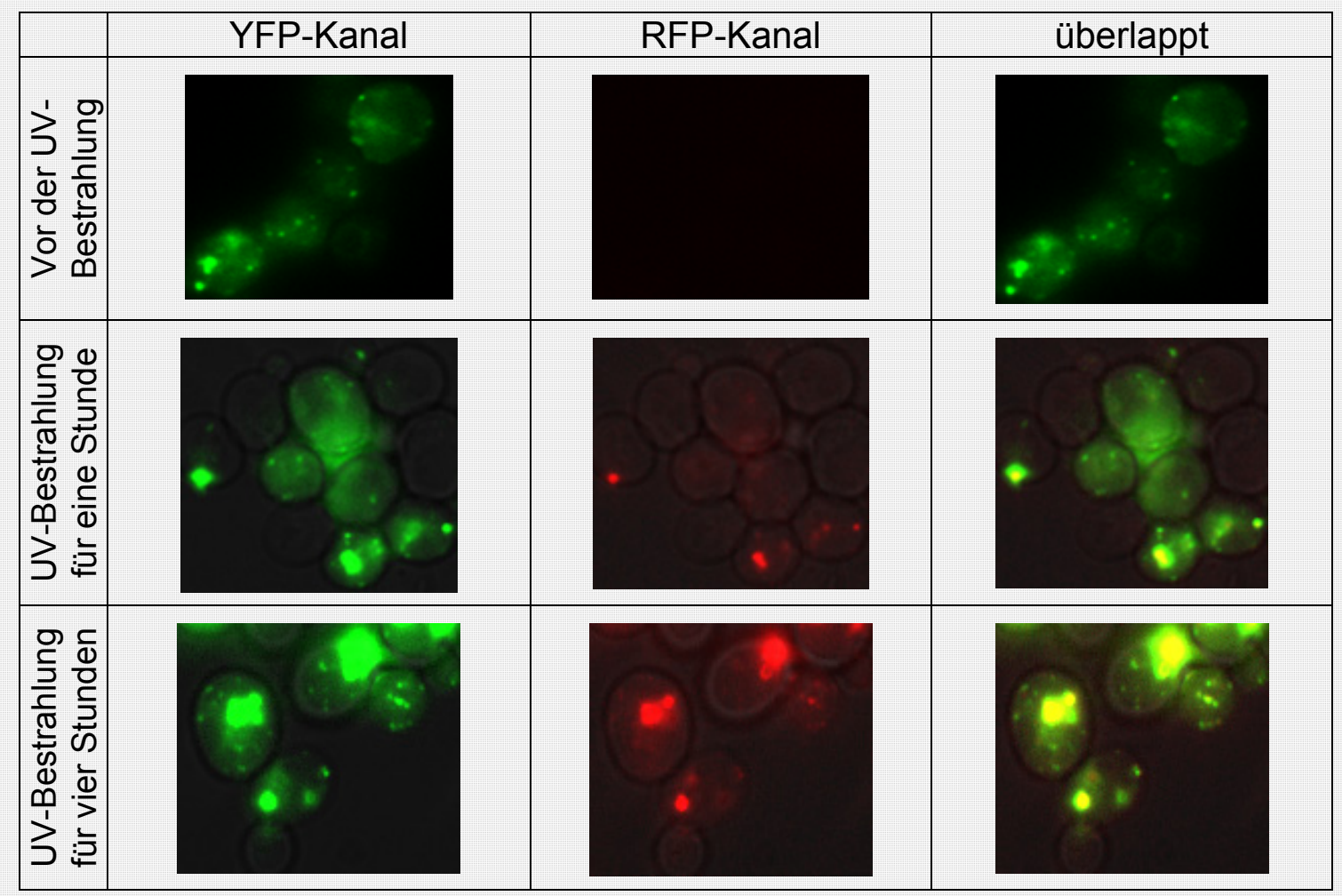

Abbildung 29: Batch-Umwandlung der Zellen sämtlich mit Medium vom YKO-025. Es wurde nach vierstündiger Bestrahlung keine ausreichende Fluoreszenzkonversion erreicht. 
Wie in Abbildung 29 veranschaulicht, war die Effektivität nach vierstündiger Bestrahlung nicht ausreichend: 2xDendra2-Pex3p war sowohl im GFP-Kanal als auch im RFP-Kanal auch nach vierstündiger Bestrahlung noch gleich stark zu sehen.

Um eine optimale Bestrahlung mit UV-Licht zu bewerkstelligen, wurde eine UV-LichtAnlage entwickelt, die eine konzentrierte und somit effektive UV-Licht-Bestrahlung ermöglichte. Wie in Abbildung $30 \mathrm{zu}$ ersehen, ermöglichte diese UV-Licht-Anlage eine nahezu vollständige Umwandlung der Fluoreszenzeigenschaft. Nahezu alle Peroxisomen waren nach der Konversion lediglich im RFP-Kanal sichtbar. Die Effektivität der Fluoreszenzkonversion wurde, wie im nächsten Abschnitt dargestellt, anhand der Aufnahmen vor und nach der Bestrahlung quantifiziert.

\subsection{Effektivität der Fluoreszenzkonversion}

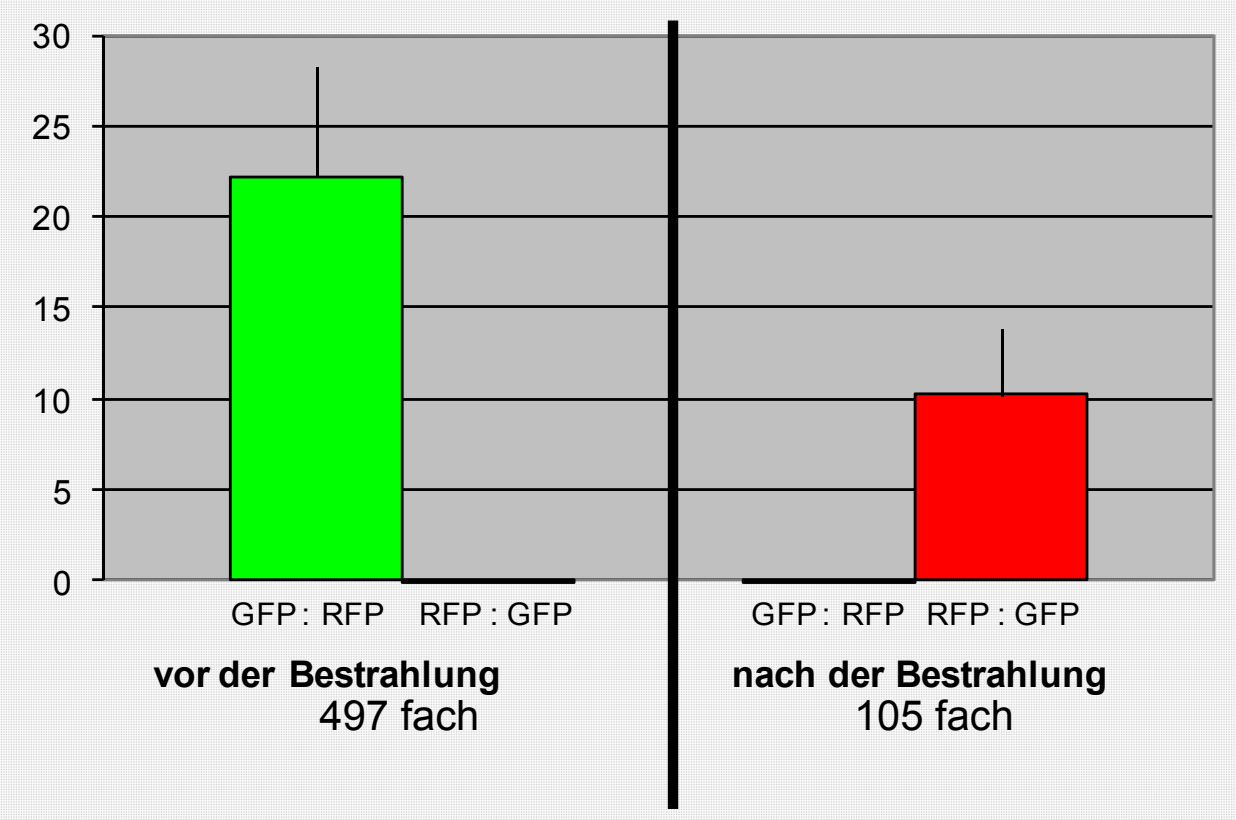

Abbildung 30: Grauwertanalyse vor und nach der Fluoreszenzkonversion von Dendra2Pex3p von YKO-025. Aus dem Summenwert vom gemessenen Grauwert Mittelwert vom Hintergrundgrauwert wurden Quotienten von GFP zu RFP und RFP zu GFP vor und nach der Fluoreszenzkonversion berechnet. Der Quotient von GFP zu RFP war 497 fach so groß wie der von RFP zu GFP vor der Fluoreszenzkonversion. Nach der Fluoreszenzkonversion war der Quotient von RFP zu GFP $105 f a c h$ so groß wie der von GFP zu RFP.

Zur Quantifizierung der Fluoreszenzumwandlung wurde die Grauwertbestimmung mit dem Axiovision-Programm durchgeführt. Es wurden also mikroskopische Schwarz-Weiß-Bilder 
vor und nach der UV-Licht-Exposition verglichen. Dafür wurden die Bilder in Abbildung 31 direkt vor und nach der Fluoreszenzkonversion verwendet. In Abbildung 30 ist in Form eines Balkendiagramms zuerst ein Quotient vom GFP- zum RFP-Wert, und danach der vom RFPzum GFP-Wert dargestellt. Wie zu erwarten war, waren vor der Bestrahlung überwiegend hohe GFP-Werte zu registrieren, welches einen hohen Quotient der GFP- zu RFP-Wert erbrachte. Der Quotient vom RFP- zu GFP-Wert war so klein, dass dieser in dieser Darstellung nicht zu sehen war. Der Quotient vom GFP- zu RFP-Wert war 497 fach höher als der vom RFP- zu GFP-Wert.

Nach der Bestrahlung war diese Konstellation umgekehrt: Wie zu erwarten waren überwiegend hohe RFP-Werte zu registrieren, welche einen hohen Quotient von RFP- zu GFP-Wert erbrachte. Der Quotient vom GFP- zu RFP-Wert war so klein, dass dieser in dieser Darstellung kaum zu sehen war. Der Quotient vom RFP- zu GFP-Wert war nun 105fach größer als der vom GFP- zu RFP-Wert.

\subsubsection{Doppel-Pulse-Chase-Experiment und Batch-Umwandlung}

Als zweites Verfahren zur Untersuchung bezüglich der Fragestellung in dieser Arbeit wurde ein Doppel-Pulse-Chase-Experiment mit YKO-025 durchgeführt. Es sollte geklärt werden, wozu die zweite Induktion von Pex3p in den Zellen mit bereits existierenden Peroxisomen führte. In Abbildung 31 ist zu ersehen, dass sich kein sichtbares 2x Dendra2-Pex3p vor der Induktion feststellen leiß. Direkt nach der Beendigung der Induktion mit Galactose für zwei Stunden war 2x Dendra2-Pex3p in Peroxisomen zu sehen.

Zwei Stunden danach war 2x Dendra2-Pex3p mikroskopisch noch gut erkennbar. Ummittelbar wurde die Fluoreszenzumwandlung gestartet: Die Zellen wurden mit UV-Licht bestrahlt. 2x Dendra2-Pex3p wies nach halbstündiger Bestrahlung eine ca. 70\%ige Umwandelung von GFP nach RFP auf. Nach einstündiger Bestrahlung wurde das Flureszenzprotein nahezu vollständig konvertiert. Das Fluoreszenzprotein im YFP-Kanal war kaum mehr zu erkennen. Nach der zweiten Induktion wurde erneut 2xDendra2-Pex3p induziert, das sich wiederum als GFP darstellen ließ.

Peroxisomen im YFP- und RFP-Kanal wiesen eine Stunde nach der zweiten Induktion einerseits eine Kolokalisation miteinander auf. Andererseits waren Vesikel mit 2xDendra2Pex3p zu sehen, die sich nur im YFP-Kanal darstellen ließen. Möglicherweise entstanden diese in der zweiten Induktion neu. 


\begin{tabular}{|c|c|c|c|c|c|}
\hline $\begin{array}{c}\text { Raffinose } \\
16 \text { Std. }\end{array}$ & $\begin{array}{c}\text { Galactose } \\
2 \text { Std. }\end{array}$ & $\begin{array}{c}\text { Glucose } \\
1 \text { Std. }\end{array}$ \\
\hline
\end{tabular}

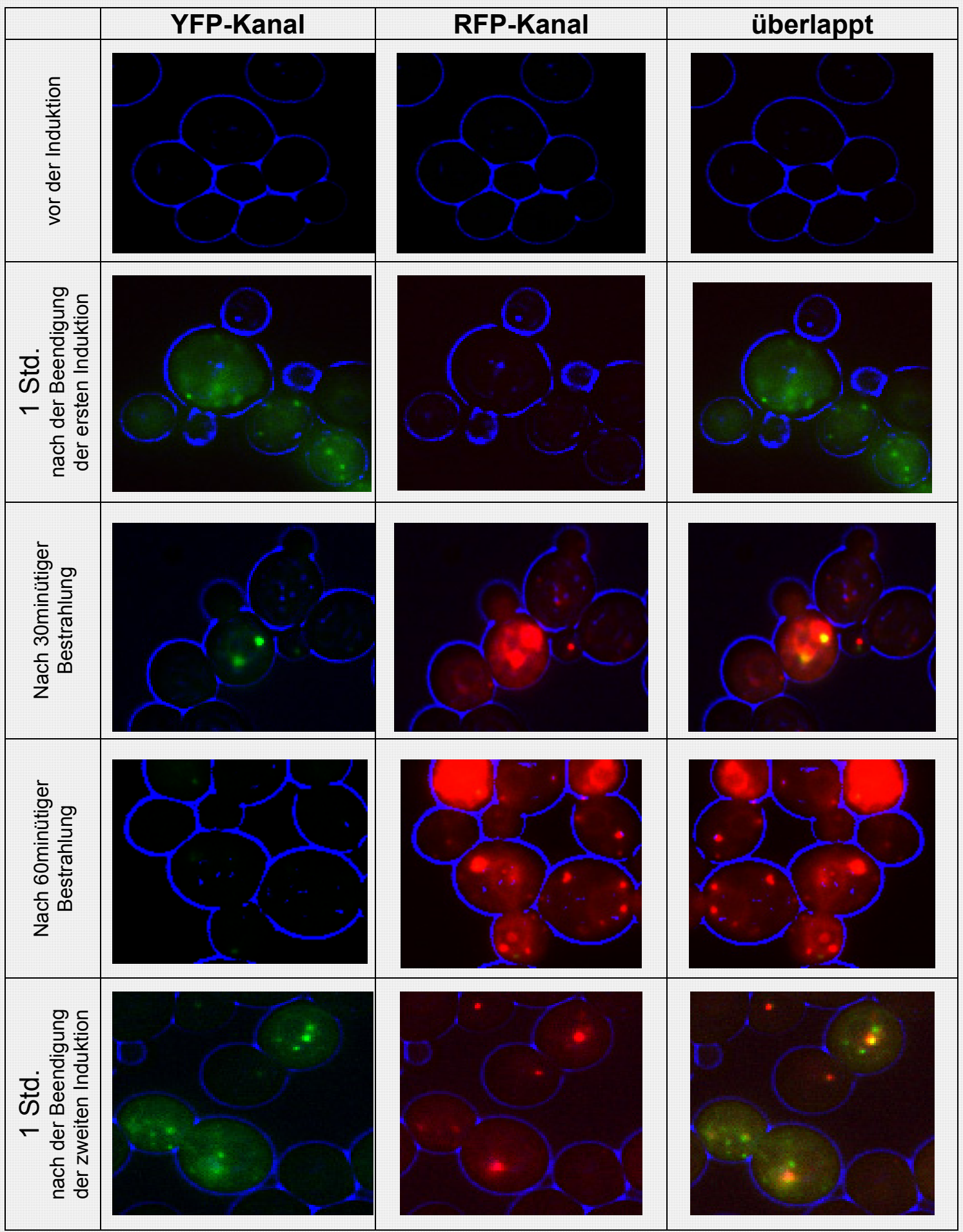

Abbildung 31: Doppel-Pulse-Chase-Experiment mit einer Fluoreszenzumwandlung mit YKO025 (GAL1 prom-2x Dendra2-PEX3). Nach der Fluoreszenzkonversion wurde 2x Dendra2-Pex3p von GFP nach RFP nahezu vollständig umgewandelt. Pex3p stellte sich in der zweiten Induktion als GFP dar. Eine Stunde nach der Beendigung der zweiten Induktion waren Peroxisomen nur in GFP zu sehen. 


\subsection{Experimente zur Darstellung der räumlichen Beziehung zwischen ER und Peroxisomen}

Eine der wichtigen Fragestellung in dieser Arbeit besteht in der Untersuchung des räumlichen Verhältnisses zwischen ER und Peroxisomen sowohl in menschlichen Fibroblasten als auch in Hefen.

Hierfür sollte zuerst ein Experiment mit einer Immunfluoreszenz in Wildtyp-Fibroblasten und den PEX19-deletierten Fibroblasten durchgeführt werden. Durch die Immunfluoreszenz mit dem Anti-Pex3p-Antikörper und PDI-Antikörper werden Peroxisomen und ER mikroskopisch dargestellt.

Zweitens soll der Hefestamm YKO-026 mit dem Genotyp (GAL1prom-yECFP-PEX3) durch die Transformation des Gens für einen ER-Marker (dsREDER) in das Genom des YKO-026 erweitert werden, damit sich das ER konstitutiv im Fluoreszenzlicht darstellen lässt. Dies ermöglicht die Untersuchung des räumlichen Verhältnisses zwischen ER und Peroxisomen im zeitlichen Verlauf. Zunächst wird das Experiment mit den menschlichen Fibroblasten, dann das mit den Hefezellen gezeigt, die in der Lage waren, sowohl Peroxisomen als auch ER mit Fluoreszenz zu markieren.

\subsubsection{Immunfluoreszenz in menschlichen Fibroblasten zur Darstellung der räumlichen Beziehung zwichen ER und Peroxisomen}

Durch Immunfluoreszenz wurde versucht, in menschlichen Fibroblasten das räumliche Verhalten zwischen reifen Peroxisomen und ER, sowie die Lokalisation von Pex3p am ER zu untersuchen. Es wurden zwei Zelllinien, Wildtyp und $\triangle P E X 19$ sowie zwei verschiedene Antikörper, PDI- und Anti-Pex19-Antikörper, verwendet. Der PDI-Antikörper ist ein Marker für das ER.

In Abbildung 32 ist die mikroskopische Analyse der Immunfluoreszenz dargestellt. Pex3p wurde in grün, ER in rot dargestellt. In den Wildtyp-Zellen ließen sich Peroxisomen als grüne Vesikel erkennen.

Im Wildtyp wiesen Peroxisomen nur teilweise eine Kolokalisation mit dem ER auf. Viele Peroxisomen waren im Zytosol, andere nah am ER lokalisiert. In Zellen fehlenden PEX19Gens waren hingegen keine Peroxisomen zu erkennen. Pex3p war ubiquitär teilweise im Zytosol zerstreut. Die Kolokalisation zwischen Pex3p und ER war auf diesem Bild jedoch schwer zu beurteilen. 


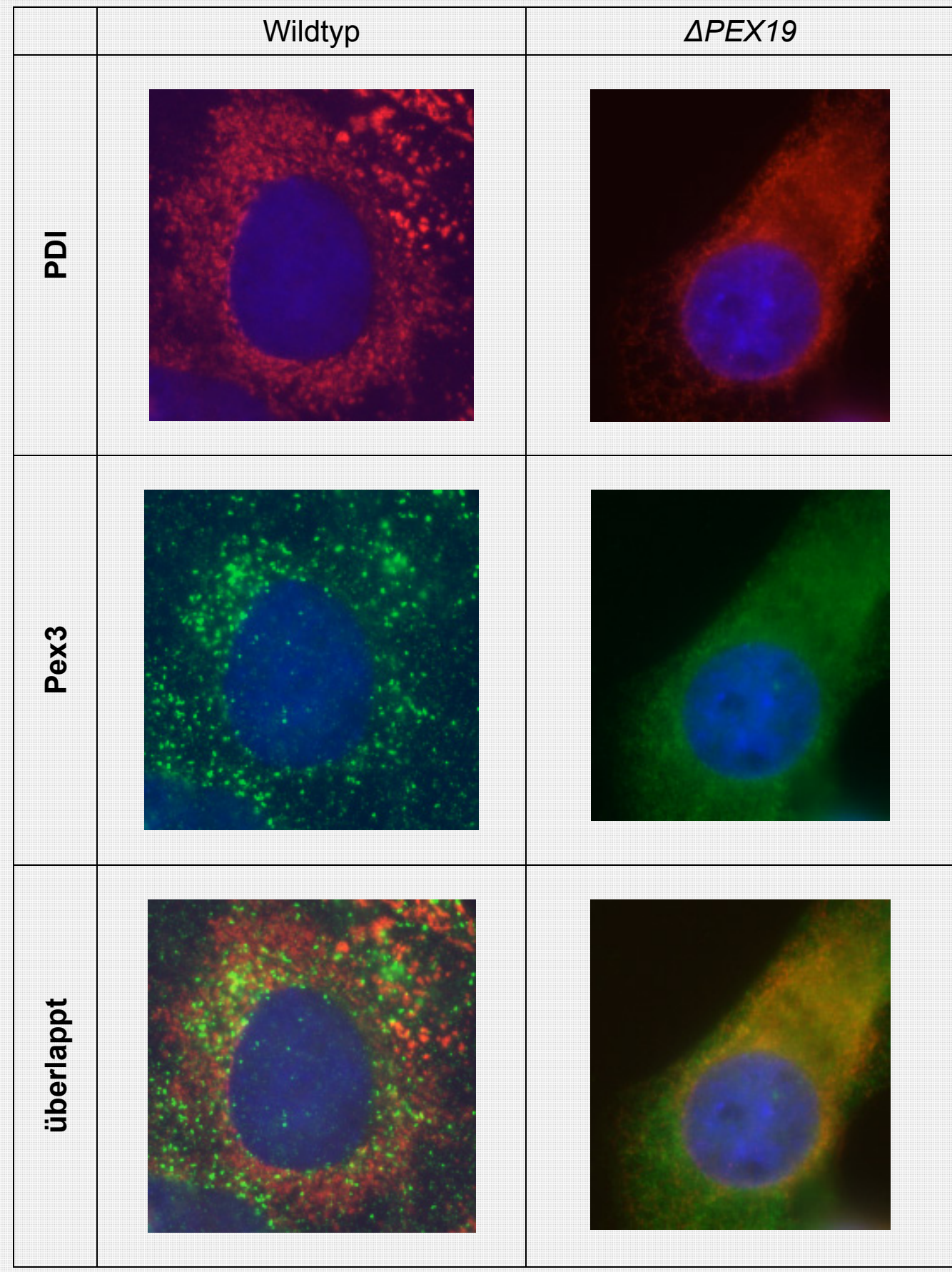

Abbildung 32: Mikroskopische Analyse der Immunfluoreszenz in Fibroblasten (Wildtyp und PEX19 ${ }^{-1}$ ) mit PDI- und Anti-Pex3p-Antikörper. Im Wildtyp ließen sich Peroxisomen mit anti-Pex3-Antikörper punktförmig darstellen. Peroxisomen sind nur teilweise mit dem ER kolokalisiert. Bei PEX19deletierten Zellen war Pex3p teils am ER und teils im Zytosol lokalisiert. 


\subsubsection{Untersuchung mit dem Hefestamm YKO-027 (GAL1prom-CFP-PEX3 mit dsRED-ER)}

In diesem Abschnitt wird auf die Untersuchung der räumlichen Beziehung zwischen

Peroxisomen und ER bei Hefezellen eingegangen. Durch eine Transformation des Plasmids dsREDER in das Genom von YKO-026 war der Hefestamm YKO-027 entstanden, der in der Lage war, das ER mit einem rotfluoreszierenden Protein dsRed zu markieren (dsRED-ER). Durch das Einzel-Pulse-Chase-Experiment wurde das räumliche Verhältnis zwischen den Beiden im zeitlichen Verlauf untersucht.

\subsubsection{Einzel-Pulse-Chase-Experiment mit YKO-027}

\begin{tabular}{|c|c|c|}
\hline $\begin{array}{c}\text { Raffinose } \\
16 \text { Std. }\end{array}$ & $\begin{array}{c}\text { Galactose } \\
90 \text { Min. }\end{array}$ & $\begin{array}{c}\text { Glucose } \\
5 \text { Std. }\end{array}$ \\
\hline
\end{tabular}

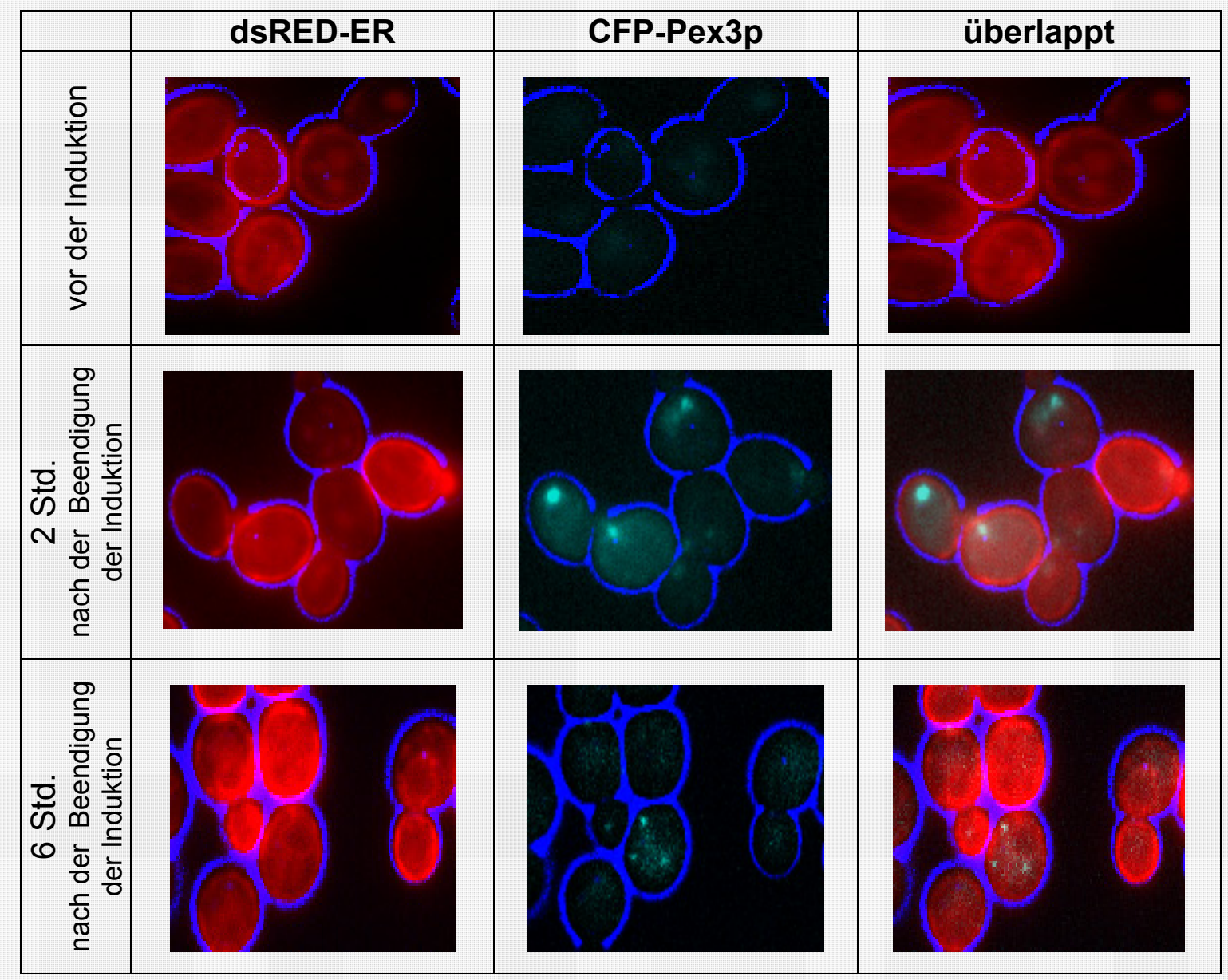

Abbildung 33: Pulse-Chase-Experiment mit YKO-027 (GAL1prom-CFP-PEX3 mit DsREDER). Nach der Induktion waren Peroxisomen am ER verteilt, wobei sich Peroxisomen nach einer Stunde eher am zellkernnahen und nach vier Stunden eher am zellrandnahen ER befanden. 
Wie in Abbildung $33 \mathrm{zu}$ ersehen, wurde dsRed-ER konstitutiv zu jedem Zeitpunkt exprimiert. Die Induktion von CFP-Pex3p mit Galactose fand nach der Transformation vom Plasmid dsREDER in das Hefegenom weiterhin statt: Es wurden keine Vesikel mit CFP-Pex3p vor der Induktion erkannt. 120 Minuten nach der Inkubation mit Galactose wurden am meisten die Vesikel mit CFP-Pex3p beobachtet. Die mikroskopischen Bilder gaben einen sehr guten Hinweis auf die räumliche Beziehung zwischen ER und Peroxisomen: Peroxisomen wiesen nach ihrer Bildung bis zum Ende des Experimentes einen engen Kontakt mit dem ER auf: Peroxisomen saßen eine Stunde nach der Induktion eher am zellkernnahen ER und Ende des Experimentes eher am zellrandnahen ER.

\subsubsection{Messung des Abstands zwischen Peroxisomen und Zellrand}

Um den Abstand zwischen Peroxisomen und Zellrand zu quantifizieren, wurde dieser, wie im Kapitel, Material und Methoden, dargestellt, gemessen. Es wurden die mikroskopischen Bilder in Rahmen eines Pulse-Chase-Experimentes in den Zeitpunkten eine Stunde und vier Stunden nach der Induktion verwendet. Das Ergebnis ist in Abbildung 34 dargestellt.
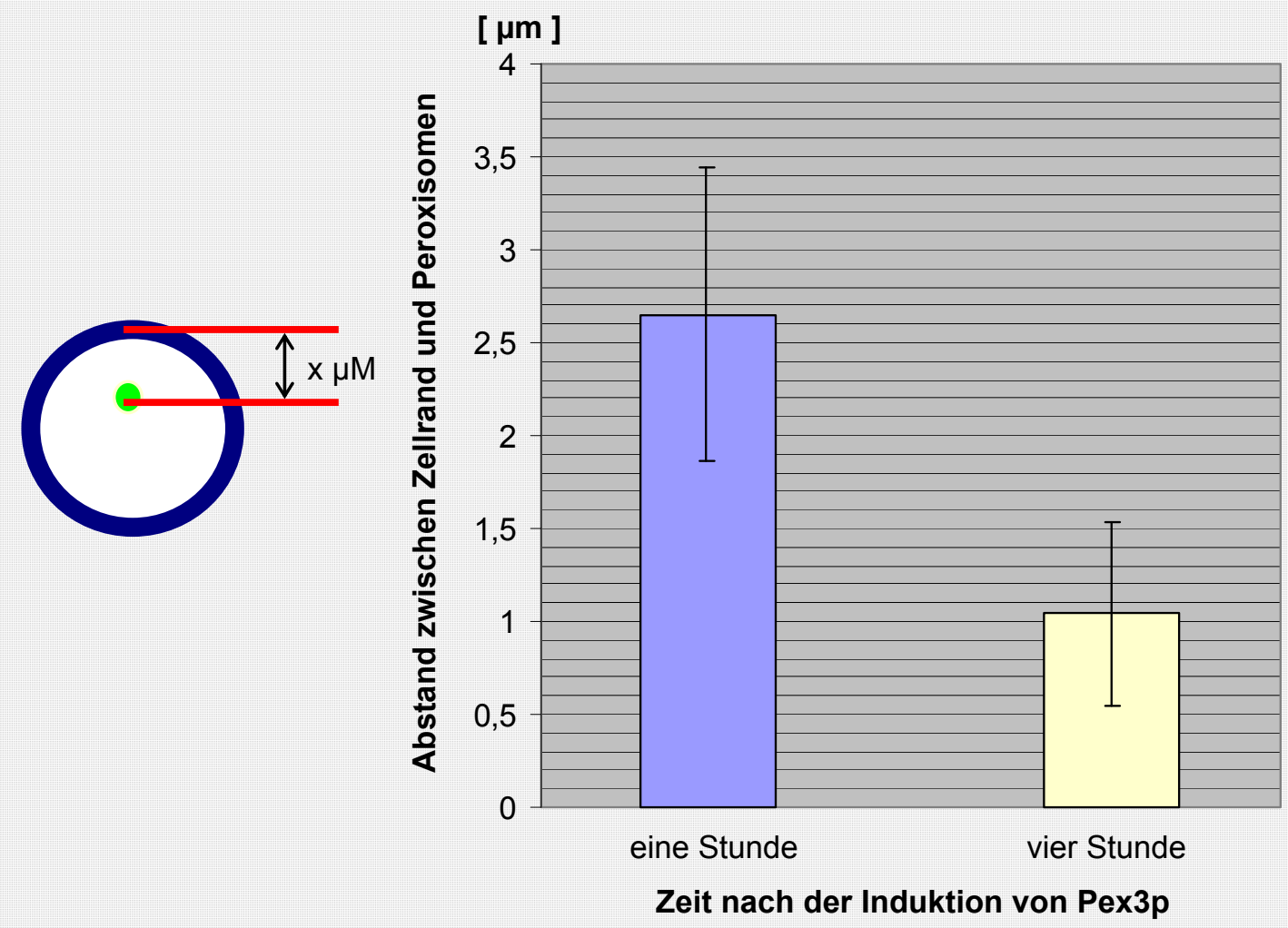

Abbildung 34: Quantifizierung von Abstand zwischen Peroxisomen und Zellrand. Die linke Darstellung zeigt das Messprinzip. Der Abstand nahm während der Reifung von Peroxisomen ab. Durchschnittlich reduzierte sich dieser von 2,65 $\mu \mathrm{m}$ auf 1,04 $\mu \mathrm{m}$. Die Mittelwertedifferenz erwies sich nach dem Auswertung mit t-Test als signifikant. $p<0,0001$ 
Ersichtlich ist der Mittelwert von 100 Messwerten zu den Zeitpunkten eine Stunde und vier Stunden nach der Inkubation. Deutlich zu erkennen ist es, dass der Abstand zwischen Peroxisomen und Zellrand vier Stunden nach Induktion durchschnittlich von 2,65 $\mu \mathrm{m}$ auf 1,04 $\mu \mathrm{m}$ abnahm. Die Mittelwertedifferenz wurde mit Hilfe von t-Test ausgewertet und erwies sich als signifikant $(\mathrm{p}<0,0001)$.

\subsubsection{Paarung: GAL1prom-CFP-PEX3 + dsREDER mit CUP1prom-YFP-PEX3}

Bleibt das räumliche Verhältnis zwischen ER und Peroxisomen im Doppel-Pulse-ChaseExperiment bei einer erneuten Pex3p Induktion ebenfalls gleich?

Um die Fragestellung zu klären, wurden der Hefestamm YKO-027 (GAL1prom-CFP-PEX3 mit dsRED-ER) und der Hefestamm YKO-006 (CUP1prom-YFP-PEX3) miteinander gepaart (YKO-029). Es erwies sich, dass die Einzelinduktion vom Pex3p mit Kupfersulfat bzw. mit Galactose intakt war. Das dsRED-ER war in nahezu jeder Zelle im RFP-Kanal gut sichtbar.

\subsubsection{Doppel-Pulse-Chase-Experiment mit einem gepaarten Hefestamm YKO-029 (GAL1prom-CFP-PEX3 + dsRED-ER mit CUP1prom-YFP-PEX3)}

Wie in Abbildung $35 \mathrm{zu}$ ersehen, waren vor der Inkubation mit Galactose keine Peroxisomen zu erkennen. Erst nach der Inkubation mit Galactose waren die Vesikel mit CFP-Pex3p zu ersehen. Nach der Inkubation mit Kupfersulfat waren sowohl vom CFP-, als auch vom YFPPex3p markierte Vesikel entstanden. Hierbei waren die Vesikel mit CFP-Pex3p mit denen mit YFP-Pex3p sehr gut miteinander kolokalisiert. Es waren keine Vesikel zu beobachten, die nur von YFP-Pex3p markiert waren, falls die Vesikel mit CFP-Pex3p bereits in den Zellen existierten. Das rot markierte ER war zu jedem Zeitpunkt des Experimentes zu erkennen. Peroxisomen und ER wiesen nach der Peroxisomenneubildung stets eine enge räumliche Beziehung miteinander auf. Vier Stunden nach der Beendigung der zweiten Induktion, also acht Stunden nach der Beendigung der ersten Induktion befanden sich Peroxisomen sehr nah am ER. In diesem Experiment waren die Vesikel eine Stunde nach der Induktion eher am zellkernnahen und vier Stunden danach eher am zellrandnahen ER. 


\begin{tabular}{|c|c|c|c|c|}
\hline $\begin{array}{c}\text { Raffinose } \\
16 \text { Std. }\end{array}$ & $\begin{array}{c}\text { Galactose } \\
1 \text { Std. }\end{array}$ & $\begin{array}{c}\text { Glucose } \\
3 \text { Std. }\end{array}$ & $\begin{array}{c}\text { Kupfersulfat } \\
1 \text { Std. }\end{array}$ & $\begin{array}{c}\text { Glucose } \\
4 \text { Std. }\end{array}$ \\
\hline
\end{tabular}

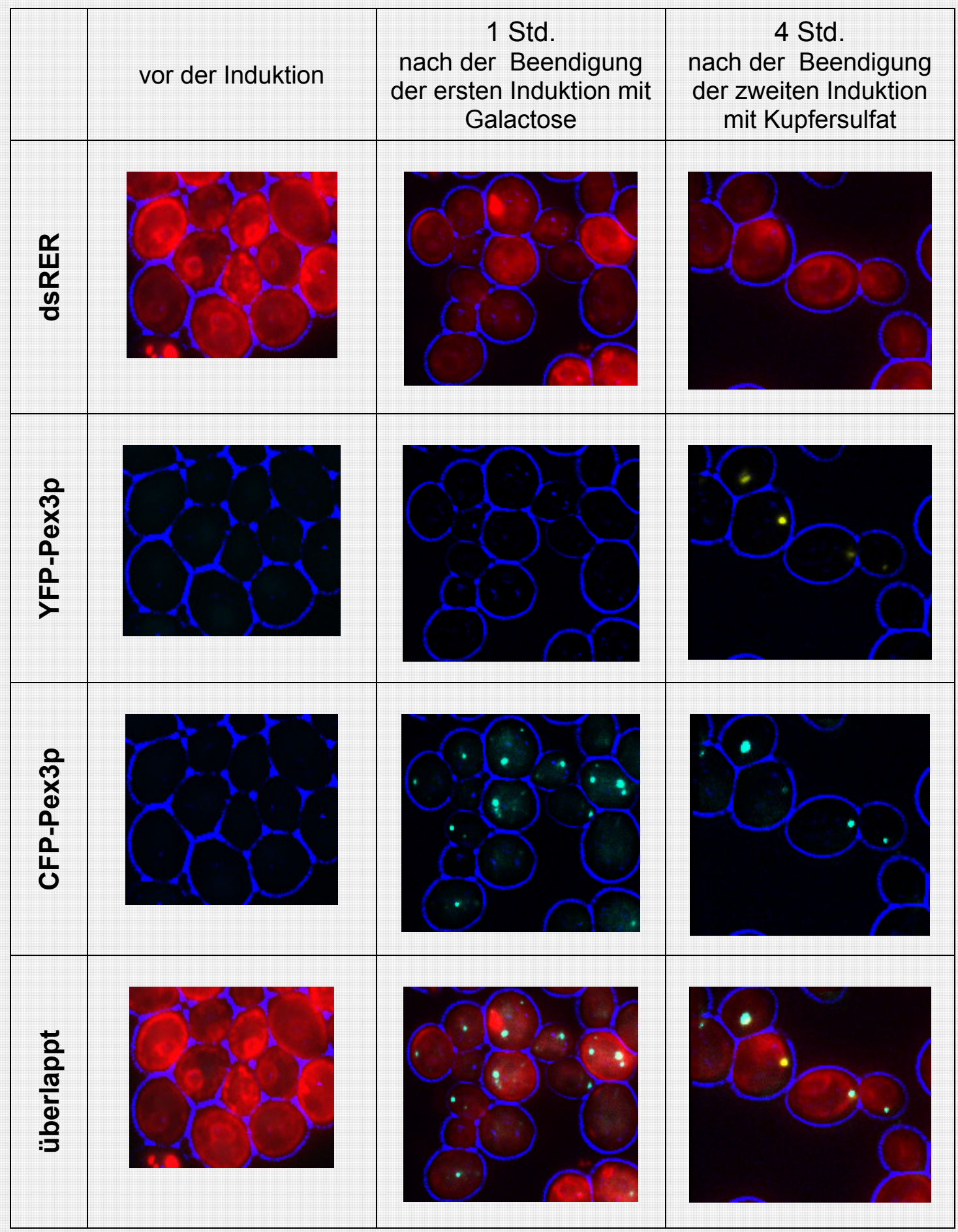

Abbildung 35: Doppel-Pulse-Chase-Experiment mit dem YKO-028 (GAL1prom-CFP-PEX3 + dsRED-ER mit CUP1prom-YFP-PEX3). Peroxisomen lagen stets am ER, wobei sich Peroxisomen nach einer Stunde eher am zellkernnahen und nach acht Stunden eher am zellrandnahen ER befanden. Bezüglich des Verhältnisses zwischen CFP- und YFP-Pex3p führte die zweite Induktion dazu, dass Pex3p vorwiegend zu den bereits vorhandenen Peroxisomen gelangte, wenn die Zellen bereits Peroxisomen besaßen. 


\section{DisKUSSION}

In dieser Arbeit wurde versucht, zum Verständnis der Entstehung von Peroxisomen beizutragen durch Klärung, ob Vorstufen von Peroxisomen entstehen und $\mathrm{zu}$ reifen Peroxisomen werden (Reifungsmodell), oder ob Vorstufen von Peroxisomen miteinander fusionieren (Fusionsmodell). Um diese Modelle zur Peroxisomenneubildung prüfen zu können, wurde eine Serie von Hefestämmen unter Manipulation des PEX3-Gens eines Wildtyp-Hefestamms hergestellt. Zunächst werden das Grundprinzip und anschließend die Charakterisierung der Hefen sowie Experimente zur Optimierung der Experimentbedingung erörtert.
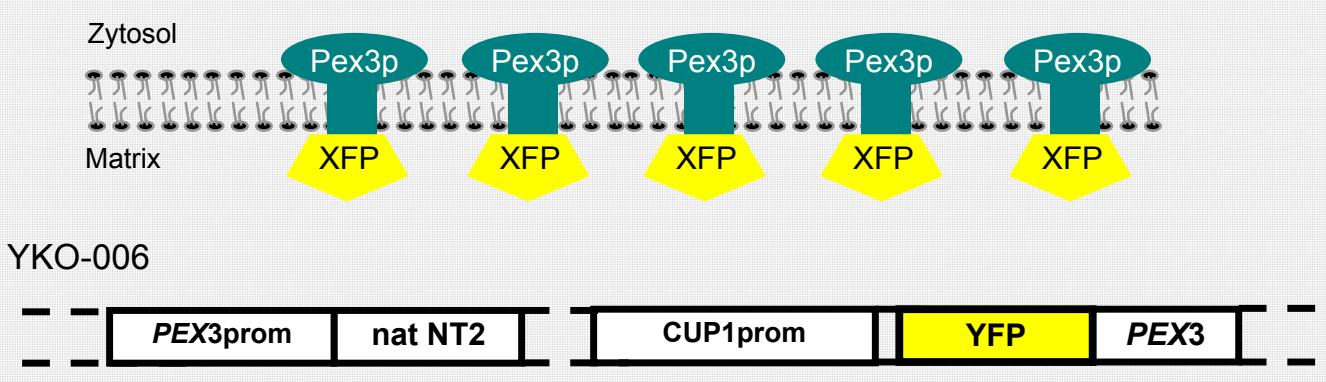

YKO-026
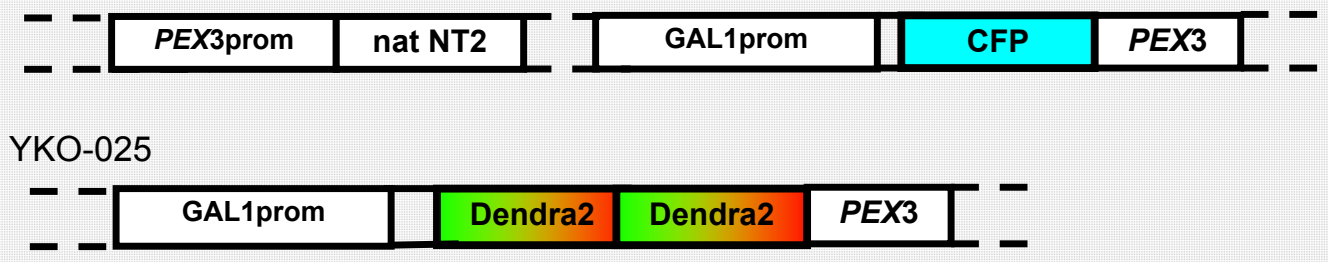

Abbildung 36: Vereinfachte Darstellung der Methode zur Fluoreszenzdarstellung und schematische Darstellung der Genotypen von drei Hefestämmen unter einer Manipulation des PEX3-Gens. Mit diesem Konzept wurde es ermöglicht, die Peroxisomen in der mikroskopischen Analyse mit Fluoreszenz darzustellen. Die Markierung von Pex3p führt zur Markierung von Peroxisomen. Die drei Hefestämme haben eine Gemeinsamkeit: Anschaltung des PEX3-Gens durch eine Inkubation in Kupfersulfat bzw. in Galactose führt zur Induktion und Markierung von Pex3p.

Eine genetische Veränderung des PEX3-Gens in S. cerevisiae ist deswegen sinnvoll, weil die Abschaltung des PEX3-Gens zur Abwesenheit von Peroxisomen, und dessen Anschaltung zur Peroxisomenneubildung führt [Hettema 2000, KRAGT et al. 2005, HoEPFNER et al. 2005, FABER et al. 2002, FuJIKI et al. 2006, THOMS und ERDMANN 2005 b]. Die PEX3-Regulation 
wurde durch zwei verschiedene regulierbare Promotoren ermöglicht: Der CUP1-Promotor sowie der GAL1-Promotor. Weiter war es wichtig, dass Peroxisomen in der mikroskopischen Analyse mit Fluoreszenz dargestellt werden konnten. Wie in Abbildung 36 dargestellt, wurde dafür ein Fusionsprotein von Pex3p mit einem Fluoreszenzprotein konstruiert. Es wurde das Gen für ein fluoreszierendes Protein direkt vor das $P E X 3$-Gen eingefügt, welches dem Hefestamm die Synthese eines Fusionsproteins aus Pex3p und einem Fluoreszenzprotein erlaubte (XFP-Pex3p). Insgesamt wurden Hefestämme mit folgenden Genotypen hergestellt (Abbildung 36).

- In YKO-006 (CUP1prom-YFP-PEX3) war es möglich, in Anwesenheit von Kupfersulfat das Fusionsprotein, YFP-Pex3p $\mathrm{zu}$ induzieren, und somit die Peroxisomen am Fluoreszenzmikroskop in gelb darzustellen.

- YKO-026 (GAL1prom-CFP-PEX3) war in der Lage, in Anwesenheit von Galactose das Fusionsprotein, CFP-Pex3p zu induzieren, und somit Peroxisomen in der mikroskopischen Analyse in hellblau darzustellen.

Der Genotyp und die Regulierbarkeit der Promotoren wurden mit Kolonie-PCR, Pulse-ChaseExperimenten und mikroskopischer Analyse sowie im Western Blot erfolgreich nachgewiesen.

Durch Paarung der beiden Hefestämme wurde der diploide Hefestamm YKO-028 (CUP1prom-YFP-PEX3 und GAL1prom-CFP-PEX3) herstellt, der in der Lage war, in Anwesenheit von Galactose CFP-Pex3p, und in Anwesenheit von Kupfersulfat YFP-Pex3p zu induzieren.

- Der Genotyp von YKO-025 (GAL1prom-Dendra2-Dendra2-PEX3) erlaubt diesem Hefestamm, in Anwesenheit von Galactose, das Fusionsprotein Dendra2-Dendra2-Pex3p zu induzieren. Das Dendra2-Protein ist ein Fluoreszenzprotein, das sich unter Einwirkung von einem UV-Licht von GFP zu RFP konvertieren lässt. In Form eines Einzel-PulseChase-Experimentes mit mikroskopischer Analyse, sowie Western Blot wurde die Steuerbarkeit der Induktion von Pex3p erfolgreich nachgewiesen. Das fehlende PEX3Gen wurde somit ausgeglichen.

\subsection{Fluoreszenzumwandlung von Dendra2-Dendra2-Pex3p in UV-Licht}

Ließ sich Dendra2-Dendra2-Pex3p durch UV-Licht von GFP nach RFP umwandeln?

Die Konvertierbarkeit des Fluoreszenzproteins wurde dadurch bewiesen, dass die Zellen nach einer Induktion von 2xDendra-Pex3p mit dem Licht durch den DAPI-Filter am Mikroskop 
bestrahlt wurden. Da jedoch mehr Zellen für das Doppel-Pulse-Chase-Experiment nach der Fluoreszenzkonvertierung benötigt wurden, als die Zellmenge, die sich mit dieser Methode bestrahlen ließ, wurde eine UV-Licht-Bestrahlung von den ganzen Zellen, wie im Kapitel, Material und Methoden, beschrieben, durchgeführt.

Die Effektivität der Fluoreszenzkonvertierung wurde sowohl in Form einer Bilddokumentation, als auch einer Fluoreszenzgrauwertbestimmung von dargestellten Peroxisomen auf dem Bild objektiviert. Sowohl in Abbildung 31 als Bilddokumentation als auch in Abbildung $30 \mathrm{im}$ Balkendiagramm $\mathrm{zu}$ ersehen, war die Umwandlung von Fluoreszenzprotein für die Fragestellung dieser Arbeit ausreichend. Die einstündige Fluoreszenzumwandlung erfolgte zwar in nährstofffreiem Wasser, aber es war keine Benachteiligung für die Zelle hinsichtlich Zellwachstum sowie Zellmorphologie festzustellen. Die in dieser Arbeit etablierte Fluoreszenzkonvertierung war somit für das Doppel-PulseChase-Experiment anwendbar.

\subsection{Optimale Kupferkonzentration für die Induktion des CUP1-Promotors}

Da bisher noch keine Erfahrungen vorlagen, in denen der CUP1-Promotor in Verbindung mit Pex3p verwendet wurde, war es essentiell, die optimale Konzentration von Kupfersulfat für die Induktion mittels CUP1-Promotor in Verbindung mit YFP-Pex3p herauszufinden. Kupfersulfat ist außerdem eine zytotoxische Substanz, und daher war es wichtig, dass das Zellwachstum sowie die Zellmorphologie durch zu hohe Mengen an Kupfersulfat nicht beeinträchtigt wurden. Es stellte sich heraus, dass $100 \mu \mathrm{M}$ die optimale Konzentration von Kupfersulfat für die Induktion von YFP-Pex3p war: Wie in Abbildung $16 \mathrm{zu}$ ersehen, war die Induktion von YFP-Pex3p am Mikroskop gut zu erkennen. Außerdem war das Zellwachstum nicht beeinträchtigt. Die Zellmorphologie war mit der von Hefezellen in YPD-Medium vergleichbar. Da Kupfersulfat nahezu in jedem handelsüblichen Nährmedium vorkommt, war es nicht unerheblich, ein kupferfreies Medium herzustellen, das in dieser Arbeit als SD1Medium bezeichnet wird. Nach Bestimmung vom Kupfersulfat in diesem Medium stellte es sich heraus, dass dies weitgehend kupferfrei war. Die Kohlenstoffquelle enthielt jedoch eine geringe Menge von Kupfersulfat, dessen Konzentration jedoch unter 0,5 $\mu \mathrm{M}$ betrug. Dies war nicht als Störfaktor zu betrachten, weil keine sichtbare Induktion in den Zellen mit $10 \mu \mathrm{M}$ Kupfersulfat stattfand. 


\subsection{Fluoreszenzdoppelmarkierung von Peroxisomen durch Pex3p und PTS1}

Um sicher zu stellen, dass das Fluoreszenzprotein mit Pex3p wirklich in der Lage ist, reife Peroxisomen $\mathrm{zu}$ markieren, wurden Peroxisomen mit einem weiteren Marker, einem fluoreszierenden PTS1, markiert. Das Grundprinzip dieser Peroxisomenmarkierung durch PTS1 ist in Abbildung 37 dargestellt. Wie in der Einleitung erläutert, werden die von PTS1 markierten Matrixproteine Pex5p-abhängig in Peroxisomen transportiert. Die Markierung von PTS1 durch ein Fluoreszenzprotein führt daher zu einer Markierung von Peroxisomen. Das PTS1-tragende Matrixprotein und Pex3p können ebenso extraperoxisomal vorkommen. PTS kann im Zytosol, und Pex3p an ER sichtbar sein.

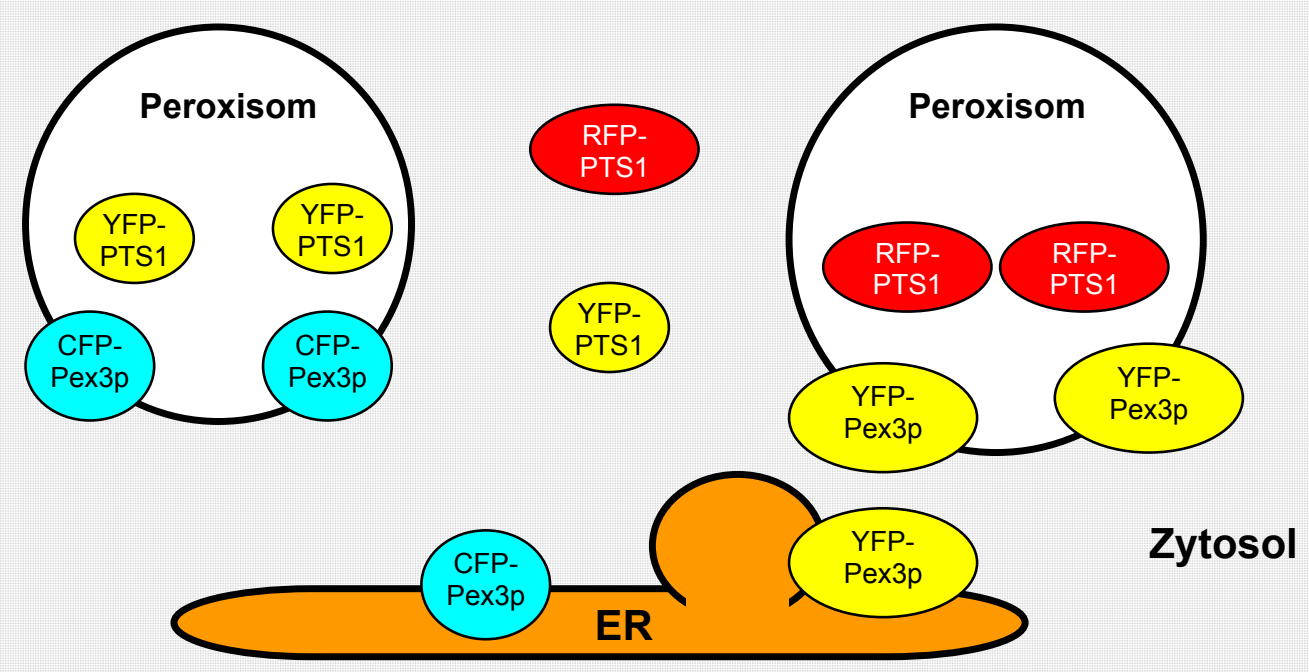

Abbildung 37: Grundprinzip einer Doppel-Markierung von Peroxisomen durch fluoreszierendes PTS1. Pex3p befindet sich an der peroxisomalen Membran, und PTS1 in der peroxisomalen Matrix. Somit führt die Markierung von PTS1 ebenso zur Markierung von Peroxisomen. Pex3p und PTS1 könnten jedoch extraperoxisomal vorkommen: Pex3p kann am ER lokalisiert sein. PTS1 kann im Zytosol vorhanden sein. Die beiden Proteine kolokalisieren jedoch nur an Peroxisomen miteinander.

Dieses Experiment wurden in dieser Arbeit durch eine Transformation von Plasmiden in den jeweiligen Hefestamm ermöglicht: YKO-026, (GAL1prom-CFP-PEX3) wurde mit gelbfluoreszierendem YFP-PTS1, sowie YKO-006 (CUP1-prom-YFP-PEX3) mit rotfluoreszierendem eqFP611-PTS1, kombiniert. Die dadurch neu entstandenen Hefestämme wurden jeweils als YKO-021 und YKO-017 genannt.

Wie in Abbildung 23 und $24 \mathrm{zu}$ ersehen, war fünf Stunden nach der Induktion eine exakte Kolokalisation zwischen Peroxisomen mit CFP-Pex3p und YFP-PTS1 sowohl in YKO-021 (GAL1prom-CFP-PEX3 mit YFP-PTS1), als auch in YKO-017 (CUP1prom-YFP-PEX3 mit 
eqFP611-PTS1) zu ersehen. Damit ließ es sich bestätigen, dass es sich bei den fluoreszierenden Vesikel mit CFP bzw. YFP-Pex3p tatsächlich um Peroxisomen handelt.

\subsubsection{Langsame Reifung von Peroxisomen}

Eine wichtige Frage ist, wann Vorstufen von Peroxisomen, die von Pex3p markiert werden, reife Peroxisomen werden. HoEPFNER et al. (2005) und TABAK et al. (2008) beobachteten, dass die Markierung von Peroxisomen durch fluoreszierendes PTS1 erst vier Stunden nach der Beendigung der Neuinduktion von Pex3p erfolgte. In dieser Arbeit konnten wir durch PulseChase-Experiment mit YKO-021 (GAL1prom-CFP-PEX3 mit YFP-PTS1) weitere Ergebnisse zur Klärung der Reifungsfrage beitragen. Es wurden die Peroxisomenbildung sowie das Verhältnis zwischen CFP-Pex3p und YFP-PTS1 nach Beendigung der einstündigen Induktion von CFP-Pex3p untersucht. Wie in Abbildung 23 dargestellt erfolgte die Peroxisomendarstellung durch YFP-PTS1 erst ab vier Stunden nach der Neuinduktion von CFP-Pex3p, obwohl die Vesikelbildung mit CFP-Pex3p bereits eine Stunde nach dessen Induktion erfolgte. Zu diesem Zeitpunkt war YFP-PTS1 noch ubiquitär im Zytosol verteilt, was auf eine Abwesenheit von reifen Peroxisomen hinwies. Das lässt sich so interpretieren, dass die Vesikel mit CFP-Pex3p eine Stunde nach der Beendigung der Induktion noch keine reifen Peroxisomen waren und daher noch nicht in der Lage waren, das PTS1-tragende Matrixprotein zu importieren. Erst nach einer Reifungszeit von mindestens vier Stunden sind Peroxisomen in der Lage, Matrixproteine zu importieren.

Nach Beschreibungen einiger Autoren sind Peroxisomen dann reif, wenn PMPs in die Präperoxisomen komplett eingegliedert wurden und diese dann in der Lage sind, Matrixproteine zu importieren. Dieser ganze Reifungsprozess dauert vier bis fünf Stunden [KUNAU 2005, TABAK et al. 2008, TABAK et al. 2003].

Interessanterweise wurde dieses Phänomen nur in YKO-021 beobachtet. Im YKO-017 (CUP1prom-YFP-PEX3 mit eqFP611-PTS1) ergab sich dagegen Folgendes: Die Darstellung von Peroxisomen mit eqFP611-PTS1 erfolgte, wie in Abbildung $24 \mathrm{zu}$ ersehen, bereits vor der Induktion von YFP-Pex3p. Außerdem waren Peroxisomen mit eqFP611-PTS1 und YFPPex3p bereits eine Stunde nach der Beendigung der Induktion exakt miteinander kolokalisiert. Dieses Ergebnis deutet darauf hin, dass eine geringfügige Induktion von YFP-Pex3p auch in Abwesenheit von Kupfersulfat bereits erfolgte, und dass die Zellen somit bereits reife Peroxisomen besaßen. Dieser Befund ist mit dem Western Blot sowie der mikroskopischen 
Analyse vereinbar, in denen geringe Mengen von YFP-Pex3p bereits vor der Induktion ersichtlich waren.

\subsection{2 Überexpression vom Pex3p: Funktionsverlust von Peroxisomen}

Nach einer Induktion von Pex3p für zwölf Stunden waren übermäßig große Vesikel mit Pex3p sichtbar. In dieser Konstellation stellte sich die Frage, ob es sich bei diesen Vesikeln nach wie vor um funktionsfähige Peroxisomen handelt.

Um diese Frage zu beantworten, wurde ein Experiment mit dem Hefestamm YKO-017 (CUP1prom-YFP-PEX3 mit eqFP611-PTS1) durchgeführt, in dem YFP-Pex3p für zwölf Stunden induziert wurde. Wie in Abbildung 25 dargestellt ließ sich zwar feststellen, dass kleinere Vesikel mit YFP-Pex3p und eqFP611-PTS1 kolokalisiert waren. Übermäßig vergrößerte Vesikel mit YFP-Pex3p zeigten jedoch keinerlei Kolokalisation mit eqFP611PTS1.

Dieses eher unerwartete Ergebnis ist schwer $\mathrm{zu}$ interpretieren: Entweder führt die Überexpression von Pex3p zur Bildung von Vesikeln mit mislokalisiertem Pex3p, die somit keine funktionierenden Peroxisomen darstellen, oder Peroxisomen sind bei überexprimiertem Pex3p nicht mehr in der Lage, Matrixprotein zu importieren. Dieser Befund ist mit den Beobachtungen von BAERENDS et al. (1997) vereinbar. Diese Arbeitsgruppe stellte in Hansenula polymorpha fest, dass die Überexpression von Pex3p zur Abnormalität der peroxisomalen Membranzusammensetzung führte. Sie zeigte, dass das peroxisomale Matrixprotein, Alkoholoxidase, bei der Pex3p-Überexpression im Zytosol lokalisiert war. Es könnte daher sein, dass die Überexpression von Pex3p zu einer Schädigung der Funktionalität von Peroxisomen führt.

Pex3p hat mehrere wichtige Funktionen: Stabilisierung der peroxisomalen Membran, Lokalisation von PMPs, sowie Verteilung von Peroxisomen von Mutter- zur Tochterzelle bei der Zellteilung [MunCK et al. 2009, HeTtEMA et al. 2000]. Welche Funktion in welcher Weise bei der Pex3p-Überexpression beeinflusst wird, ist bisher noch nicht untersucht. Hierzu sind weitere Experimente wie die elektromikroskopische Darstellung und Fluoreszenzkolokalisierung von Pex3p mit anderen peroxisomalen Membran- und Matrixproteinen bei Pex3pÜberexpression durchzuführen. 


\subsection{Peroxisomenbiogenese: Reifung oder Fusionierung von Präperoxisomen}

Die erneute Induktion von Pex3p führt zur Fusionierung der neu entstandenen Vorstufen von Peroxisomen mit bereits vorhandenen Peroxisomen, wenn diese bereits in den Zellen existieren. Peroxisomen vermehren sich in diesem Fall ausschließlich durch Teilung unter Einwirkung von Dynamin ähnlichen Proteinen [MotLey und Hettema 2007, Nagotu et al. 2008 a, NAgotu et al. 2008 b, Hettema und MotLey 2009]. In menschlichen Zellen ließ sich beobachten, dass neue Peroxisomen auch in Anwesenheit von bereits vorhandenen Peroxisomen entstehen und auch dass Vorstufen von Peroxisomen mit bereits existierenden Peroxisomen fusionieren [KIM et al. 2006].

Um diese Beobachtungen weiter zu überprüfen, wurde ein Pulse-Chase-Experiment mit zwei verschiedenen Hefestämmen durchgeführt: YKO-028 (GAL1prom-CFP-PEX3 + CUP1promYFP-PEX3), der eine diploide Eigenschaft besaß, sowie mit dem Hefestamm YKO-025 (GAL1prom- 2xDendra-PEX3).

Das Doppel-Pulse-Chase-Experiment mit YKO-028 erbrachte folgendes Ergebnis: Wie in Abbildung $26 \mathrm{zu}$ ersehen, wurde eine exakte Kolokalisation zwischen CFP- und YFP-Pex3 am Ende des Experimentes beobachtet. Bei der zweiten Induktion mit YFP-Pex3p gelangten neu entstandenen Vorstufen von Peroxisomen $\mathrm{zu}$ den bereits vorhandenen reifen Peroxisomen, welches zur Kolokalisierung von CFP-Pex3p mit YFP-Pex3p führte. Außerdem waren keine Peroxisomen zu erkennen, die lediglich vom YFP-Pex3p markiert waren. Dieses Ergebnis weist darauf hin, dass die zweite Induktion Pex3p zur Fusionierung von Vorstufen von Peroxisomen mit bereits vorhandenen Peroxisomen führte. Dieses Ergebnis unterstreicht somit die Ergebnisse von Motley und Hettema (2007), NAgotu et al. (2008 a) sowie NAGOTU et al. (2008 b).

Das Doppel-Pulse-Chase-Experiment mit dem Hefestamm YKO-025 (GAL1prom-Dendra2Dendra2-PEX3) erbrachte folgendes Ergebnis: Ein Ausschnitt nach der zweiten Induktion in Abbildung 31 ist detailliert in Abbildung 38 dargestellt, um dieses Ergebnis zu verdeutlichen. Peroxisomen mit 2x Dendra2p-Pex3, die in der ersten Induktion entstanden waren, wurden bereits durch die Fluoreszenzkonvertierung von GFP nach RFP umgewandelt. So ist Pex3p aus der ersten Induktion im RFP-Kanal, und aus der zweiten Induktion im YFP-Kanal dargestellt. Wie in der Darstellung des YFP-Kanals der Abbildung 38 mit weißen Pfeilen 
markiert, waren mehrere Peroxisomen ersichtlich, die sich nicht im RFP-Kanal, sondern nur im YFP-Kanal darstellen ließen.

Diese Konstellation kann folgendermaßen interpretiert werden: Erstens kann die zweite Induktion von Pex3p Teil zur Kolokalisierung von unreifen Pex3p-Vesikeln mit den bereits vorhandenen Peroxisomen führen und teilweise auch zu einer Neubildung von unabhängigen Vesikeln mit Pex3p wie es KIM et al. (2006) bei menschlichen Zellen feststellten. Da diese Autoren die ähnliche Konstellation beobachteten, kann es sein, dass dieses Phänomen nicht nur in humanen Zellen, sondern auch in Saccharomyces cerevisiae vorkommt.

Zweitens kann es sein, dass sich die neu entstandenen Vorstufen von Peroxisomen noch auf dem Weg zu bereits vorhandenen Peroxisomen befanden, um mit diesen zu fusionieren. Um dies auszuschließen wäre eine Untersuchung mit einer mikroskopischen Videoaufnahme sinnvoll, um zu beobachten, ob die Vesikel sich zu bereits vorhandene Peroxisomen bewegen und schließlich damit fusionieren oder isoliert bleiben.

Drittens kann es sein, dass das Dendra-Pex3p im RFP-Kanal zum Zeitpunkt der letzten mikroskopischen Untersuchung bereits so abgeschwächt war, dass es sich mikroskopisch nicht mehr darstellen ließ. Hier muss noch die physikalische Eigenschaft von umgewandeltem Dendra2-Protein zu dem Zeitpunkt der letzten mikroskopischen Analyse auf den Prüfstand gestellt werden.

Als eine Möglichkeit, die Induktion nach Beendigung der Inkubation sicher zu bewerkstelligen, sollten pharmakologische Proteinsyntheseinhibitoren wie Cyclohexemid im Pulse-Chase-Experiment nach der Induktionsphase eingesetzt werden.

Dieses Ergebnis widerspricht dem von MotLEy und HetTema (2007), NAGOtu et al. (2008 a), sowie NAGOTU et al. (2008 b), so dass die oben genannten Aspekte durch weitere Experimente zu klären sind. 


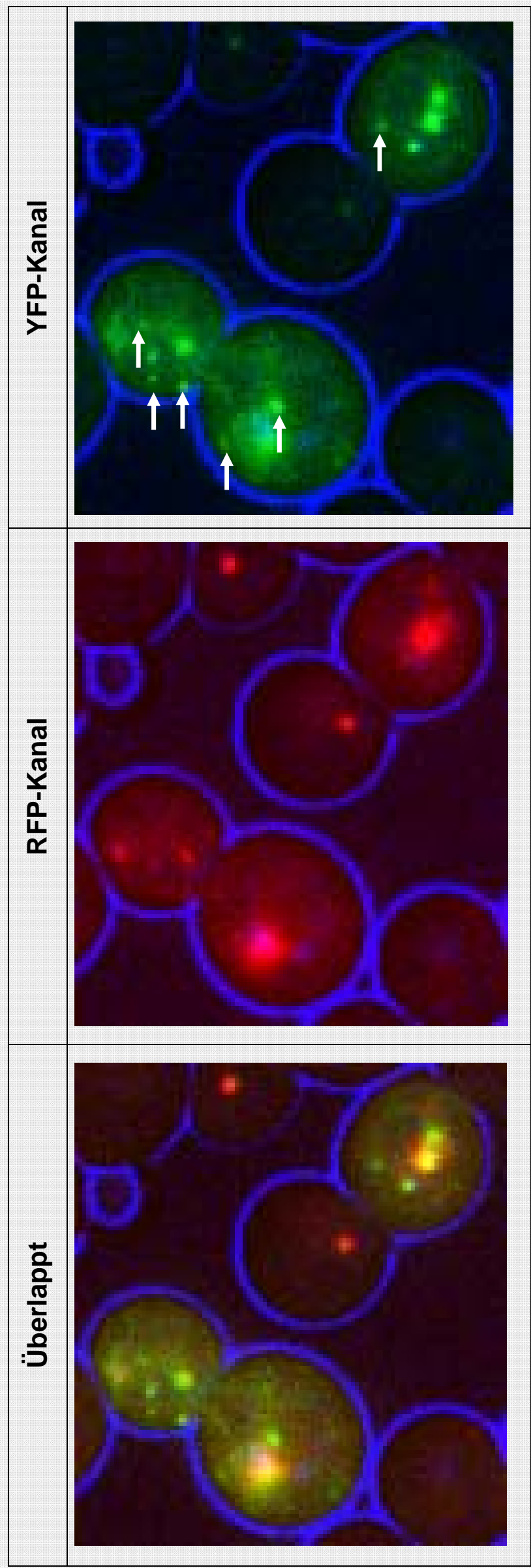

Abbildung 38:

Detaillierte Darstellung von Doppel-Pulse-Chase-

Experiment mit YKO-025 eine Stunde nach der Beendigung der zweiten Induktion. Nach der Logik des Experimentes könnten die grünen Peroxisomen in der zweiten Induktion neu entstanden sein. (weiße Pfeile). 


\subsection{Enge Räumliche Beziehung zwischen ER und Peroxisomen}

Eine der wichtigen Fragestellungen in dieser Arbeit besteht in der Untersuchung der räumlichen Beziehung zwischen ER und Peroxisomen. Zahlreiche Autoren betonen die Wichtigkeit des ERs bei der Peroxisomenbiogenese, und auch die enge räumliche Beziehung zwischen ER und Peroxisomen [Thoms et al. 2009, HetTEMA und MotLey 2009, TABAK et al. 2008, Mullen und Trelease 2006, HoePfNer et al. 2005]. Es gibt einige peroxisomale Membranproteine, die über das ER in die Peroxisomen gelangen und von manchen Autoren als PMP vom Typ II bezeichnet werden [HoEPFNER et al. 2005, MotLeY und HeTtEMA 2007, TABAK et al. 2008, HEILAND und ERDMANN 2005, GEUZE et al. 2003].

In dieser Arbeit wurde zuerst ein Immunfluoreszenzexperiment mit Wildtypzellen und Zellen mit deletiertem PEX19-Gen durchgeführt, um die Beziehung zwischen ER und Peroxisomen bzw. Pex3p näher darzustellen. Dafür wurden ein Anti-Pex3p-Antikörper und ein Antikörper gegen das ER-Protein PDI verwendet. Wie bereits in verschiedenen Publikationen beschrieben, waren keine Peroxisomen in den Fibroblasten mit deletiertem PEX19-Gen zu erkennen [FUJIKI et al. 2006, FANG et al. 2004, SACKSTEDER et al. 2000].

Es wurde in dieser Arbeit festgestellt, dass ein Teil von Pex3p in Zellen mit deletiertem PEX19-Gen am ER lokalisiert, jedoch auch ein Teil im Zytosol zu finden war. Das Verhalten des Wildtyps stellte sich folgendermaßen dar: Nur ein Teil der Peroxisomen waren mit dem ER kolokalisiert. Der große Teil von Peroxisomen lag zwar nah am ER, war aber nicht mit dem ER kolokalisiert. Dieser Befund gab somit keinen eindeutigen Hinweis hinsichtlich dieser Fragestellung. TORO et al. (2009) führten ein vergleichbares Experiment mit lebenden Fibroblasten durch. Dabei zeigten sie ein am ER liegendes Pex3p in Zellen mit fehlendem PEX19-Gen. Außerdem stellten sie fest, dass Peroxisomen mit dem ER exakt kolokalisiert waren. Das uneindeutige Ergebnis der Immunfluoreszenz in dieser Arbeit lag sehr wahrscheinlich daran, dass fixierte Zellen verwandt wurden. Daher wurde anschließend versucht, die Experimente mit Hefen durchzuführen.

An dieser Stelle wird daher jetzt auf das Pulse-Chase-Experimente mit YKO-025 (GAL1prom-Dendra2-Dendra2-PEX3), sowie mit YKO-027 (GAL1prom-CFP-PEX3 mit dsRED-ER) eingegangen. Zunächst wird das Experiment mit dem YKO-025 an dieser Stelle noch einmal erwähnt. In Abbildung 39 ist eine Bilddokumentation des Doppel-Pulse-ChaseExperiments eine Stunde nach der Induktion mit Galactose dargestellt. Ersichtlich ist, dass $2 x D e n d r a 2-P e x 3 p$ an perinukuleären ringförmigen Strukturen lokalisiert war. Es waren Peroxisomen sichtbar, die möglicherweise gerade aus dieser ringförmigen Struktur entstanden 
sein könnten. Die Lokalisation von Pex3p an dieser ringförmigen Struktur nahm im Verlauf des Experimentes ab: Drei Stunden nach der Induktion war diese Konstellation kaum zu erkennen. Es läßt sich vermuten, dass es sich bei dieser Struktur aufgrund ringförmiger Darstellung um das ER handelt. Wenn diese ringförmigen Strukturen dem ER entsprechen, wäre diese Konstellation ähnlich wie die, die HoEPFNER et al. (2005) in ihrer Publikation zeigten. Die Induktion von Pex3p in Hefezellen mit fehlendem Pex3p führte zur vom ER ausgehenden Peroxisomenbildung. Pex3p erschien zuerst am ER, sammelte sich und bildete Vesikel. Danach wurden die Vesikel aus dem ER freigesetzt [HoEPFNER et al. 2005]. Die Peroxisomenbildung aus dem ER wird auch von anderen Autoren befürwortet [HETTEMA und MotLEy 2009, TABAK et al. 2008, HAAN et al. 2006, TAMS et al. 2006, TABAK et al. 2003].

\section{YKO-025 (GAL1prom-Dendra2-Dendra2-PEX3)}
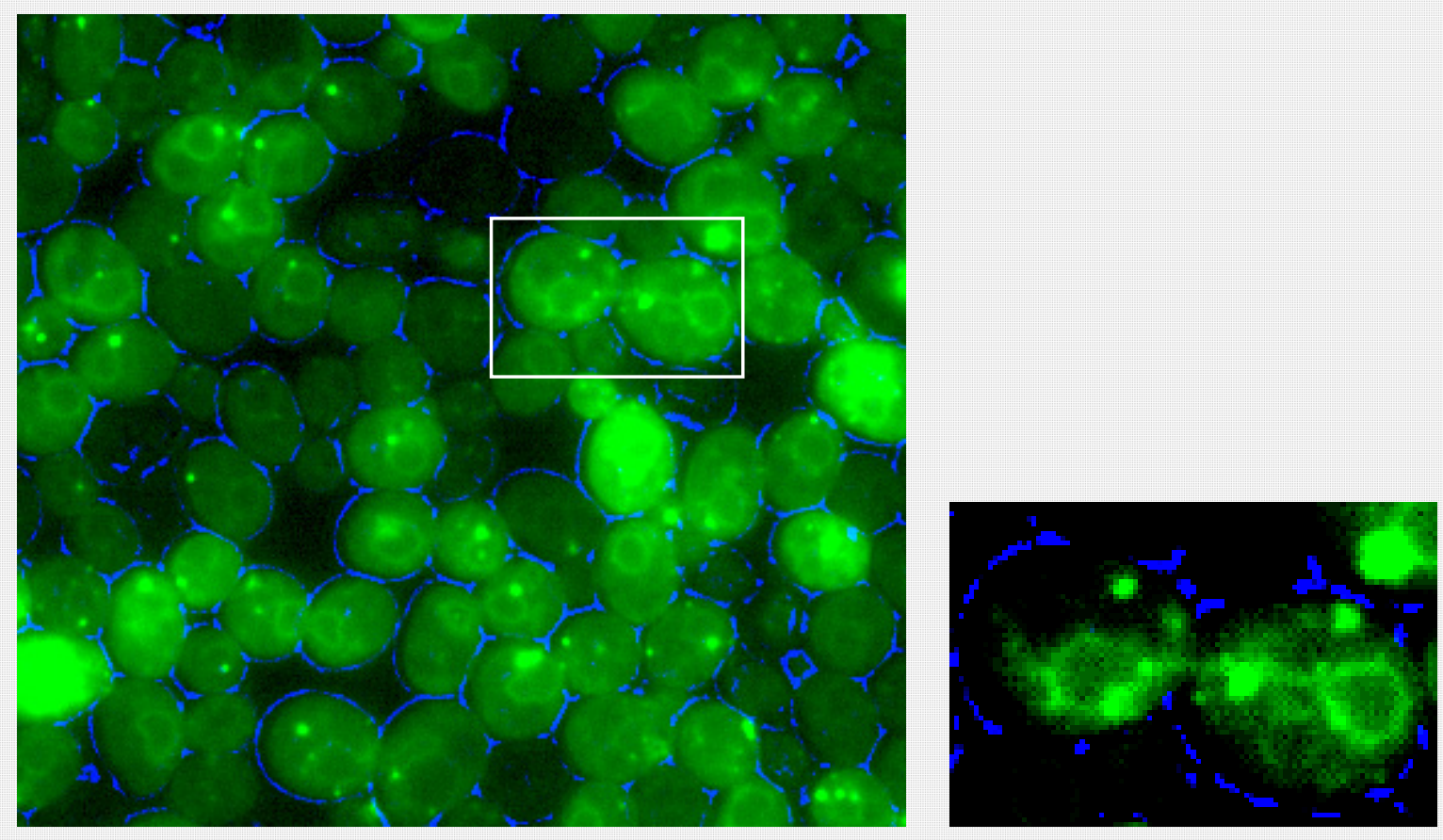

Abbildung 39: Darstellung von ringförmigen Strukturen mit 2xDendra-Pex3p. Ersichtlich ist auf dem Bild, dass sich Pex3p nicht nur als Peroxisomen sondern auch als ringförmige Strukturen darstellte, bei denen es sich mit großer Wahrscheinlichkeit um das ER handelt. Diese Konstellation weist auch darauf hin, dass Pex3p über das ER in Peroxisomen gelangt.

Um diese Konstellation sicher zu untersuchen, wurden weitere Hefestämme hergestellt, die in der Lage waren, das ER mit Fluoreszenz zu markieren. Was die Lokalisation von Peroxisomen eine Stunde nach der Induktion von Pex3p betrifft, so war eine ähnliche Konstellation in YKO-027 zu ersehen. In Abbildung 40 sind die Bilder aus dem Einzel-Pulse- 
Chase-Experiment mit YKO-027 (GAL1-prom-CFP-PEX3 mit dsRED-ER) detailliert dargestellt. Die Anfärbung mit dsRed verdeutlicht, dass Peroxisomen überwiegend an bzw. im perinukuleären ER zu liegen scheinen. Eine Reihe von Peroxisomen, die auf dem zweiten Bild mit einem Pfeil markiert sind, gab einen guten Hinweis darauf, dass Peroxisomen möglicherweise am perinukuleären ER entstehen, und sich dann zur Peripherie bewegen.

Der Kontakt zwischen Peroxisomen und ER scheint auch bei reifen Peroxisomen zu bestehen. Es wurden Pulse-Chase-Experimente mit den Hefestämmen durchgeführt, die in der Lage waren, das ER mit Fluoreszenz zu markieren, um sicher die räumliche Beziehung zwischen ER und Peroxisomen darzustellen.

Das Ergebnis des Einzel-Pulse-Chase-Experiments mit YKO-027 (GAL1prom-CFP-PEX3 mit dsRED-ER), sowie des Doppel-Pulse-Chase-Experiments mit YKO-029 (GAL1promCFP-PEX3 mit dsRED-ER x Cup1prom-YFP-PEX3) legt diese Hypothese nahe. In Abbildung 41 sind Details der Aufnahmen aus diesen beiden Experimenten dargestellt. Der Aufnahmezeitpunkt war bei YKO-027 vier Stunden nach der Beendigung der Induktion von CFP-Pex3p und bei YKO-029 drei Stunden nach der Beendigung der zweiten Induktion von CFP-Pex3p. Dieser Befund ist damit vereinbar, dass Peroxisomen möglicherweise auch nach ihrer Reifung noch eine enge räumliche Beziehung mit ER haben.

Nach HoEPFNER et al. (2005) dissoziieren Peroxisomen vom ER nach ihrer Entstehung und der Kontakt zwischen den Beiden besteht lediglich zum Zeitpunkt der Peroxisomenneubildung.

ZIPOR et al. (2009) zeigten, dass mRNA von PEX3 in Wildtyphefezellen mit dem ER kolokalisiert war, was auf eine bestehende räumliche Beziehung zwischen Peroxisomen und ER hinweist.

In der Literatur ist der Transportprozess für PMPs zwischen ER und Peroxisomen nicht verstanden. Wie in der Einleitung bereits erläutert findet kein Vesikeltransport statt [KIM et al. 2006 MAtsuzono et al. 1999, SOUth et al. 2000, VoORn-Brouwer et al. 2001]. Einige Autoren schlagen vor, dass es eine Membranverlängerung zwischen ER und Peroxisomen gibt, über die PMPs transportiert werden [Hettema und Motley 2009, GeuZE et al. 2003, TABAK et al. 2003, TABAK et al. 2008]. Diese Aussage legt nahe, dass der enge Kontakt zwischen ER und Peroxisomen möglicherweise bestehen bleibt. Es könnte aber auch sein, dass Peroxisomen eine räumlich getrennte Verlängerung des ERs darstellen. 


\subsection{Dynamik der Peroxisomenbiogenese}

Peroxisomen scheinen sich während ihrer Reifung vom perinukuleär gelegenen zum Zellmembran nahen ER zu bewegen. An dieser Stelle werden die Aufnahmen in der Abbildung 40 und Abbildung 41 hinsichtlich der Lokalisation von Peroxisomen in Zellen noch einmal betrachtet.

In Abbildung 40 sind die Zellen eine Stunde nach der Beendigung der Induktion von CFPPex3p detailliert dargestellt. Die Mehrzahl von Peroxisomen scheint zu diesem Zeitpunkt eher am zellkernnahen Peroxisomen lokalisiert zu sein.

In der Abbildung 41 sind die Zellen vier bzw. drei Stunden nach der Induktion von Pex3p gezeigt. Es ist ersichtlich, dass die Mehrzahl von Peroxisomen nun nicht mehr perinukuleär, sondern kortikal lokalisiert ist. Die Quantifizierung von Abstand zwischen Peroxisomen und Zellrand diente dazu, um diese Aussage quantitativ zu bestätigen

In Abbildung 34 ist diese Quantifizierung in Form eines Balkendiagramms dargestellt. Nach dieser Quantifizierung verringert sich der Abstand zwischen Peroxisomen und Zellrand durchschnittlich um ca. 1,6 $\mu \mathrm{m}$. Peroxisomen scheinen sich somit während der Reifung vom randfernen Bereich zum randnahen Bereich zu bewegen.

Aus der Literatur gibt es noch keinen direkten Hinweis, dass sich Peroxisomen allgemein während ihrer Reifung vom kernnahen zum zellrandnahen Bereich bewegen. Jedoch gibt es einen indirekten Hinweis für dieses Phänomen: Peroxisomen, die bei der Zellteilung in Mutterzellen zurückgehalten werden, sind überwiegend in der Peripherie lokalisiert. Vermutlich hält der Faktor Inp1 Peroxisomen in der Peripherie fest [MUNCK et al. 2009, FAgarasanu et al. 2005]. Die Aussage gilt lediglich für die Peroxisomen, die bei der Zellteilung in Mutterzellen zurückgehalten, und somit nicht allgemein für reife Peroxisomen. Jedoch wäre ein Experiment mit einem Hefestamm fehlenden INP1-Gens sinnvoll, um festzustellen, ob ein anderes Bild hinsichtlich der Lokalisation von Peroxisomen entsteht. Auf welchem Weg, Peroxisomen in die Peripherie, d.h zum kortikalen ER gelangen, ist ungeklärt. Es ist möglich, dass sich Peroxisomen entlang des ERs bewegen, oder aber es gibt einen besonderen Transportweg. Zur endgültigen Klärung dieser Fragestellung sind eine genauere mikroskopische Analyse mit besserer Bildauflösung, sowie eine genauere Verfolgung der Peroxisomenbiogenese z.B. durch eine mikroskopische Videoaufnahme vonnöten. Das ER besitzt offensichtlich eine sehr wichtige Funktion für die Peroxisomenbiogenese. Es lässt sich vermuten, dass das ER in der Lage ist, die Peroxisomenbiogenese zu regulieren, zum Beispiel durch ein biochemisches Signal. 

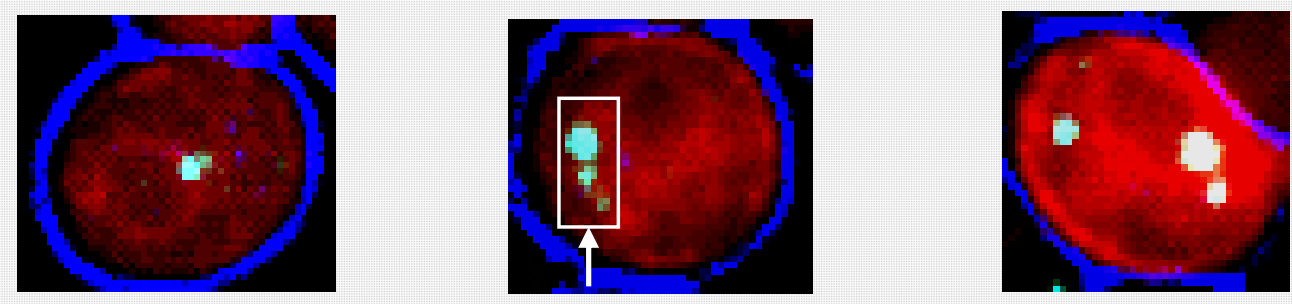

Abbildung 40: Detaillierte Darstellung des Einzel-Pulse-Chase-Experiments mit dem YKO-027 eine Stunde nach der Beendigung der einstündigen Induktion mit Galactose. Die Mehrzahl von Peroxisomen war zu diesem Zeitpunkt am perinukleären ER zu finden.

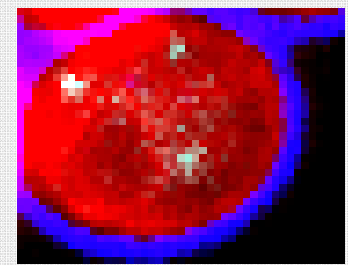

YKO-027 (GAL1prom-CFP-PEX3 mit DsRER)
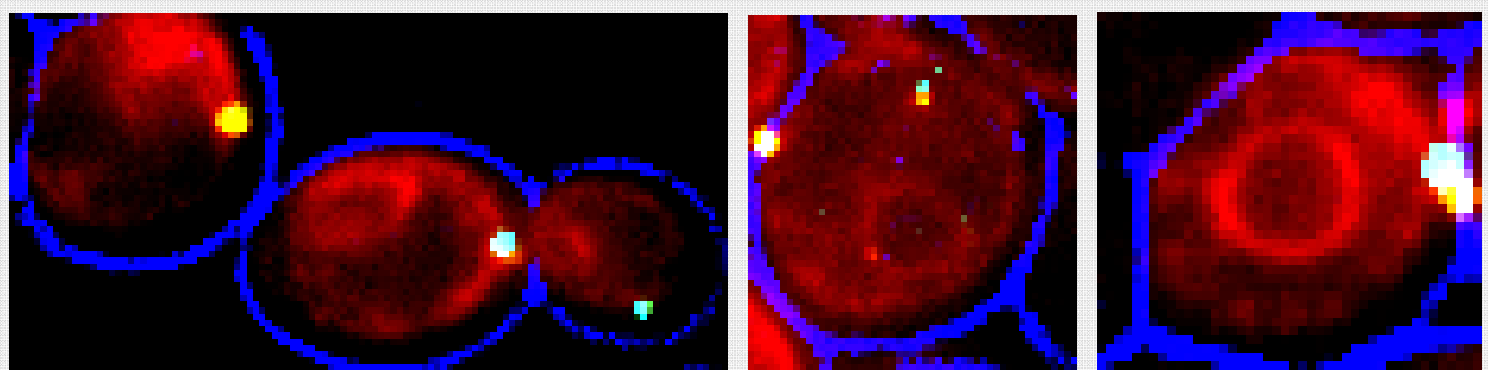

YKO-029 (GAL1prom-CFP-PEX3 mit DsRER x Cup1prom-YFP-PEX3)

Abbildung 41: Detail der Aufnahme des Einzel-Pulse-Chase-Experiments mit YKO-027 vier Stunden nach der Beendigung der Induktion mit Galactose, sowie detaillierte Darstellung des Doppel-Pulse-Chase-Experiments drei Stunden nach der Beendigung der zweiten Induktion im Kupfersulfat. Die Mehrzahl von Peroxisomen ist in der Peripherie zu finden. Peroxisomen haben möglicherweise auch zu diesem Zeitpunkt noch eine enge räumliche Beziehung mit dem ER. 


\subsection{Modell zur zellulären Dynamik der Peroxisomenbiogenese}

Als Zusammenfassung der Ergebnisse dieser Arbeit wurde ein hypothetisches Modell der Peroxisomenbiogenese erstellt. (Abbildung 42). Die Peroxisomenbiogenese beginnt überwiegend am perinukuleären ER, indem sich Pex3p in Vesikeln sammelt. Während der Reifung bewegen sich Präperoxisomen möglicherweise entlang des ERs oder auf einem anderen noch unbekannten Weg in die Peripherie zum kortikalen ER. Der enge Kontakt zwischen ER und Peroxisomen bleibt möglicherweise im ganzen Leben eines Peroxisoms erhalten. Ein Teil der Vorstufen von Peroxisomen fusionieren stets über das ER mit Peroxisomen. Ein anderer Teil der Vorstufen von Peroxisomen kann sehr wahrscheinlich als unabhängige Vesikeln entstehen. Eine enge permanente Verbindung zwischen ER und reifen Peroxisomen ist jedoch anzunehmen.

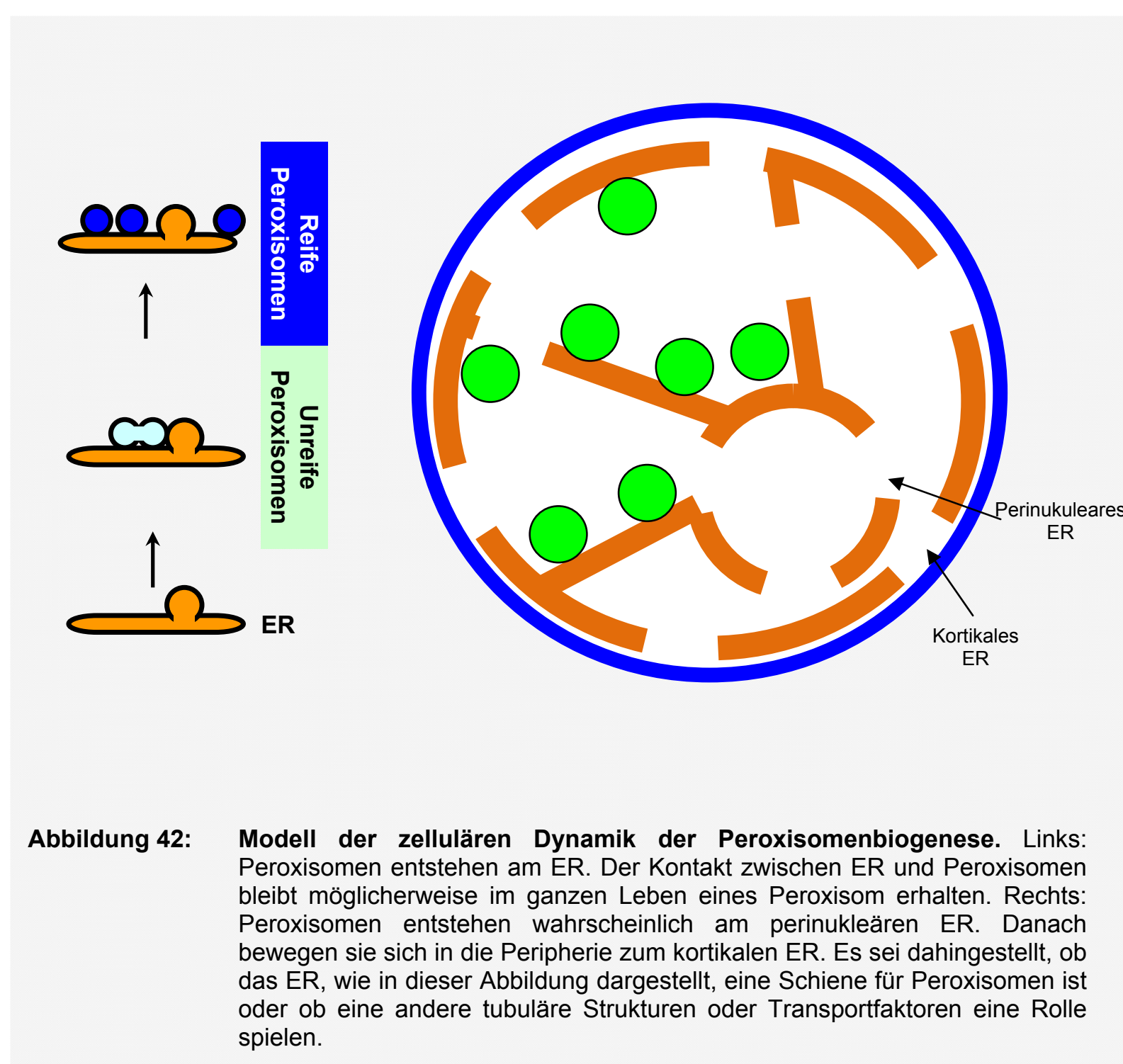




\section{ZUSAMMENFASSUNG}

In dieser Arbeit wurde versucht, die Mechanismen der Peroxisomenbiogenese weiter zu klären, d.h. ob Vorstufen von Peroxisomen zu Peroxisomen heranreifen (Reifungsmodell), oder ob Vorstufen von Peroxisomen miteinander fusionieren (Fusionsmodell). Um diese Frage zu klären, wurden Pulse-Chase-Experimente mit verschiedenen Hefestämmen mit steuerbaren Genen für Pex3-Markerproteine etabliert.

Die Untersuchung mit dem Hefestamm, der in der Anwesenheit von Galactose CFP-Pex3p und in der Anwesenheit von Kupfer YFP-Pex3p induzierte, erbrachte die Erkenntnis, dass eine erneute Induktion von Peroxisomen-Vorstufen zur Fusionierung mit bereits vorhandenen Peroxisomen und nicht zur Neuentstehung unabhängiger Peroxisomen führte, falls die Zellen bereits existierende Peroxisomen besaßen. Das Experiment mit dem Hefestamm, der in der Anwesenheit von Galactose mit UV-Licht konvertierbares fluoreszierendes Pex3p induzierte, erbrachte einen weiteren Hinweis. Bei der erneuten Induktion von Peroxisomen-Vorstufen fusionierten die neu entstandenen Vorstufen von Peroxisomen mit bereits existierenden Peroxisomen, aber es entstanden auch neue unabhängige Vorstufen von Peroxisomen, und dies auch in Zellen mit bereits vorhandenen Peroxisomen. Durch die bisherigen Experimente konnte noch nicht geklärt werden, ob diese neu entstandenen Peroxisomen sich auf dem Weg zu existierenden Peroxisomen befanden, um zu fusionieren oder als Einzelperoxisom weiter bestanden.

Darüber hinaus ließ sich in den beiden Hefestämmen darstellen, dass die Mehrzahl der Peroxisomen eine enge räumliche Beziehung zum ER aufweist. Peroxisomen bewegen sich möglicherweise während der Reifung vom zellkernnahen Bereich in die Peripherie zum Zellrand. Die Mehrzahl von reifen Peroxisomen befand sich am ER in der Peripherie. Unreife Peroxisomen benötigten bis zur Reifung vier bis fünf Stunden, um Matrixproteine importieren zu können. Eine Überexpression von Pex3p führte zum Funktionsverlust von Peroxisomen, da diese Matrixproteine nicht eingliedern konnten. 


\section{LITERATURVERZEICHNIS}

Baerends RJS, Salomons FA, Kiel JAKW, van der Klei IJ, Veenhuis M (1997): Deviant pex3p levels affect normal peroxisome formation in Hansenula polymorpha: a sharp increase of protein level induces the proliferation of numerous, small protein-import competent peroxisomes. Yeast $\underline{13}, 1449-1463$

Baes M, Gressens P, Baumgart E, Carmeliet P, Casteels M, Fransen M, Evrard P, Fahimi D, Declercq PE, Collen D, van Veldhoven PP, Mannerts GP (1997): A mouse model for Zellweger syndrome. Nat Genet 17, 49-57

Bascom RA, Chan H, Rachubinski RA (2003): Peroxisome biogenesis occurs in an unsynchronized manner in close association with the endoplasmic reticulum in temperaturesensitive Yarrowia lipolytica pex3p mutants. Mol Biol Cell 14, 939-957

Brosius U, Gärtner J (2002): Cellular and molecular aspects of Zellweger syndrome and other peroxisome biogenesis disorders. Cell Mol Life Sci 59, 1058-1069

Brown LA, Baker A (2008): Shuttles and cycles: transport of proteins in the peroxisome matrix (review). Mol Membr Biol 25, 363-375

Clayton PT, Thompson E (1988): Dysmorphic syndoromes with demonstrable biochemical abnormalities. J Med Genet 25, 463-472

Cole L, Davies D, Hyde GJ, Ashford AE (2000): Brefeldin A affects growth, endoplasmic reticulum, golgi bodies, tubular vacuole system, and secretory Pathway in pisolithus tinctorius. Fungal Genet Biol 29, 95-106

de Craene JO, Coleman J, de Martin PE, Pypaert M, Anderson S, III, Yates JR, FerroNovick, S, Novick P (2006): Rtn1p is involved in structuring the cortical endoplasmic reticulum. Mol Biol Cell 17, 3009-3020

Dammai V, Subramani S (2001): The human peroxisomal targeting signal receptor, Pex5p, is translocated into the peroxisomal Matrix and recycled to the Cytosol. Cell 105, 293-296

Dana JR, Tunnessen WW (1999): Picture of the month. Arch Pediatr Adolesc Med 153, 1105-1106

Doenecke D, Koolman J, Fuchs G, Gerok W: Karlsons Biochemie. (15. Auflage), GeorgThieme-Verlag, Stuttgart 2005

de Duve C, Baudhuin P(1966): Peroxisomes (microbodies and related particles). Physiol Rev $\underline{46}, 323-357$

Faber KN, Haan GJ, Baerends RJS, Kram AM, Veenhuis M (2002): Normal peroxisome development from vesicles induced by truncated Hansenula polymorpha pex3p. J Biol Chem $\underline{277}, 11026-11033$ 
Fagarasanu M, Fagarasanu A, Tam YY, Aitchison JD, Rachubinski RA (2005): Inplp is a peroxisomal membrane protein required for peroxisome inheritance in Saccharomyces cerevisiae. J Cell Biol 169, 765-775

Fang Y, Morrell JC, Jones JM, Gould SJ (2004): PEX3 functions as a PEX19 docking factor in the import of class I peroxisomal membrane proteins. J Cell Biol 164, 863-875

Folz SJ, Trobe JD (1991): The peroxisome and the eye. Surv Ophthalmol $\underline{35}, 353-368$

Fujiki Y, Matsuzono Y, Matsuzaki T, Fransen M (2006): Import of peroxisomal membrane proteins: the interplay of Pex3p- and Pex19p-mediated interaction. Biochim Biophys Acta $\underline{1763}, 1639-1646$

Gärtner J (2000): Organelle disease: peroxisomal disorders. Eur J Pediatr 159 Suppl. 3, 236239

Gärtner J: Erkrankungen des Nervensystems. In: Koletzko B: Kinder- und Jugendmedizin. (13. Auflage), Springer Verlag, Berlin 2007, 559-605

Geuze HJ, Murk JL, Stroobants AK, Griffith JM, Kleijmeer MJ, Koster AJ, Verkleij AJ, Distel B, Tabak HF (2003): Involvement of the endoplasmatic reticulum in peroxisome formation. Mol Biol Cell 14, 2900-2907

Gietz RD, Sugino A (1988): New yeast-Escherichia coli shuttle vectors constructed with in vietro mutagenized yeast genes lacking six base pair restriction site. Gene $\underline{74}, 527-534$

Gietz RD, Schiestl RH, Willems AR, Woods RA (1995): Studies on the Transformation of Intact Yeast Cells by the LiAc/SS-DNA/PEG Procedure. Yeast $11,355-36$

Gietz RD, Schiestl RH (2007): Quick and easy yeast transformation using the LiAc/SS Carrier DNA/PEG method. Nat Protoc 2, 35-37

Gurskaya NG, Verkhusha VV, Shcheglov AS, Staroverov DB, Chepurnykh TV, Fradkov AF, Lukyanov S, Lukyanov KA (2006): Engineering of a monomeric green-to-red photoactivatable fluorescent protein induced by blue light. Nat Biotechnol 24, 461-465

Haan GJ, Baerends RJ, Krikken AM, Otzen M, Veenhuis M, van der Klei IJ (2006): Reassembly of peroxisomes in Hansenula polymorpha pex3 cells on reintroduction of Pex3p involves the nuclear envelope. FEMS Yeast Res. $\underline{6}$, 186-194

Hasilik A: Zelluläre Organellen, Strukturen und Transportvorgänge. In: Löffler G, Petrides PE, Heinrich PC: Biochemie und Pathobiochemie. (8. Auflage), Springer Verlag, Berlin 2007, 173-215

Heiland I, Erdmann R (2005): Biogengesis of peroxisomes topogenesis of the peroxisomal membrane and matrix proteins. FEBS J 272, 2362-2372

Hettema EH, Tabak HF (2000): Transport of fatty acids and metabolites across the peroxisomal membrane. Biochim Biophys Acta 1486, 18-27 
Hettema EH, Motley AM (2009): How peroxisomes multiply. J Cell Sci 15, 2331-2336

Hettema EH, Girzalsky W, van den Berg M, Erdmann R, Distel B (2000): Saccharomyces cerevisiae Pex $3 p$ and Pex19p are required for proper localization and stability of peroxisomal membrane proteins. EMBO J $\underline{19}, 223-233$

Hoepfner D, Schildknegt D, Braakman I, Philippsen P, Tabak HF (2005): Contribution of endoplasmic reticulum to peroxisome formation. Cell 122, 85-95

Hoffmann GF, Mayatepek E: Stoffwechselerkrankungen. In: Speer CP, Gahr M: Pädiatrie. (2. Auflage), Springer Verlag, Berlin 2005, 105-152

Janke C, Magiera MM, Rathfelder N, Taxis C, Reber S, Maekawa H, Moreno-Borchart A, Doenges G, Schwob E, Schiebel E, Knop M (2004): A versatile toolbox for PCR-based tagging of yeast genes: new fluorescent proteins, more markers and promoter substitution cassettes. Yeast $\underline{21}, 947-962$

Jones JM, Morrell JC, Gould SJ (2004): PEX16 is a predominantly cytosolic chaperone and import receptor for class 1 Peroxisomal membrane proteins. J Cell Biol 164, 57-67

Kamei A, Hondou S, Takashima S, Suzuki Y, Becker LE, Armstrong D (1899): Peroxisomal disorders in children: immunohistochemistry and neuropathology. J Pediatr 122, 573-579

Kammerer S, Holzinger A, Welsch U, Roscher AA (1998): Cloning and characterization of the gene encoding the human peroxisomal assembly proteil Pex3p. FEBS Lett $\underline{429}$, 53-60

Kassmann CM, Lappe-Siefke C, Baes M, Brügger B, Mildner A, Werner HB, Natt O, Michaelis T, Prinz M, Frahm J, Nave KA (2007): Axonal loss and neuroinflammation caused by peroxisome deficient oligodendrocytes. Nat Genet $\underline{39}$, 969-976

Keane MH, Overmars H, Wikander TM, Ferdiandusse S, Duran M, Wanders RJ, Faust PL (2007): Bile acid treatment alters hepatic disease and bile acid transport in peroxisomedeficient PEX2 Zellweger Mice. Hepatology 45, 982-997

Kim PK, Mullen RT, Schumann U, Lippincott-Schwartz J (2006): The origin and maintenance of mammalian peroxisomes involves a de novo PEX16-dependent pathway from the ER. J Cell Biol 173, 521-532

Klein AT, Barnett P, Bottger G, Konings D, Tabak HF, Distel B (2001): Recognition of peroxisomal targeting signal type I by the import receptor PEX5. J Biol Chem 276, 1503415041

Kragt A, Voorn-Brouwer T, van den Berg M, Distel B (2005): Endoplasmic reticulumdirected Pex3p routes to peroxisomes and restores peroxisome formation in a Saccharomyces cerevisiae pex3Delta strain. J Biol Chem $\underline{280}$, 34350-34357

Kunau WH (2005) Peroxisome biogenesis: end of the debate. Curr Biol 15, R774-R776 
Kunau WH, Agne B, Girzalsky W (2001): The diversity of organelle protein transport mechanisms. Trends Cell Biol 11, 358- 361

Lazarow PB (2003): Peroxisome biogenesis: advance and conundrums. Curr Opin Cell Biol $\underline{15}, 489-497$

Ma C, Subramani S (2009): Peroxisome matrix and membrane protein biogenesis. IUBMB Life $\underline{61}, 713-722$

Martinez M (2001): Restoring the DHA levels in the brains of Zellweger patients J Mol Neurosci 16, 309-316

Matsuzaki T, Fujiki Y (2008): The peroxisomal membrane protein import receptor Pex3p is directly transported to peroxisomes by a novel Pex19p and Pex16p-dependent pathway. J Cell Biol $\underline{183}, 1275-1286$

Matsuzono Y, Kinoshita N, Tamura S, Shimozawa N, Hamasaki M, Ghaedi K, Wanders RJ, Suzuki Y, Kondo N, Fujiki Y (1999): Human PEX19: cDNA cloning by functional complementation, mutation analysis in a patient with Zellweger syndrome, and potential role in peroxisomal membrane assembly. Proc Natl Acad Sci USA 96, 2116-2121

Mayerhofer PU, Kattenfeld T, Roscher AA, Muntau AC (2002): Two splice variants of human PEX19 exhibit distinct functions in peroxisomal assembly. Biochem Biophys Res Commun 291, 1180-1186

Moser HW (2000): Molecular genetics of peroxisomal disorders. Front Biosci $\underline{5}$, 298-306

Motley AM, Hettema EH (2007): Yeast peroxisomes multiply by growth and division. J Cell Biol 178, 399-410

Mullen RT, Trelease RN (2006): The ER-peroxisome connection in plants: development of the "ER semi-autonomous peroxisome maturation and replication" model for plant peroxisome biogenesis. Biochim Biophys Acta 1763, 1655-1668

Munck JM, Motley AM, Nuttall JM, Hettema EH (2009): A dual function for Pex3p in peroxisome formation and inheritance. J Cell Biol 187, 463-471

Muntau AC, Mayerhofer PU, Paton BC, Kammerer S, Roscher AA (2000): Defective peroxisome membrane synthesis due to mutations in human PEX3 cause Zellweger Syndrome, Complementation Group G. Am J Hum Genet 67, 967-975

Nagotu S, Krikken AM, Otzen M, Kiel JA, Veenhuis M, van der Klei IJ (2008a): Peroxisome fission in Hansenula polymorpha requires Mdv1 and Fis1, two proteins also involved in mitochondrial fission. Traffic $\underline{9}, 1471-1484$

Nagotu S, Saraya R, Otzen M, Veenhuis M, van der Klei IJ (2008b): Peroxisome proliferation in Hansenula polymorpha requires Dnm1p which mediates fission but not de novo formation. Biochim Biophys Acta 1783, 760-769 
Purdue PE, Lazarow PB (1995): Identification of peroxisomal membrane Ghost with an epitope-tagged integral membrane protein in Yeast mutants lacking peroxisomes. Yeast $\underline{11}$, $1045-1060$

Raychaudhuri S, Prinz WA (2008): Nonvesicular phospholipids transfer between peroxisomes and the endoplasmatic reticulum. Proc Natl Acad Sci U S A 105, 15785-15790

Raymond GV (2001): Peroxisomal disorders. Curr Opin Neurol 14, 783-787

Reddy JK, Mannaerts GP (1994): Peroxisomal lipid metabolism. Annu Rev Nutr 14, 343370

Rhodin J: Correlation of ultrastructural organizaton and function in normal and experimentally changed peroxisomal convoluted tubule cells of the mouse kidney. Stockholm University Aktiebolaget Godvil, Stockholm 1954

Rottensteiner H, Kramer A, Lorenzen S, Stein K, Landgraf C, Volkmer-Engert R, Erdmann $R$ (2004): Peroxisomal membrane protein contain common pex19p-binding site that are an integral part of their targeting signals. Mol Biol Cell $\underline{15}$, 3406-3417

Sacksteder KA, Gould SJ (2000): The genetic of peroxisome Biogenesis. Annu Rev Genet $\underline{34}, 623-652$

Sacksteder KA, Jones JM, South ST, Li X, Liu Y, Gould SJ (2000): PEX19 binds multiple peroxisomal membrane proteins, is predominantly cytoplasmatic and is required for peroxisome membrane synthesis. J Cell Biol 148, 931-944

Salomons FA, van der Klei IJ, Kram AM, Harder W, Veenhuis M (1997): Brefeldin A interferes with peroxisomal protein sorting in the yeast Hansenula polymorpha. FEBS Lett $\underline{411}, 133-139$

Santos MJ, Quintanilla RA, Toro A, Grandy R, Dinamarca MC, Godoy JA, Inestrosa NC (2005): Peroxisomal proliferation protects from beta-amyloid neurodegeneration. J Biol Chem $\underline{280}, 41057-41068$

Schrader M, Fahimi HD (2006 a): Peroxisomes and oxidative stress. Biochim Biophys Acta $\underline{1763}, 1755-1766$

Schrader M, Fahimi HD (2006 b): Growth and division of peroxisomes. Int Rev Cytol $\underline{129}$, 421-440

Schrader M, Fahimi HD (2008): The peroxisome: still a mysterious organelle. Histochem Cell Biol 129, 421-440

Sheff MA, Thorn KS (2004): Optimized cassettes for fluorescent protein tagging in Saccharomyces cerevisiae. Yeast 21, 661-670

Shimozawa N, Suzuki Y, Zhang Z, Imamura A, Ghaedi K, Fujiki Y, Kondo N (2000): Identification of PEX3 as the gene mutated in Zellweger syndrome patient lacking peroxisomal remnant structures. Hum Mol Genet $\underline{9}$, 1995-1999 
Smith MD, Schnell DJ (2001): Peroxisomal protein import: the paradigm shifts. Cell 105, 293-296

Snyder WS, Koller A, Choy AJ, Subramani S (2000): The peroxin pex19p interacts with multiple integral membrane proteins at the peroxisomal membrane. J Cell Biol $\underline{149}$, 11711177

South ST, Gould SJ (1999): Peroxisome synthesis in the absence of preexisting peroxisomes. J Cell Biol 144, 255-266

South ST, Sacksteder KA, Li X, Liu Y, Gould SJ (2000): Inhibitor of COPI and COPII do not block PEX3-mediated peroxisome synthesis. J Cell Biol 149, 1345-1359

South ST, Baumgart E, Gould SJ (2001): Interactivation of the endoplasmatic reticulum protein translocation factor, Sec61p, or its homolog, Ssh1p, does not affect peroxisome biogenesis. Proc Natl Acad Sci U S A 모, 12027-12031

Street JM, Evans JE, Natowicz MR (1996): Glucuronic acid-conjugated dihydroxy fatty acid in the urine of patients with generalized peroxisomal disorders. J Biol Chem $\underline{271}$, 3507-3516

Tabak HF, Murk JL, Braakmann I, Geuze HJ (2003): Perosixomes start their life in the endoplasmatic reticulum. Traffic $\underline{4}, 512-518$

Tabak HF, van der Zand A, Braakman I (2008): Peroxisomes: minted by the ER. Curr Opin Cell Biol 20, 393-400

Tams YY, Fagarasanu A, Fagarasanu M, Rachubinski RA (2005): Pex3p initiates the formation of a preperoxisomal compartment from a subdomain of the endoplasmatic reticulum in Saccharomyces cerevisiae. J Biol Chem 280, 34933- 34939

Tanaka K, Shimizu T, Ohtsuka Y, Yamashiro Y, Oshida K (2007): Early dietary treatment with Lorenzo's oil and decosahexaenoic acid for neurological development in case with Zellweger syndrome. Brain Dev 29, 586-589

Thoms S, Erdmann R (2005 a): Import of proteins into peroxisomes. Eurekah Biosci 1, 324328

Thoms S, Erdmann R (2005 b): Dynamin-related proteins and Pex11 proteins in peroxisome division and proliferation. Eur J Biochem 272, 5169-5181

Thoms S, Erdmann R (2006): Peroxisomal matrix protein receptor ubiquitination and recycling. Biochim Biophys Acta 1763, 1620-1628

Thoms S, Grønborg S, Gärtner J (2009): Organelle interplay in peroxisomal disorders. Trends Mol Med 15, 293-302

Titorenko VI, Rachubinski RA (1998): Mutants of the yeast Yarrowia lipolytica defective in protein exit from the endoplasmatic reticulum are also defective in peroxisome Biogenesis. Mol Cell Biol 18, 2789-2803 
Titorenko VI, Rachubinski RA (2001): Dynamics of peroxisome assembly and function. Trends Cell Biol 11, 22-29

Titorenko VI, Mullen RT (2006): Peroxisome biogenesis: the peroxisomal endomembrane system and the role of the ER. J Cell Biol 174, 11-17

Toro AA, Araya CA, Córdova GJ, Arredondo CA, Cárdenas HG, Moreno RE, Venegas A, Koenig CS, Cancino J, Gonzalez A, Santos MJ (2009): Pex3p-dependent peroxisomal biogenesis initiates in the endoplasmic reticulum of human fibroblasts. J Cell Biochem. $\underline{15}$, 1083-1096

Vizeacoumar FJ, Vreden WN, Fagarasanu M, Eitzen GA, Aitchison JD, Rachubinski RA (2006): The dynamin-like protein Vps1P of the yeast Saccharomyces cerevisiae associates with peroxisomes in a pex19-dependent manner. J Biol Chem 281, 12817-12823

Voorn-Brouwer T, Kragt A, Tabak HF, Distel (2001): Peroxisomal membrane proteins are property targeted to peroxisomes in the absence of COPI- and COPII-mediated vesicular transport. J Cell Sci 2199-2204

Wanders RJA, Schutgens RBH, Barth PG (1995): Peroxisomal disorder: a review. J Neuropathol Exp Neurol 54, 726-739

Wanders RJA, Waterham HR (2004): Peroxisomal disorders I: biochemistry and genetic of peroxisome biogenesis disorders. Clin Genet 67, 107-133

Weller S, Gould S, Valle D (2003): Peroxisome Biogenesis Disorders. Annu Rev Genomics Hum Genet $\underline{4}, 165-211$

van der Zand A, Braakman I, Geuze HJ, Tabak HF (2006): The return of peroxisome. J Cell Sci $\underline{119}, 989-994$

Zipor G, Haim-Vilmovsky L, Gelin-Licht R, Gadir N, Brocard C, Gerst JE (2009): Localization of mRNAs coding for peroxisomal proteins in the yeast, Saccharomyces cerevisiae. Proc Natl Acad Sci U S A 106, 19848-19853 


\section{DANKSAGUNG}

Der Direktorin der Abteilung, Frau Prof. Dr. med. J. Gärtner sowie Frau Dr. med. S. Grønborg und Herrn Dr. rer. nat. Thoms danke ich für die Bereitstellung des Themas, die Aufnahme in die Arbeitsgruppe und die Korrekturen der Dissertationsschrift.

Herrn Dr. rer. nat. S. Thoms danke ich ganz besonders herzlich für die intensive Betreuung, die Einführung in die Labormethoden, die Unterstützung im Laboralltag sowie seine konstruktiven Anregungen und hilfreiche Kritik.

Dem Laborteam auf der Ebene 1 der Universitätsmedizin Göttingen für die Unterstützung im Laboralltag sowie aufmunternde Kommunikation.

Meinen Mitdoktorandinnen Carolin Strohm, Jana Rabenau danke ich herzlich für die freundschaftliche Zusammenarbeit.

Herrn Dr. phil. K.-H. Stubenrauch für die grundliche Korrektur der Dissertationsschrift.

Frau U. Appuhn, Frau Prof. Dr. phil. S. Appuhn-Radtke, Frau E. Appuhn, Frau W. Perfahl, sowie verstorbener Frau Dr. phil. A Heimendahl für die Geschwisterlichkeit, die freundliche Unterstützung sowie die hilfreichen Ratschläge.

Der Chorgemeinschaft St. Ursula und den Chören des Bamberger Doms für die musikalische und geistliche Begleitung des Studiums.

Den sonstigen Personen, die mich während des Studiums in irgendeiner Weise unterstützten.

Mein besonderer Dank gilt meinen Eltern für Ihre Unterstützung und für die Ermöglichung des Studiums. 